\title{
Treatment effects of the Forsus Fatigue Resistant Device: A cephalometric investigation
}

\author{
Dean Heinrichs \\ West Virginia University
}

Follow this and additional works at: https://researchrepository.wvu.edu/etd

\section{Recommended Citation}

Heinrichs, Dean, "Treatment effects of the Forsus Fatigue Resistant Device: A cephalometric investigation" (2010). Graduate Theses, Dissertations, and Problem Reports. 3211.

https://researchrepository.wvu.edu/etd/3211

This Thesis is protected by copyright and/or related rights. It has been brought to you by the The Research Repository @ WVU with permission from the rights-holder(s). You are free to use this Thesis in any way that is permitted by the copyright and related rights legislation that applies to your use. For other uses you must obtain permission from the rights-holder(s) directly, unless additional rights are indicated by a Creative Commons license in the record and/ or on the work itself. This Thesis has been accepted for inclusion in WVU Graduate Theses, Dissertations, and Problem Reports collection by an authorized administrator of The Research Repository @ WVU. For more information, please contact researchrepository@mail.wvu.edu. 


\title{
TREATMENT EFFECTS OF THE FORSUS
}

\author{
FATIGUE RESISTANT DEVICE: A
}

\section{CEPHALOMETRIC INVESTIGATION}

Dean Heinrichs, DMD

A THESIS

\author{
Submitted to: \\ The School of Dentistry \\ at West Virginia University \\ in partial fulfillment of the requirements \\ for the degree of \\ Master of Science \\ In \\ Orthodontics
}

Peter Ngan, D.M.D., Chair

Chris Martin, D.D.S., M.S.

Thomas Razmus, D.D.S., M.S.

West Virginia University

Department of Orthodontics

Morgantown, West Virginia

2010 


\title{
ABSTRACT \\ Treatment Effects of the Forsus Fatigue Resistant Device: A Cephalometric Investigation
}

\author{
Dean A. Heinrichs, D.M.D.
}

Objectives: To evaluate the correction obtained from the Forsus Fatigue Resistant (FRD) device and orthodontic appliances compared to an untreated control group. Methods: Twenty four patients were treated with the Forsus FRD and fixed orthodontic appliances and were compared to twenty two untreated control patients who were matched in age, sex and craniofacial morphology. Lateral Cephalograms were taken before treatment (T1) and after Forsus FRD and removal of orthodontic appliances (T2). Results: Statistically significant differences were found for 12 of the 29 variables measured. Significant differences were found at Co-Gn minus Co-Apt., Wits, Is-OLp, Ii-OLp, overjet, Mi-OLp, Molar relationship, Overbite, Mic-ML, SNA, ANB, and Ii-ML between the treated and control groups. Linear measurements in the net position of the maxilla and mandible showed changes that included a reduction in maxillary forward growth and a stimulation of mandibular forward growth; however, these changes were not statistically significant. Net overjet correction was $4.7 \mathrm{~mm}$. $1.9 \mathrm{~mm}(40 \%)$ of the correction was skeletal and $2.8 \mathrm{~mm}(60 \%)$ was dental. Overjet correction was obtained by decreased maxillary growth (25\%), increased mandibular growth (15\%), retraction of the upper incisor (32\%), and proclination of the lower incisor (28\%). Conclusions: The Forsus FRD is successful in treating Class II malocclusions; however, there is a significant proportion of the correction which is dental in nature. 


\section{DEDICATION}

To my wife Thea Heinrichs, for always supporting me and for all the sacrifices you have made. You were always there for me and believed in me when I did not. Without you I never could have made it here. You are the love of my life and the best wife I ever could have asked for, and the best mother Alexander could ever have. We are so lucky to have you in our lives. Your hard work and sacrifice has paid off. Thank you and I love you so much.

To my son Alexander Heinrichs, my little Mountaineer. Thank you for your unconditional love. Your smile was all I needed to melt away the frustration of the day. I love you.

To my parents, Alan and Jennifer Heinrichs, who taught me the importance of hard work and integrity. Thank you for all your help, love and support throughout the years. I would not be where I am today without you. I love you.

To my parents in-law, Lloyd and Sheila Wiebe, thank you for your love and support. You have always been a second set of parents for me, and I appreciate everything you have done for us. I love you.

To my Lord and Saviour, Jesus Christ, thank you for leading me to West Virginia. You have blessed me beyond belief; much more than I ever could ask for. I love you.

To The People of West Virginia, who accepted us as one of their own, your kindness will never be forgotten. Thank you for three of the best years of my life, and I appreciate all that you have done for us. We will miss you. 


\section{ACKNOWLEDGEMENTS}

Dr. Peter Ngan - For your help with my research and for acting as my committee chairman. No one at this institution works harder than you and we appreciate you for it. Dr. Chris Martin - For your help in the clinic and as a member of my thesis committee. Your advice and humour has been greatly appreciated.

Dr. Thomas Razmus - For your help as a member of my thesis committee Dr. Imad Shammaa - for the use of your records and help throughout my project Part time Faculty Drs. Tim Tremont, Michael Hazey, Jeff Gilmore, Ed McFarland, Thomas Jarrett, Dan Foley, Kerry Kirsch, and Glenn Boyles for your knowledge and patience in the clinic. I appreciate your dedication and commitment to the program and thank you for your sacrifice of your time to help us.

Staff Carrie, Hillary, Joyce, Karen, and Leona, for putting up with me and for all your help in the clinic.

Classmates Michael Munn and Kolin Weaver, for your friendship and support you have shown me throughout our time here. I hope that we will continue to work up cases and bounce ideas off each other. I could not have asked for better classmates, Holler! Fellow residents Rob, Erica, Maggie, Holly, Ronnie, Jung Mee, as well as former residents Michael, Thuy, Rajia, Lindsay, Nikia and Tim for all the laughs and for all you have taught me. You all made my time here extremely enjoyable and I wish you all the best. 


\section{TABLE OF CONTENTS}

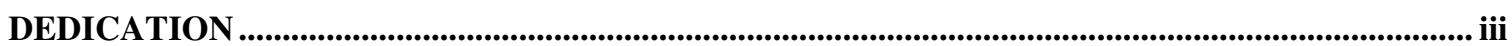

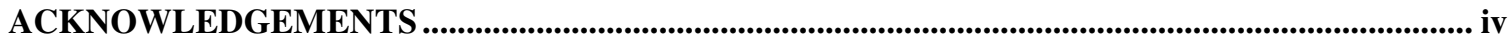

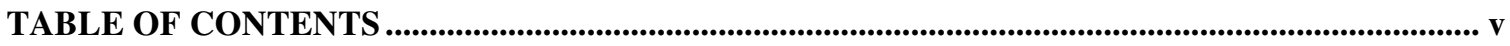

LIST OF TABLES............................................................................................................................................. vii

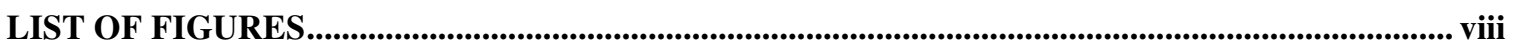

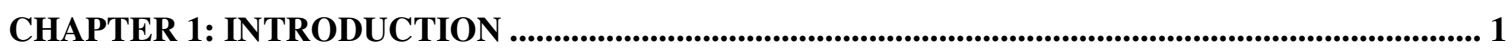

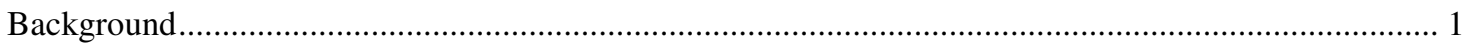

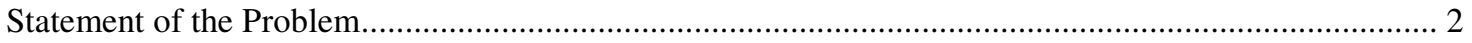

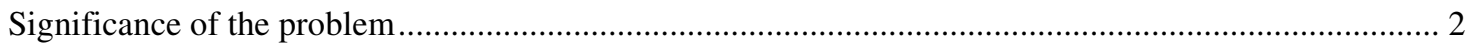

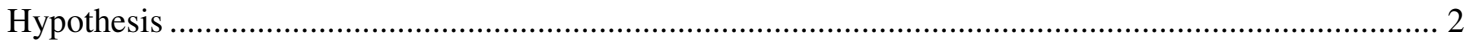

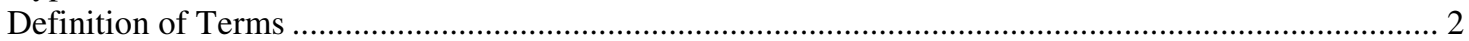

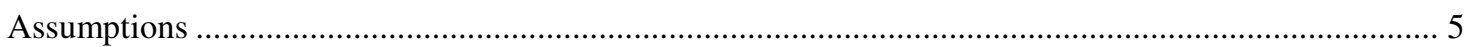

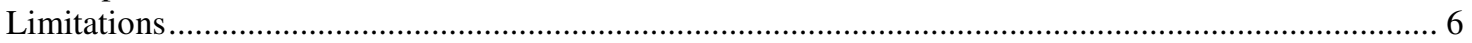

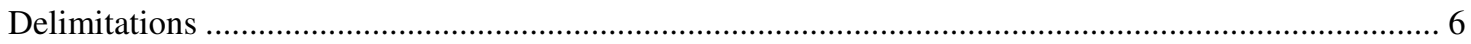

CHAPTER 2: REVIEW OF LITERATURE ............................................................................................... 8

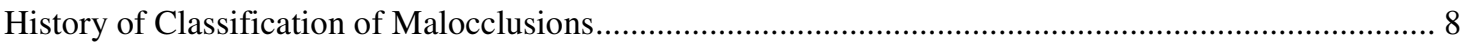

Etiology of malocclusions and the need for orthodontic therapy ....................................................... 9

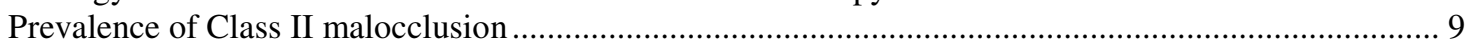

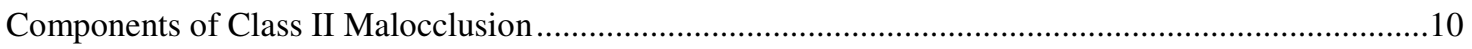

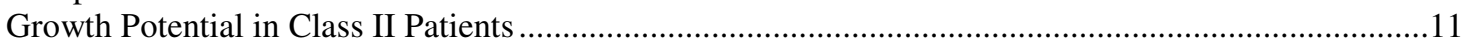

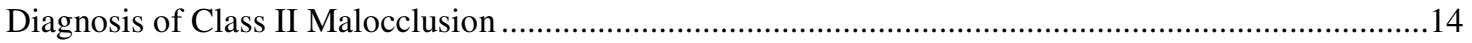

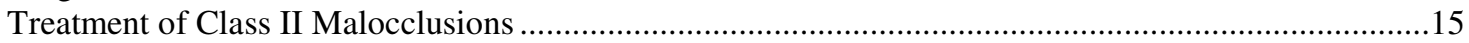

History of functional appliances used to treat Class II malocclusions...................................................17

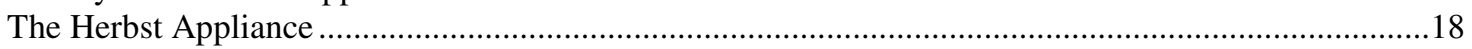

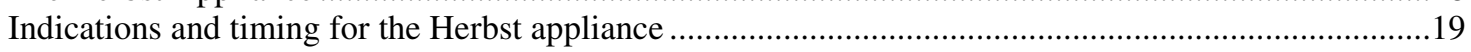

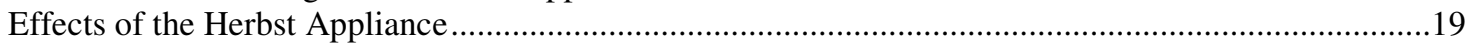

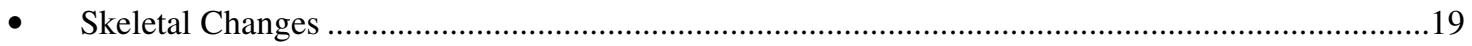

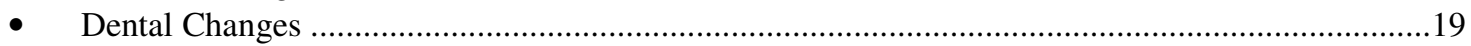

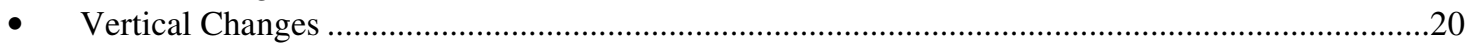

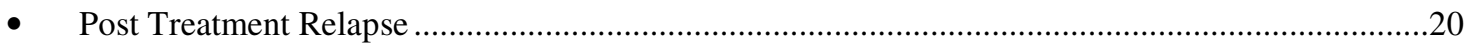

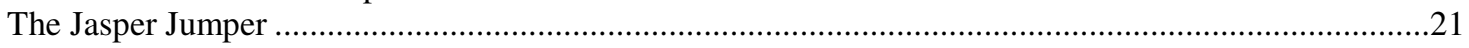

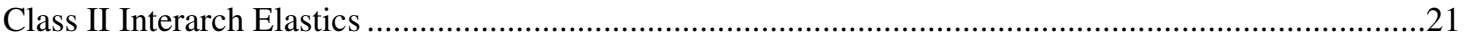

The Forsus FRD .

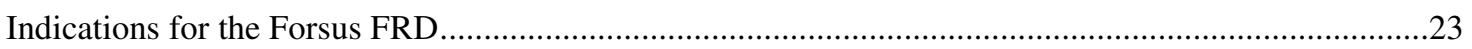

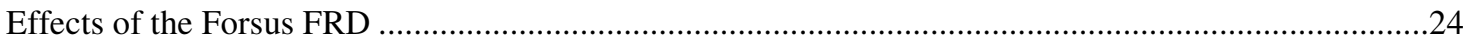

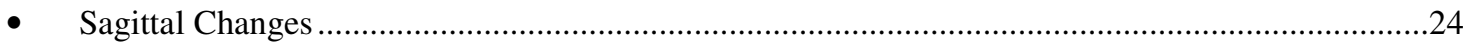

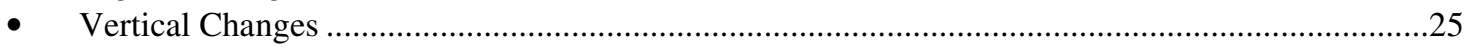

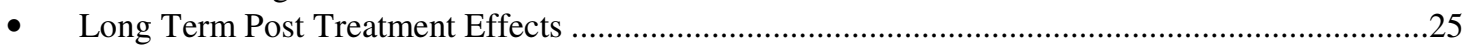

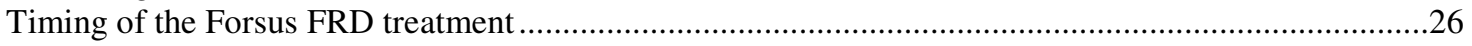

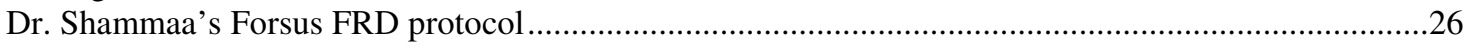

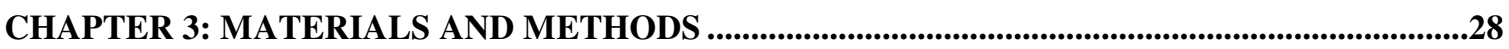

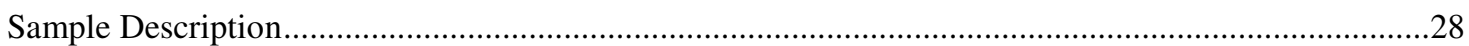

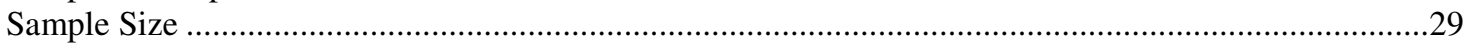

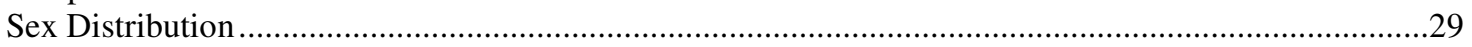

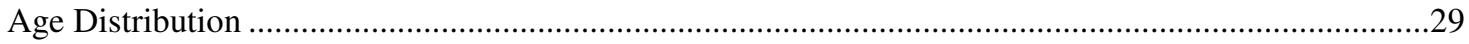




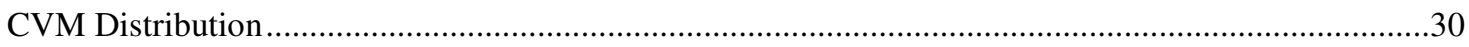

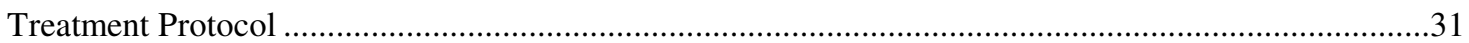

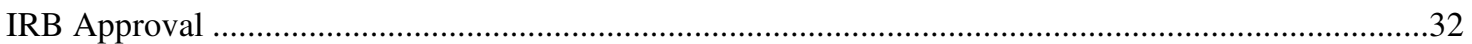

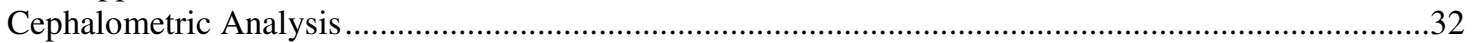

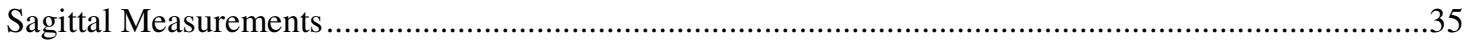

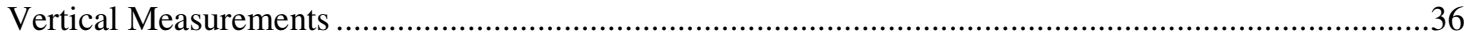

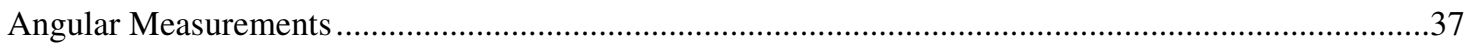

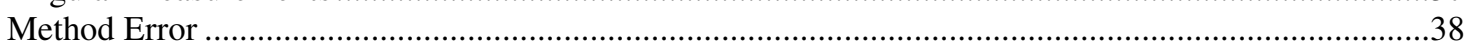

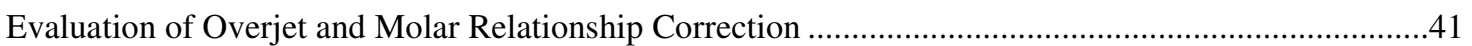

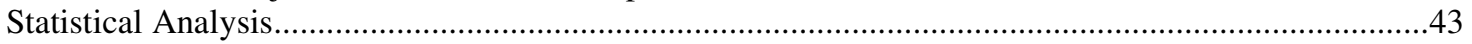

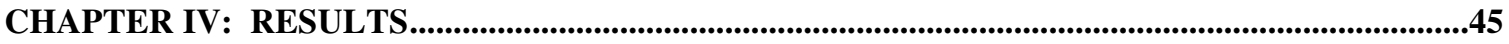

Distribution of Variable Measurements ..................................................................................................45

Pre-treatment Craniofacial Morphology of the Treatment vs. the Control Group ....................................45

Comparison of the Treatment Group and the Control Group Across the Time Periods ...........................50

Comparison of the Treated Group vs. the Control Group...........................................................................53

Comparison of T2-T1 (Treatment Effects of Orthodontic Appliances and the Forsus FRD) ...................53

Overjet and Molar Relationship Correction-Treatment Group (T2-T1) .................................................59

Net Overjet and Molar Relationship Correction - Tx vs Control Group (T2-T1)...................................63

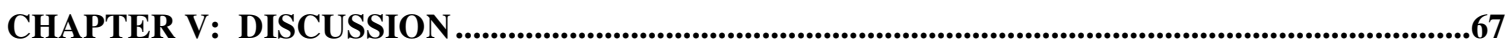

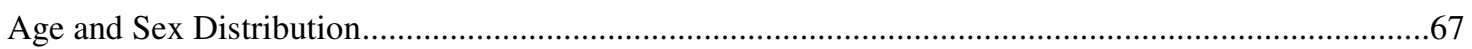

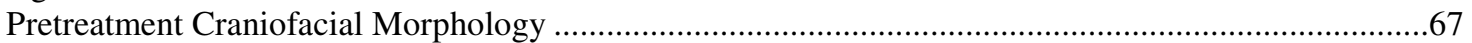

Comparison of the Treated Group Versus the Control Group (T2-T1) ...................................................68

CHAPTER VI: SUMMARY AND CONCLUSIONS..................................................................................79

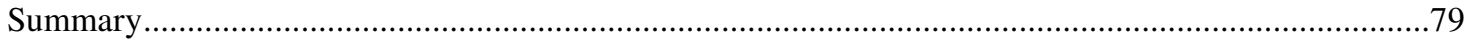

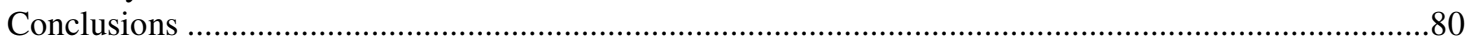

CHAPTER VII: RECOMMENDATIONS FOR FUTURE RESEARCH..............................................82

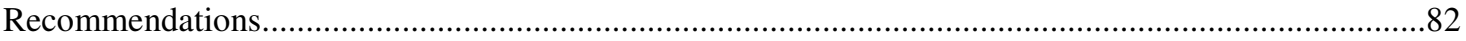

REFERENCE LIST ............................................................................................................................83

APPENDICIES ........................................................................................................................................93

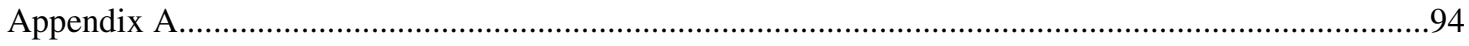

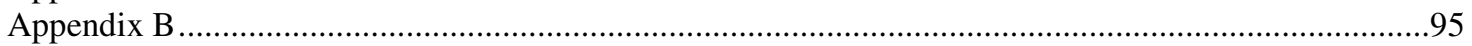

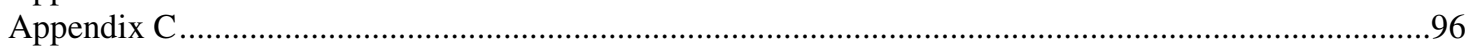

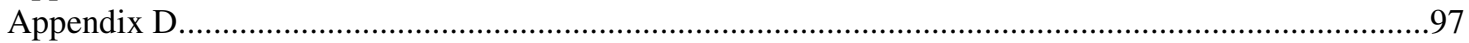

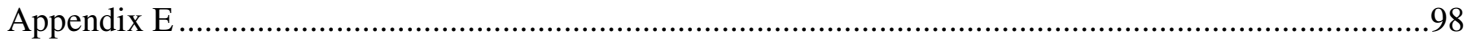

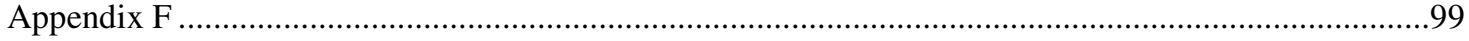

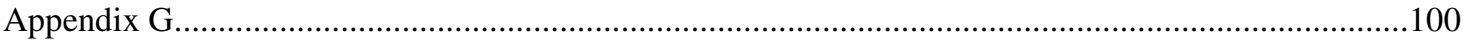

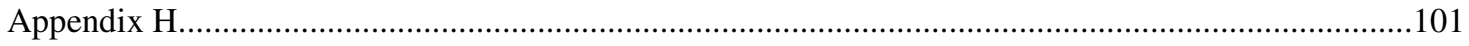




\section{LIST OF TABLES}

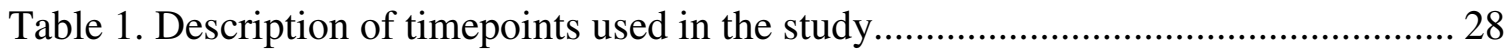

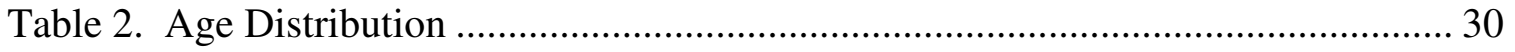

Table 3. Skeletal and Dental Landmarks ..................................................................... 34

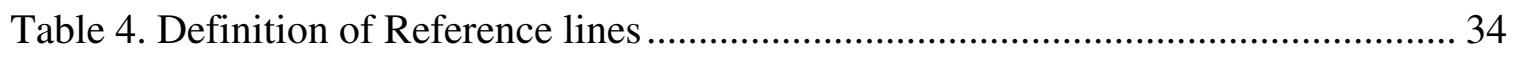

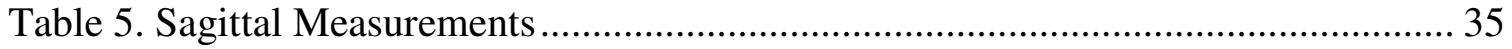

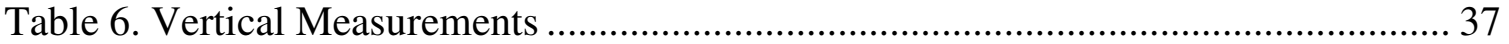

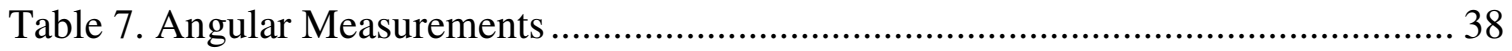

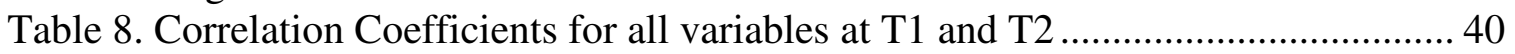

Table 9. Calculation of Overjet and Molar Relationship Changes ................................. 41

Table 10. Comparison of the pretreatment craniofacial morphology in pooled subjects 47

Table 11. Comparison of the pretreatment craniofacial morphology in male subjects ... 48

Table 12. Comparison of the pretreatment craniofacial morphology in female subjects 49

Table 13. Comparison of the Treatment group vs the Control group across the time

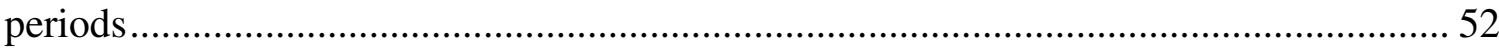

Table 14. Comparison of the Treatment group vs the Control group in pooled subjects

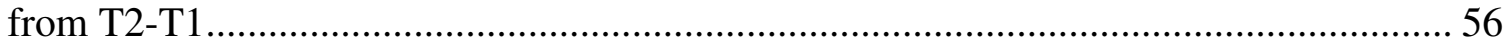

Table 15. Comparison of the Treatment group vs the Control group in male subjects

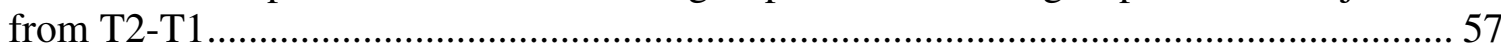

Table 16. Comparison of the Treatment group vs the Control group in female subjects

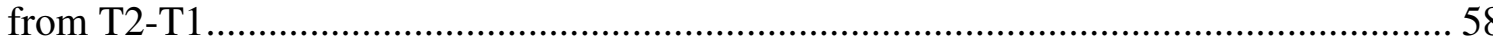




\section{LIST OF FIGURES}

Figure 1. The Forsus Fatigue Resistant Device ........................................................... 23

Figure 2. Cephalometric landmarks and lines for sagittal measurements ...................... 36

Figure 3. Cephalometric landmarks and lines for vertical measurements ........................ 37

Figure 4. Cephalometric landmarks and lines for angular measurements ........................ 38

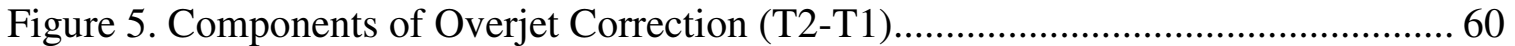

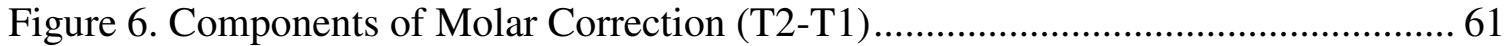

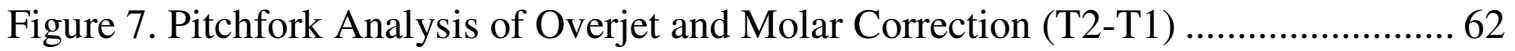

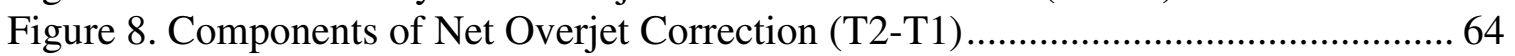

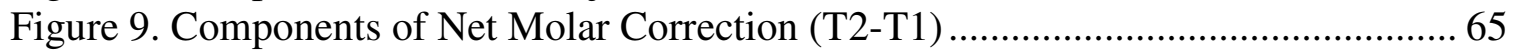

Figure 10. Pitchfork Analysis of Net Overjet and Molar Correction (T2-T1)................. 66 


\section{CHAPTER 1: INTRODUCTION}

\section{Background}

A common practice to correct a retrognathic mandible with a Class II malocclusion is to use a functional appliance. ${ }^{1-3}$ There are two types of functional appliances; removable and fixed. Removable appliances, such as the Frankel regulator, Bionator, Activator, Twin Block, and even Class II elastics, often have inconsistent results due to the fact that these appliances require high levels of patient cooperation. ${ }^{4}$ A major advantage of fixed appliances, such as the Herbst, The Jasper Jumper, MARA, and Forsus Fatigue Resistant Device, is that they require very little patient cooperation which can lead to more consistent results. ${ }^{5}$ Since Emil Herbst first developed his Herbst appliance in the early 1900 's ${ }^{5}$, the treatment effects of the various types of Herbst appliances have been well documented in the literature. There is a significant amount of evidence that Class II malocclusion with mandibular retrusion can be corrected with a combination of maxillary restraint, mandibular lengthening, dental changes, and glenoid fossa remodeling. ${ }^{6-15}$ More recently, the Forsus Fatigue Resistant Device (Forsus FRD), has some have claimed to achieve similar results as the Herbst appliance. However, documented evidence on the effects of this appliance is scarce in the literature.

This study investigated the skeletal and dental changes of 24 patients treated with fixed orthodontic appliances and the Forsus FRD. Results were compared to 22 untreated patients who were matched in age, sex and craniofacial morphology. Cephalometric radiographs were taken before orthodontic treatment (T1) and at a recall appointment after treatment with the Forsus FRD and fixed orthodontic appliances (T2). The amount 
of skeletal and dental change was determined using a published cephalometric analysis and was statistically analyzed.

\section{Statement of the Problem}

- What are the treatment effects of the Forsus FRD appliance when used in conjunction with fixed orthodontic appliances?

\section{Significance of the problem}

- The Forsus Fatigue Resistant Device was introduced by 3M/Unitek in 1999 and was marketed as a modified Herbst type appliance and Class II elastic alternative, but to date little research has been done on the correction obtained. Many orthodontists routinely use the Forsus FRD in their practices and it is difficult to determine the amount of skeletal or dental changes that are obtained.

- Results of this study will provide information about the magnitude of skeletal and dental changes in patients treated with fixed orthodontic appliances and the Forsus FRD. Clinicians will be able to use this data to aid them in deciding which appliance is most suitable to correct Class II malocclusions in the growing patient.

\section{Hypothesis}

- There are no mean changes over time between the maxillary and mandibular growth in patients treated with fixed orthodontic appliances and the Forsus FRD and an untreated control group.

\section{Definition of Terms}

- Cephalogram: 
- A cephalometric radiograph.

- Cephalometric Radiograph:

- A lateral head film made with the patient in a fixed reproducible position with precise relationships between x-ray source, subject, and film. The generally accepted distances between x-ray source and the center of the subject are 5 feet or $150 \mathrm{~cm}$. The distance between the subject and film is usually $15 \mathrm{~cm}$, but may be standardized at a different value or varied with patient size and recorded for each exposure.

- Cephalometrics:

- The scientific measurement of the bones and teeth of the cranium by utilizing a fixed, reproducible position for the exposure of a lateral head film.

- Cephalometric Analysis:

- A description of positions and relationships of various skeletal, dental and soft tissue components based on a number of landmarks.

- Cephalometric Landmark:

- A point located on a cephalometric radiograph from which lines, planes, and angles may be constructed to analyze the configuration and relationship of elements of the craniofacial skeleton.

- Cephalometric tracing: 
- A tracing of structures from a cephalometric radiograph, made on translucent drafting paper or digitized on computer software for purposes of measurement and evaluation.

- Bolton-Brush Study:

- A longitudinal growth study performed at the Case Western University, which involved subjects with Class I, Class II, and Class III malocclusions who did not receive orthodontic treatment. These individuals were followed with orthodontic records for several years and their growth patterns were measured.

- Class II malocclusion:

- A type of malocclusion in which the mesiobuccal cusp of the maxillary first molar is located mesial to the buccal groove of the mandibular first molar when the teeth are in centric occlusion.

- Class II skeletal pattern:

- A type of skeletal discrepancy in which the mandible is in a retrusive position relative to the maxilla and the face has a convex profile.

- Functional appliance:

- An appliance that is temporarily placed in a patient's mouth to allow some type of growth guidance treatment to be carried out.

- Removable Functional Appliance: 
- A functional appliance which can be removed and inserted by the patient

- Fixed Functional Appliance:

- A functional appliance that cannot be removed by the patient.

- Herbst appliance:

- A type of fixed functional appliance that protrudes the mandible into a forward position to stimulate mandibular growth and inhibit forward maxillary growth in patients with skeletal Class II skeletal patterns.

- Forsus Fatigue Resistant Device (Forsus FRD):

- A type of fixed functional appliance, manufactured and sold by 3M Unitek, which protrudes the mandible into a forward position to stimulate mandibular growth in patients with Class II skeletal patterns.

- Retrognathic:

- A term used to define the position of a skeletal component that is located more posterior than normal.

\section{Assumptions}

- Cephalometric radiographs taken with different machines at different times can be compared by adjusting the magnification.

- Cephalometric measurements can be utilized to evaluate mandibular growth.

- Orthopedic force can modify growth of the maxilla and mandible. 
- Radiographs traced by 2 operators can be compared

\section{Limitations}

- All lateral cephlograms are not always taken with the mandible in centric relation.

- The growth patterns of the experimental and control groups, who are matched in skeletal age, sex, and craniofacial morphology, may not be similar.

- The experimental and control groups were selected from different geographical sources. (Charleston, WV; Case Western University/ Bolton Brush Study Center in Cleveland, $\mathrm{OH}$ )

- Individual growth patterns and growth periods were not available.

- Skeletal age of the experimental groups cannot be obtained.

- The follow up cephalograms were taken at different time intervals.

- The decision to place the Forsus FRD was based on the clinical judgment of one of the investigators (Dr. Imad Shammaa), and there were no set criteria in determining the severity of Class II malocclusion that would be treated with the Forsus FRD.

- Data was collected from two separate investigators

\section{Delimitations}

- It is a retrospective study of a group of patients from the offices of one of the investigators Dr. Imad Shammaa, and untreated patients from the Bolton-Brush Study 
- The Forsus FRD experimental group was composed of 24 patients treated by one clinician (Dr. Imad Shammaa).

- All patients must have exhibited continued growth throughout treatment, as confirmed by CVM.

- The experimental and control groups were limited to patients who had acceptable quality radiographs for the various time points of the study.

- All patients must have had a retrognathic mandible.

- All patients were matched by age, gender and craniofacial morphology. 


\section{CHAPTER 2: REVIEW OF LITERATURE}

\section{History of Classification of Malocclusions}

Around 1850, the first text that described orthodontics appeared named Treatise on oral deformities as a branch of mechanical surgery, by Norman Kingsley. Full dentitions were rare due to the high prevalence of tooth extraction, so occlusal relationships were unimportant. ${ }^{16}$ The concept of occlusion developed in the late 1800's because of the need for better prosthetic teeth, and Edward H. Angle applied these concepts to the natural dentition in the 1890's. Angle's classification of malocclusion subdivided the major types of malocclusion and was the first definition of a normal occlusion. ${ }^{17}$ Angle felt that the upper first molars were a key factor in a balanced occlusion and that the mesiobuccal cusp of the upper first molar should occlude in the buccal groove of the lower first molar. He felt that a normal occlusion would result from this ideal molar relationship, and having all the teeth aligned in a smooth curving line. ${ }^{17}$ The three malocclusions he described were:

Class I - The mesiobuccal cusp of the maxillary first molar occludes in the mandibular first molar's buccal groove, but there was a discrepancy in the arch curvature.

Class II - The mesiobuccal cusp of the maxillary first molar was mesial to the buccal groove of the mandibular first molar.

Class III - The mesiobuccal cusp of the maxillary first molar was distal to the buccal grove of the mandibular first molar. ${ }^{16,18,19}$

While there are shortcomings of this classification published by Angle, it still remains the gold standard to describe occlusal relationships. 


\section{Etiology of malocclusions and the need for orthodontic therapy}

Growth in a Class II skeletal pattern is a complex process influenced by: 1) Genetics, 2) Function, 3) Deformities, and 4) Size and position of bones. The facial bones that contribute to a Class II skeletal pattern are divided into several parts; the anterior and posterior cranial base, nasomaxillary complex and the corpus and ramus of the mandible. ${ }^{20}$ Most Class II malocclusions North America are due to a mandibular deficiency. ${ }^{16}$ As the severity of a Class II malocclusion increases, there is more likely a combination of genetics and environmental causes. ${ }^{16}$ Specific interferences with growth can cause a few types of Class II malocclusion. Functional causes acting by themselves play a relatively small role in the prevalence of Class II malocclusions but alterations in the equilibrium of growth can accentuate Class II tendencies that are already present.

Historically, there are several justifiable reasons for orthodontic treatment. A few of the problems that can occur without orthodontic treatment include: Psychosocial problems, such as low self esteem due to teasing because of facial appearance; improper oral function, such as difficulties chewing, swallowing, or speaking; increased risk of trauma to the teeth or jaws; increased risk of periodontal disease; and increased risk of tooth decay. ${ }^{16,17}$

\section{Prevalence of Class II malocclusion}

About one third of the population in the United States has a Class II malocclusion. ${ }^{21-}$

${ }^{24}$ A higher prevalence of Class II malocclusions appear in individuals with northern European descent (30-40\%) than other racial groups (African Americans: 14-18\%). Between $8-10 \%$ of the entire population has an overjet larger than six millimeters. 


\section{Components of Class II Malocclusion}

The first component of a Class II malocclusion is that the mesiobuccal cusp of the maxillary first molar is mesial to the buccal groove of the mandibular first molar. In addition to this occlusal malocclusion there are a number of skeletal and dental

combinations. ${ }^{16}$ A true skeletal malocclusion is either caused by deficient mandibular growth, excessive maxillary growth, or a combination. ${ }^{25-27}$ Class II malocclusions can be further subdivided into the following categories; anterior position of the maxilla, anterior position of the maxillary dentition, mandibular skeletal retrusion in absolute size or

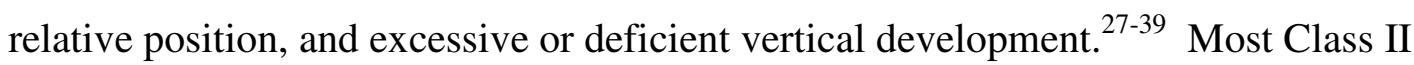
patients have either mandibular retrusion or both vertical and horizontal abberations of the mandible. ${ }^{18,27}$

Class II skeletal patterns normally present with a convex profile because of the retrognathic mandible. The convexity of the face may also be due to a prognathic maxilla, but is much less common. The tip of the chin and the lower lip usually lie behind nasion perpendicular, which presents as a convex profile. ${ }^{27}$

There are two types of Class II malocclusion; Class II division 1 and Class II division 2. Class II division 1 is characterized by proclined maxillary incisors whereas Class II division 2 is characterized by normal or retroclined maxillary central incisors and tipping of the maxillary lateral incisors in a labial and mesial direction. ${ }^{19,38,40,41}$ Class II division 1 patients typically have a deep bite and an overactive mentalis muscle because of the contraction patterns of the facial muscles due to the concave profile and large overjet. Commonly, a tongue thrust is developed because of the lack of lip seal. ${ }^{26}$ Class II division 2 patients typically have better lip seal and a less retrognathic mandible. ${ }^{19}$ 
Class II division 1 and division 2 patients cephalometrically differ from each other at the upper incisor relation to the occlusal plane, NA, and SN. These measurements varied as much as 15 degrees between the two types of malocclusions. Class II division 1 central incisors are always more proclined, and usually have at least $3 \mathrm{~mm}$ more overjet on average than Class II division 2. Class II division 2 tend to have on average a $2.4 \mathrm{~mm}$ deeper overbite. ${ }^{41}$

\section{Growth Potential in Class II Patients}

Alignment of the facial bones contributes to the Class II skeletal malocclusion. The different components of the craniofacial complex are: the anterior and posterior cranial base, the nasomaxillary complex and the mandible. ${ }^{20}$

\section{Cranial Base}

The primary sites of growth in the cranium are the outer cortex (bone deposition), inner cortex (bone resorption) and the spheno-occipital synchondrosis (endochondral growth). The spheno-occipital synchondrosis is bi-directional in its growth direction which is a pressure adaptive growth mechanism causing displacement of bones. ${ }^{20}$ Ngan et al. ${ }^{42}$ found no significant differences between Class I and Class II samples at four cranial base measurements; S-N, S-Ar, saddle angle (N-S-Ar), and the articulare angle (S-Ar-Go). In the horizontal dimension, the mandibular position (S-N-B and S-N-Pog) was found to be significantly more retrusive in Class II subjects and there were no significant differences at S-N-A.

\section{Nasomaxillary Complex}

The growth of the maxilla occurs at the sutures between the cranium and the maxilla by bony apposition. As the maxilla grows, it has a downward and forward 
movement andlarger than normal growth in the anterior-posterior dimension may result in a Class II skeletal pattern. ${ }^{20}$ McNamara ${ }^{27}$ found that the anterior-posterior position of the maxilla was normal in most Class II skeletal cases, and in a retruded position in the remaining cases. He also found that patients who had long lower anterior facial height and large mandibular plane often have a retruded maxilla and mandible.

Proffit $^{16}$ describes the growth of the nasomaxillary complex as a result of passive displacement and active growth of the maxillary sutures and nose. Passive displacement is created by the growth at the cranial base and pushes the maxilla forward. It is an important growth mechanism in the primary dentition years but its importance diminishes when the synchondrosis of the cranial base slows as neural growth completes around age 7. Active growth of the maxillary sutures and nose contributes the majority of the forward movement of the maxilla from age 7 to $15 . \mathrm{McNamara}^{27}$ and Proffit ${ }^{16}$ have reported the normal rate of growth of the maxilla is about 1 to $2 \mathrm{~mm}$ per year and that the effective maxillary length to effective mandibular length growth is in a linear direction. This relationship is related to the size of the patient, not age or sex.

\section{Mandible}

Mandibular growth occurs by deposition and resorption in the posterior superior direction. Therefore, the condyle grows into the glenoid fossa, and the mandible is displaced in a downward and forward position at the same rate as the growth of the mandible. The direction of the new bone growth in the condyle and the displacement of the mandible are opposite. ${ }^{42}$ The growth of the mandible occurs at a continuous rate until puberty. The ramus increases 1 to $2 \mathrm{~mm}$ per year and the body increases 2 to $3 \mathrm{~mm}$ per year. ${ }^{16,18}$ Mandibular growth plays a very important role in the formation of a Class II 
skeletal profile. Corpus length (Go-Gn), mandibular length (Ar-Gn), y axis (S-Gn-FH), and posterior-anterior facial height (PFH/AFH) all vary significantly between Class I and Class II patients. ${ }^{42}$ An increase in the corpus length and mandibular length occur during the growth spurt in Class I patients, but does not occur in Class II patients. As well, y axis and mandibular plane angle increase in Class II patients, but decrease in Class I patients. ${ }^{42}$ Upper facial height (N-ANS) and total facial height (N-Me) increases at the same rate for Class I and II patients. Posterior facial height (PFH/AFH) increases in Class I patients, but not in Class II patients. ${ }^{42}$ A steep occlusal plane can also lead to a retrusive mandible. ${ }^{42}$ Restricted mandibular growth may also occur due to a constricted maxillary arch. This is due to the prevention of the forward movement of the maxilla and will not self correct without treatment. ${ }^{43}$

There are five different rotations of the mandible that can be used to predict growth patterns. 1) The axis of rotation is the condyle and the growth is upward. This is usually seen in Class II division 2 patients. 2) The axis of rotation is the incisal edge and causes downward rotational growth of the ramus which leads to a shallow mandibular plane angle and an increase in posterior face height. 3) The axis of rotation is a fulcrum point on the molars, and causes a downward rotation of the posterior mandible and superior rotation of the anterior mandible. This causes a decreased anterior facial height and increased posterior facial height which is commonly seen in Class II division 2 patients. 4) The axis of rotation is the center of the condyle and the rotation is downward and backward which causes an increase in anterior facial height, as seen in Class II division 1 patients. 5) The axis of rotation is a fulcrum point in the posterior dentition which leads to a downward and backward rotation of the mandible causing an 
increase in anterior facial height and convex profile as seen in Class II division 1 patients. $^{44}$

\section{Diagnosis of Class II Malocclusion}

A Class II skeletal pattern is one that includes the mandible positioned in a distal relationship to the maxilla and can be a result of mandibular retrusion, maxillary protrusion, or a combination of both. Because the mandible is a hinge joint, the vertical component of the dentofacial complex is also important in Class II malocclusions. A decrease in vertical dimension of the anterior face causes the mandible to rotate upward and forward reducing the anteroposterior discrepancy. An increase in vertical dimension will cause the mandible to rotate downward and backward worsening the skeletal relationship. In addition, the incisors can be proclined, normal, or retroclined. Many factors contribute to a Class II skeletal malocclusion, and an analysis of the dentofacial complex is important in describing the components of a particular malocclusion. These components are best analyzed cephalometrically using a number of different radiographic

analyses. Nasion perpendicular to point A (NP-A) ${ }^{45}$ and Sella-Nasion-Point A (SNA) ${ }^{33,46}$ are two measurements which measure the position of the maxilla which is usually normal or slightly retruded in Class II patients. The maxillary incisors should be 4 to $6 \mathrm{~mm}$ from a perpendicular line drawn through point $\mathrm{A} \cdot{ }^{18,45,47}$ The upper central incisor is normal in $50 \%$, retroclined in $30 \%$, and proclined in $20 \%$ of Class II patients. ${ }^{27}$ Mandibular $^{2}$ position relative to the cranial base can be measured from Pogonion to the nasion perpendicular ${ }^{48}$ and from Sella-Nasion-Point B (SNB). ${ }^{33,46}$ A line from the tip of the lower incisor to point A-Pogonion can determine the position of the lower incisor. ${ }^{49,50}$ 
As mentioned earlier, the vertical component of the skeletal malocclusion can make an impact on the extent of the Class II deformity by either concealing or magnifying the retrusion of the mandible. ${ }^{50,51}$ A decreased vertical dimension causes the mandible to rotate upward and forward which can mask a deficient mandible. Increased facial height can cause an even more retrusive mandible, poorly defined chin, a hyperactive mentalis, and open bite tendency. The vertical dimension can be measured radiographically by using the mandibular plane angle (MP-SN, MP-FH) and lower facial height (anterior nasal spine to menton). ${ }^{27}$

The transverse dimension is also important to evaluate on Class II patients. The transverse width of the dental arches may appear normal when the patient is in centric occlusion, however a discrepancy of up to $5 \mathrm{~mm}$ may exist when the mandible is moved forward so that the canines and molars are in a Class I relationship. ${ }^{52}$ Class II malocclusions tend not to self correct and through growth is continued to be related with a decreased maxillary width. ${ }^{43,53,54}$ Patients with mild to moderate Class II skeletal discrepancies may benefit from rapid maxillary expansion during the mixed dentition, as it may allow for correction the occlusal relationship by encouraging a forward posturing of the mandible and preventing further restriction of mandibular growth. ${ }^{47,55}$

\section{Treatment of Class II Malocclusions}

Treatment of a Class II malocclusion greatly depends on the growth potential of the particular patient. For patients with no remaining growth potential, treatment options include: Compromise/non-extraction, camouflage/extraction, maxillary molar distalization, and surgery. If surgery or extractions are not an option, the treatment is 
often left with a compromised result of aligned teeth but a disharmonious molar relationship and residual overjet due to the skeletal discrepancy. Camouflage treatment can sometimes use extractions to treat the malocclusion by creating space for malaligned teeth and reduction of overjet. The most common Class II malocclusion extraction pattern is to remove the maxillary first premolars and the mandibular second premolars. If there is no crowding in the mandibular arch, extraction of upper first premolars only may be warranted to allow for a compromised overjet correction. For minor Class II corrections, another option is to distalize the maxillary first molar to attain a Class I molar relationship. However, the amount of correction is limited to only $1-2 \mathrm{~mm} .{ }^{56}$ The final treatment option is surgery, which can include mandibular advancement or a mandibular and maxillary advancement. This allows full skeletal correction and is the most ideal as it places the teeth in maximum intercuspation in a Class I relationship and puts the structures of the face in their most harmonious position. However, this is the most invasive and costly of all the treatment options.

Class II treatment for the growing patient has a different set of treatment options, and is usually timed around the peak of the growth spurt, 13.9 \pm 1.0 years in males and 11.7 \pm 1.0 years in females. ${ }^{57}$ The treatment options include: Non-extraction/compromise, extractions, and growth modification with a functional appliance. Nonextraction/compromise treatment will usually align the teeth, but possibly leave some of the overjet at the finish of treatment. Extractions are sometimes necessary in the growing patient, and are usually reserved for situations of severe crowding. The most common teeth to extract are the maxillary and mandibular first or second premolars, and which teeth are removed usually depends on the degree of crowding and the patient's profile. ${ }^{58}$ 
Surgery is not an immediate option in the growing patient; however, if a patient is interested in surgically correcting a skeletal discrepancy, treatment can be postponed until growth is complete. If a patient has a moderate discrepancy and refuses surgery, or wants treatment immediately, growth modification with a functional appliance is a possible treatment option.

\section{History of functional appliances used to treat Class II malocclusions}

In 1877, Norman W. Kingsley was the first to introduce a functional appliance. His bite jumping appliance consisted of an upper plate with an inclined plane which forced the lower incisors and mandible anteriorly. The rationale behind all Class II functional appliances is to force the mandible forward during function to stimulate condylar growth and correct the Class II malocclusion. In the 1930's the Andresen activator and similar appliances became widespread throughout Germany and

Switzerland. ${ }^{16,59}$ According to Proffit ${ }^{16}$ and Graber $^{60}$, functional appliances can be either passive tooth borne, active tooth borne, tissue borne, or a combination of the three. The Activator, Bionator, Herbst and Twin Block are passive tooth borne appliances that depend on soft tissue and muscle activity to produce effects. The activator is an acrylic block that covers the teeth and the palate and fit loosely to allow advancement of the mandible several millimeters and opens the bite 3-4 mm. The Bionator is an activator with palatal coverage eliminated. Active tooth borne appliances are passive tooth borne appliances with springs or screws attached which provide a force that produces treatment effects. The tissue borne appliance rests on tissue only, and an example is the Frankel 
appliance that consists of a small pad against the lingual mucosa beneath the lower incisors to stimulate mandibular repositioning. ${ }^{16}$

The results of removable functional appliances are mixed. Some studies claim that they increase mandibular growth ${ }^{3,61-66}$, and some show no effect on mandibular growth $^{67-70}$. Evaluating the results of removable functional appliances is difficult because the appliance is in the mouth only a portion of the day and the threshold for condylar adaptation may never be reached. Patient compliance is a problem and inadequate appliance wear could produce mixed results. As well, the treatment time is relatively long (2-4 years) and adequate control groups are often hard to find.

\section{The Herbst Appliance}

Fixed functional appliances have the advantage that they are fixed in the mouth; therefore, compliance is not an issue and treatment results are much more predictable. ${ }^{5}$ Fixed appliances have the following advantages over removable appliances; no cooperation from the patient is required, is active all day and night, and treatment is shorter (6-9 months). ${ }^{71,72}$ The Herbst is one of the most common fixed functional appliances for the correction of Class II malocclusions. The Herbst appliance was first introduced in 1909 by Emil Herbst and several articles were presented on the appliance in 1934. ${ }^{73}$ The Herbst appliance stayed relatively unknown until Dr. Hans Panchrez wrote a paper about it in $1979^{71}$, and the use of the appliance spread throughout Europe and North America. Variations of the Herbst then became popular, altering from the original design of orthodontic bands on the upper first molars and the lower first premolars connected by a piston. These variations included the bonded acrylic Herbst ${ }^{74}$, cast splint Herbst ${ }^{56,75}$, and the crown Herbst ${ }^{76-79}$ 


\section{Indications and timing for the Herbst appliance}

The Herbst appliance is indicated for the treatment of growing individuals with Class II/Div 1 and Class II/Div 2 malocclusions. Research has shown that the largest amount of treatment effects occur if the Herbst placement coincides with the peak pubertal growth spurt. $^{80}$

\section{Effects of the Herbst Appliance}

\section{- Skeletal Changes}

The Herbst appliance's restrains the horizontal growth of the maxilla in a similar fashion as headgear. ${ }^{71,81}$ There is decreased horizontal growth in the maxilla ${ }^{11,12,82,83}$, and a slight clockwise rotation of the palatal plane $e^{82,83}$, but the overall size of the maxilla is unaffected. ${ }^{12,82}$ The mandible has been reported to increase in sagittal length by $1.3 \mathrm{~mm}$ to $3.5 \mathrm{~mm}$ as a result of Herbst treatment. ${ }^{12,56,71,81-87}$ An anterior-posterior remodeling of the tempromandibular joint also can occur with the Herbst appliance. There is some radiographic evidence that the articular fossa remodels in an anterior direction ${ }^{56,71,88}$, but some feel this remodeling does not significantly contribute to Class II correction. ${ }^{89}$

\section{- Dental Changes}

The Herbst appliance has maxillary dental effects very similar to a high pull headgear. The maxillary molars are both distalized and intruded ${ }^{11,56,71,82,83,85-}$ ${ }^{87,90}$, but some of these effects are temporary as some extrusion and mesial movement of the upper first molar occurs after treatment. ${ }^{90}$ The mandibular 
dentition moves in an anterior direction, proclining and intruding the lower incisors ${ }^{11,56,71,86,90}$, but they do relapse and retroclined slightly after treatment. ${ }^{82}$ The mandibular molar continues to erupt during treatment with the Herbst appliance. $^{71,82,83}$

\section{- Vertical Changes}

The Herbst appliance reduces the amount of overbite by the intrusion and proclination of the lower incisors and eruption of the lower molars. ${ }^{11,71,81,91}$ It has been noted that the Herbst does slightly increase the lower facial height ${ }^{11,71}$, but others have found no increase in lower facial height. ${ }^{56,82}$ There is little effect on the mandibular plane angle ${ }^{11,56,71,82,83}$, and the occlusal and palatal plane tip downward anteriorly. ${ }^{71,82}$

\section{- Post Treatment Relapse}

It has been reported that the changes which occur with the Herbst appliance relapse at the conclusion of treatment. These changes are a tipping of the palatal plane up anteriorly, mesial and extrusive movements of the maxillary first molar, and uprighting of the lower incisors. ${ }^{72,82}$ A long term study ${ }^{92}$ has shown that after 4 years of retention, a control group had almost the same amount of mandibular growth as a Herbst treatment group. This occurred by the growth of the treatment group slowing to less than the level of the control group until the control group's amount of growth caught up. Some studies have shown that the skeletal effects of the Herbst are temporary. ${ }^{10,83}$ Some research exists which recommends that Herbst treatment be timed so the permanent bicuspids are 
erupted and through good interdigitation, prevent a high degree of skeletal and dental relapse. ${ }^{12,56,81,83,93}$ Therefore, a solid functional occlusion can help prevent post treatment relapse.

\section{The Jasper Jumper}

The Jasper Jumper was introduced in the 1990's and consists of two flexible springs connected to the upper first molar and the lower archwire to produce a light protrusive force to the mandible. Cope et $\mathrm{al}^{94}$ found that the changes were mostly dentoalveolar, although other studies have reported up to 3-40\% skeletal effects of the appliance. ${ }^{95-97}$ Effects of the dentition include a clockwise rotation of the occlusal plane, without much alteration of the vertical dimension. ${ }^{95}$ However, Stucki et al ${ }^{98}$ found that only $60 \%$ of the changes obtained with a Jasper Jumper remained after a retention period of 7 months.

Studies have shown that short term treatment effects of functional appliances can result in correction of Class II mandibular retrusion due to mandibular lengthening, dental changes, and glenoid fossa remodeling. ${ }^{6,9-15,99,100}$ However, long term studies have been infrequent. Nelson et al ${ }^{101}$ concluded that changes associated with a functional appliance may be marked in the short term, however, long term follow up revealed that the changes were not sustained.

\section{Class II Interarch Elastics}

Another method of treating Class II malocclusions is through the use of intraoral elastics to provide an anterior force in the mandible, and a distal force on the maxilla. The treatment effects of Class II elastics have been well documented and changes can be 
seen in the glenoid fossa and the head of the condyle, however, most of the treatment effects are dentoalveolar. ${ }^{102-105}$ Thus, treatment with Class II elastics resolves the jaw discrepancy through some slight stimulation of mandibular growth ${ }^{106}$, but mostly through the rotation of the occlusal plane, proclination of the mandibular incisors, mandibular incisor intrusion, mandibular molar and maxillary incisor extrusion and retrusion of the

maxillary incisors. ${ }^{107-113}$ Nelson et. al $^{112}$ directly compared the treatment effects of Class II elastics to the Herbst appliance and found that while molars correction were similar, the mandibular plane angle and the lower facial height increased more in the elastics group than in the Herbst group. They found that skeletal correction of the Class II malocclusion for the Herbst group was $66 \%$, while only $10 \%$ for the elastics group.

\section{The Forsus FRD}

The Forsus FRD was introduced by 3M/Unitek in 1999 and was marketed as a Class II elastic and Herbst replacement. However; unlike the Herbst appliance which is designed to be used before orthodontic appliances, the Forsus FRD is designed to be used during the final stages of orthodontic appliance treatment. The Forsus appliance originally consisted of a flat Nickel Titanium rod that held the mandible in a protruded position and has now evolved to include an appliance that clips into headgear tubes on the buccal of the maxillary first molar bands. This clip (Forsus EZ2 Module) is attached to a Nickel Titanium spring and rod that hooks onto the lower archwire between the lower first premolar and the lower canine brackets to apply a maximum $200 \mathrm{~g}$ of force when fully compressed to keep the mandible in a protruded position. ${ }^{114}$ (Figure 1) 


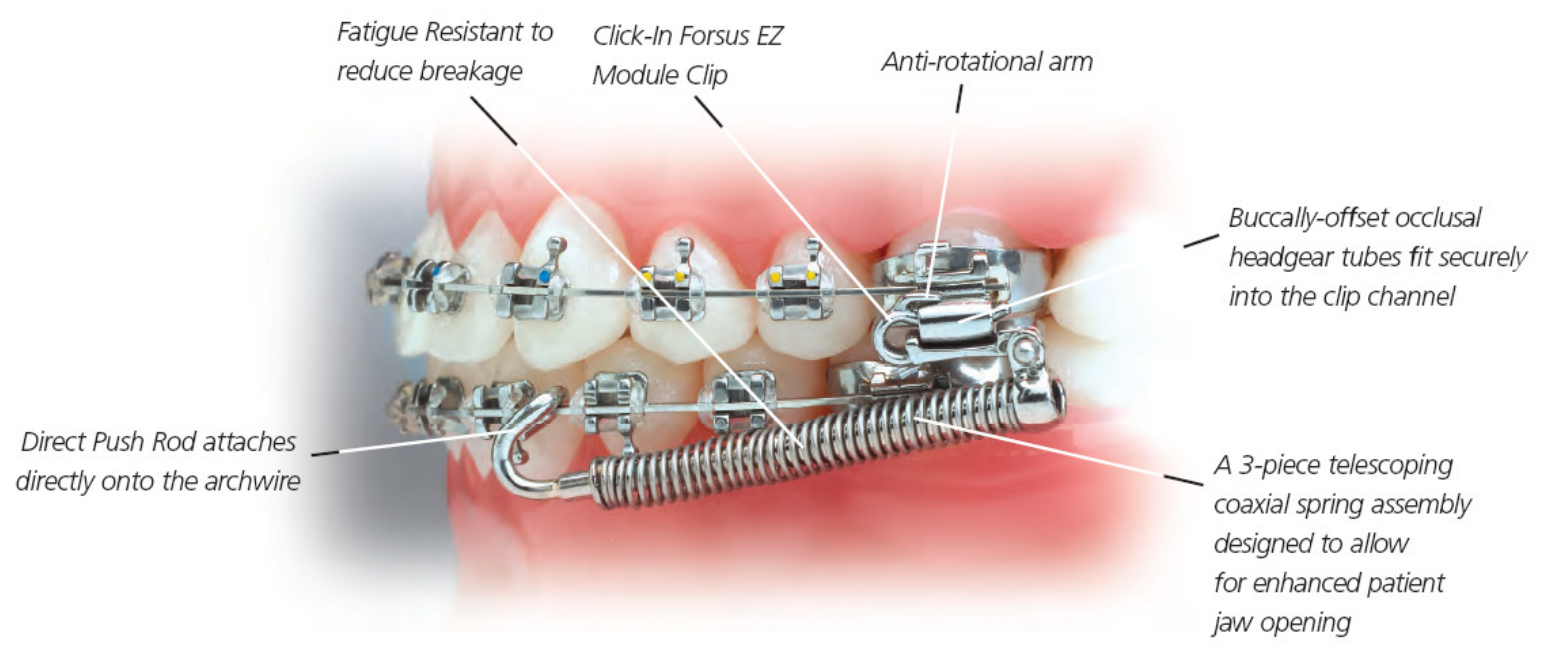

Figure 1. The Forsus Fatigue Resistant Device

The level of force applied, however, is not constant. As the patient opens, the force becomes less, and as the patient closes, the force level is increased. According to $3 \mathrm{M}$ Unitek, force levels are similar to Class II elastics, as are the treatment effects, except that Class II correction is typically seen quicker as the Forsus is fixed and cooperation is not an issue as it is with Class II elastics. ${ }^{115}$

There have been case reports of the fatigue resistant module breakage ${ }^{116}$ however, other studies document the good resiliency of the Niti springs. ${ }^{117}$ An updated EZ module has also been released to help reduce breakage, and recent 3M Unitek literature states that the Forsus appliance has been compression cycled tested over 5 million times without breakage or force fatigue. ${ }^{115}$ To date only 10 articles including case reports have been published on all the different Forsus devices.

\section{Indications for the Forsus FRD}


All functional appliances are aimed at encouraging growth and maximum skeletal results are therefore more likely in a growing individual. ${ }^{72}$ In non-growing patients, jumping the bite with any appliance would likely result in maximum dental effects ${ }^{72}$, possibility of developing a dual bite ${ }^{118}$, and possible development of TMD ${ }^{119}$. Fixed functional appliances can be useful in situations that would be difficult for a removable functional appliance such as uncooperative patients and mouth breathers. ${ }^{72}$ The Forsus FRD can be used in any situation that Class II elastics or a Herbst appliance would be used. $^{114}$ Ideally, the patient's case would be treatment planned from the beginning to use a Forsus FRD which would allow the option of using negatively inclined lower incisor brackets to minimize lower incisor flaring. However, the Forsus FRD can be used on non-compliant patients who refuse to wear Class II elastics. ${ }^{114}$ Studies have shown that the Forsus FRD worked as good as Class II elastics, and required no compliance. ${ }^{120}$

\section{Effects of the Forsus FRD}

\section{- Sagittal Changes}

Few studies exist that demonstrate the sagittal effects of the Forsus FRD. Heinig et al. ${ }^{121}$ in 2001 found that the Forsus FRD corrected Class II malocclusions and that the correction was $66 \%$ dental, and $34 \%$ skeletal. The correction was obtained by: distal movement of the maxillary molars, mesial movement of the mandibular molars, retroclination of the upper incisors, proclination of the lower incisors, retardation of the sagittal growth of the maxilla and increased growth of the mandible. ${ }^{121}$ However, this study did not compare the results to an untreated control group to account for the effects of growth. Karacay et al. ${ }^{122}$ compared the Forsus Nitinol Flat Spring to the 
Jasper Jumper and an untreated control group and found a combination of skeletal and dental effects that were similar in both appliances that lead to the correction of the Class II malocclusion. Jones et al. ${ }^{120}$ compared the Forsus FRD to Class II elastics and found that both corrected Class II malocclusions, but the Forsus FRD had statistically significantly more mandibular molar mesial movement and better total molar relationship correction. However, this study also did not compare the results to an untreated control group to account for the effects of growth. Other studies have also shown the Forsus FRD lead to a skeletal change to help reduce the overjet (forward movement of B point). ${ }^{123,124}$

\section{- Vertical Changes}

The vertical changes noticed during Forsus FRD correction include an intrusion of the maxillary first molars that allowed for correction without bite opening. ${ }^{114}$ A clockwise rotation of $4.2^{\circ}$ of the occlusal plane has also been noted due to the intrusion of the maxillary first molars and lower incisor, which lead to a reduction of the overbite. ${ }^{121}$ Similar findings have also been reported by some studies, ${ }^{122}$ while others found extrusion of both maxillary and mandibular first molars. ${ }^{120}$

\section{- Long Term Post Treatment Effects}

No articles were found describing the long-term post treatment effects of the Forsus FRD. 


\section{Timing of the Forsus FRD treatment}

As mentioned previously, functional devices should be used at the peak of the growth

spurt to maximize modification of skeletal growth and minimize dental changes. ${ }^{57,81}$ This will help minimize unwanted dental effects such as proclination of the lower incisors and maximize the amount of mandibular condylar growth. ${ }^{81}$ Placement of the Forsus FRD must wait until after the teeth are leveled and aligned and a near full size arch wire (19x25 stainless steel in .022 slot, $17 \times 25$ stainless steel in .018 slot) is in place on the mandibular arch. ${ }^{114} 3 \mathrm{M}$ Unitek also recommends that the upper and lower arch wires should be cinched distal to the most posterior bracket to allow the arches to move as a whole and minimize dental effects of the Forsus FRD.

\section{Dr. Shammaa's Forsus FRD protocol}

Dr. Imad Shammaa's patient Forsus FRD protocol is as follows:

1. Upper and lower molars are banded with Unitek .022 slot MBT prescription bands. The upper first molar bands have an occlusal headgear tube which allowed the engagement clip of the pushrod device to secure to it.

2. Upper and lower second premolar to second premolar are bonded using Unitek Victory Series .022 slot Low Profile MBT brackets.

3. The teeth are leveled and aligned using an archwire sequence of: .014 Niti, 16x22 Niti, 16x22 Stainless Steel (SS), and 19x25 SS.

4. Once all the teeth are leveled and aligned and the spaces were closed, the Forsus FRD with EZ clip is attached to the occlusal headgear tube on the upper first molar and the lower 19x25 SS wire between the lower first 
premolar and the lower canine. The maxillary and mandibular arches are colligated from first molar to contralateral first molar on a 19x25 SS wire to minimize any unwanted proclination of the lower incisors, as per manufacturer's instructions.

5. The Forsus FRD is then left in place for between 6-12 months, depending on the severity of the malocclusion. The average time the Forsus FRD in place is 9 months.

6. Once all appliances were removed, the upper and lower teeth are retained with upper and lower Hawley retainers. 


\section{CHAPTER 3: MATERIALS AND METHODS}

\section{Sample Description}

\section{Experimental Group:}

The experimental group originally was composed of 56 consecutively treated patients treated with orthodontic fixed appliances and the Forsus FRD by Dr. Imad Shammaa in his private practice in Charleston, West Virginia. The following inclusion criteria was used to obtain the sample: no history of orthodontic treatment before the initial radiograph, acceptable quality radiographs for both timepoints, and remaining growth potential as confirmed by CVM. Exclusion criteria included poor quality radiographs, missing radiographs for either timepoint, and no remaining growth potential as confirmed by CVM. The final sample size was reduced to 24 patients ( 9 females, 15 males) after ruling out patients who did not meet the criteria. The treatment records consisted of lateral cephalometric radiographs taken at two time points throughout treatment. They were taken prior to treatment (T1), and after treatment with the Forsus FRD and removal of fixed orthodontic appliances (T2).

\begin{tabular}{|l|l|}
\hline T1 & Pre Treatment \\
\hline T2 & Post treatment after Forsus FRD and Fixed Orthodontic Appliances \\
\hline
\end{tabular}

Table 1. Description of timepoints used in the study

\section{Control Group:}

The data for the control group was obtained from a collection of patients previously collected from the Bolton-Brush Study. The control group consisted of serial 
cephalometric radiographs of subjects with Class II malocclusions with no history of orthodontic treatment which were matched in age, sex, and crainiofacial morphology as closely as possible with the experimental subjects. Each control subject was matched with a cephalometric radiograph taken at the same time periods as the treatment subjects.

\section{Sample Size}

The final treatment group consisted of 24 subjects ( 9 females and 15 males). The control group was collected from Wigal ${ }^{125}$ consisted of 22 subjects (15 females and 7 males).

\section{Sex Distribution}

The sex of the treated and control groups did not exactly match. The control group consisted of 15 females and 7 males, and the treatment group consisted of 9 females and 15 males.

\section{Age Distribution}

As the treatment group was compared to existing data from the work of Wigal ${ }^{125}$, the groups age were matched as closely as possible, but were not exactly matched. (Table 2). The mean age of the treatment group at $\mathrm{T} 1$ for pooled subjects was 10.7 years. The mean age of the control group at $\mathrm{T} 1$ for pooled subjects was 10.3 years. The mean age of the treatment group at $\mathrm{T} 1$ for male subjects was 10.8 years. The mean age of the control group at $\mathrm{T} 1$ for male subjects was 10.5 years. The mean age of the treatment group at $\mathrm{T} 1$ for female subjects was 10.5 years. The mean age of the control group at $\mathrm{T} 1$ for female subjects was 10.3 years. Age distributions for both the treatment and control groups for 
pooled subjects, male subjects, and female subjects at each time point (T1 and T2) are reported in Table 2. No significant differences were found between the treatment and control groups for any of the time periods (T1 and T2). Analysis was then performed at both timepionts.

\begin{tabular}{|c|c|c|c|c|c|c|c|}
\hline & & MEAN & S.D. & MAX & MIN & DIFF & SIG \\
\hline \multicolumn{8}{|c|}{ POOLED } \\
\hline \multirow[b]{2}{*}{ T1 } & Control & 10.3 & 1.1 & 13.1 & 8.1 & \multirow[b]{2}{*}{0.3} & \multirow[b]{2}{*}{ NS } \\
\hline & Treatment & 10.7 & 1.5 & 13.6 & 7.7 & & \\
\hline \multirow[b]{2}{*}{ T2 } & Control & 14.7 & 1.5 & 18.7 & 13.0 & \multirow[b]{2}{*}{0.2} & \multirow[b]{2}{*}{ NS } \\
\hline & Treatment & 14.5 & 1.2 & 16.6 & 11.8 & & \\
\hline \multicolumn{8}{|l|}{ MALES } \\
\hline \multirow[b]{2}{*}{ T1 } & Control & 10.5 & 1.4 & 13.1 & 8.5 & \multirow[b]{2}{*}{0.3} & \multirow[b]{2}{*}{ NS } \\
\hline & Treatment & 10.8 & 1.3 & 12.5 & 8.8 & & \\
\hline \multirow[b]{2}{*}{ T2 } & Control & 15.2 & 1.9 & 18.7 & 13.0 & \multirow[b]{2}{*}{0.5} & \multirow[b]{2}{*}{ NS } \\
\hline & Treatment & 14.8 & 1.2 & 16.6 & 11.8 & & \\
\hline \multicolumn{8}{|c|}{ FEMALES } \\
\hline \multirow[b]{2}{*}{ T1 } & Control & 10.3 & 1.0 & 12.0 & 8.1 & \multirow[b]{2}{*}{0.3} & \multirow[b]{2}{*}{ NS } \\
\hline & Treatment & 10.5 & 1.9 & 13.6 & 7.7 & & \\
\hline \multirow[b]{2}{*}{ T2 } & Control & 14.4 & 1.3 & 17.0 & 13.0 & \multirow[b]{2}{*}{0.4} & \multirow[b]{2}{*}{ NS } \\
\hline & Treatment & 14.0 & 1.0 & 15.4 & 12.8 & & \\
\hline
\end{tabular}

Table 2. Age Distribution

\section{CVM Distribution}

The Cervical Vertebra Maturation (CVM) for each patient was determined in the manner as described by Baccetti et al ${ }^{126}$. The average CVM stage at the $\mathrm{T} 1$ was 1.8 . The average CVM stage at $\mathrm{T} 2$ was 4.9. According to Baccetti et $\mathrm{al}^{126}$ this means that the initial pretreatment radiograph was taken before the peak of the pubertal growth spurt which is associated with the CVM stage 3, and the final radiograph was taken after the peak of the pubertal growth spurt. Therefore, the treatment group entered their peak pubertal growth spurt between the $\mathrm{T} 1$ and $\mathrm{T} 2$ radiographs. 


\section{Treatment Protocol}

The Forsus appliance was used to correct a Class II malocclusion once the upper and lower arches have been leveled and aligned and there is a working wire with sufficient strength in use. Dr. Imad Shammaa's patient Forsus FRD protocol was as follows:

1. Upper and lower molars were banded with Unitek .022 slot MBT prescription bands. The upper first molar bands had an occlusal headgear tube which allowed the engagement clip of the pushrod device to secure to it.

2. Upper and lower second premolar to second premolar were bonded using Unitek Victory Series .022 slot Low Profile MBT brackets. The lower incisor brackets had a $-6^{\circ}$ inclination to help minimize the anterior proclination that is a side effect of all Class II correction.

3. The teeth were leveled and aligned using an archwire sequence of: .014 Niti, 16x22 Niti, 16x22 Stainless Steel (SS), and 19x25 SS.

4. Once all the teeth were leveled and aligned and the spaces were closed, the Forsus FRD with EZ clip was attached to the occlusal headgear tube on the upper first molar and the lower 19x25 SS wire between the lower first premolar and the lower canine. The maxillary and mandibular arches were colligated from first molar to contralateral first molar on a 19x25 SS wire to minimize any unwanted proclination of the lower incisors, as per manufacturer's instructions.

5. The Forsus FRD was then left in place for between 6 top 12 months with an average time of 9 months, depending on the severity of the malocclusion. 
Overcorrection with the Forsus FRD was achieved where possible to account for relapse.

6. After Forsus FRD removal, Dr. Shammaa then finalized the occlusion using the same 19x25 SS wires, and then removed all orthodontic appliances.

7. Once all appliances were removed, the upper and lower teeth are retained with upper and lower Hawley retainers.

8. Radiographs were taken before any treatment began (T1) and at a recall appointment after removal of all orthodontic appliances (T2).

\section{IRB Approval}

IRB exemption was obtained from West Virginia University prior to beginning this study (Appendix A). Approval was also obtained from Dr. Imad Shammaa for the use of his orthodontic records. (Appendix B)

\section{Cephalometric Analysis}

Lateral Cephalograms were obtained from the office of Dr. Imad Shammaa for the experimental group. The time points obtained were Pre Treatment (T1) and Post Treatment after Forsus FRD and removal of fixed orthodontic appliances (T2). The radiographs were obtained electronically via an online collaboration service Sesame (Sesame Communications, Seattle, WA). Files were downloaded in jpeg format, and then digitized in Dolphin Imaging (Dolphin Imaging, Chatsworth, CA) for initial landmark identification and to adjust for magnification. Each image was then printed 1:1 to ensure there was no magnification. The files were printed on a Dell Color Laser Printer 5110cn (Dell Inc, Round Rock, TX). Data for control subjects was obtained from 
the thesis of Wigal ${ }^{125}$, which also was adjusted for magnification so all measurements were made $1: 1$.

Tracings were made on the printouts, and final landmark identification was performed while viewing the original digital file. Tracings of the entire treatment group were performed by one operator using a \#2 HB mechanical lead pencil (Zebra $.5 \mathrm{~mm}$ lead), an orthodontic protractor, and .003 inch matte cephalometric acetate tracing film (3M Unitek, Monrovia, CA). A custom cephalometric analysis was performed as described by Bjork ${ }^{127}$, Pancherz ${ }^{91}$, VanLaecken ${ }^{79}$ and Wigal ${ }^{125}$ (Table $3 \&$ Table 4): 


\begin{tabular}{|l|l|l|}
\hline Symbol & \multicolumn{1}{|c|}{ Name } & \multicolumn{1}{c|}{ Definition } \\
\hline Ii & Incision inferious & The incisal point of the most prominent mandibular central incisor \\
\hline Is & Incision superious & The incisal point of the most prominent maxillary central incisor \\
\hline Iia & $\begin{array}{l}\text { Mandibular incisor } \\
\text { apex }\end{array}$ & The root apex of the most prominent mandibular central incisor \\
\hline Isa & Maxillary incisor apex & The root apex of the most prominent maxillary central incisor \\
\hline Mi & Molar inferious & The mesial contact point of the mandibular permanent first molar \\
\hline Mic & $\begin{array}{l}\text { Molar inferious mesial } \\
\text { cusp }\end{array}$ & The mesio-buccal cusp tip of the mandibular first molar \\
\hline Ms & Molar superious & The mesial contact point of the maxillary permanent first molar \\
\hline Msc & $\begin{array}{l}\text { Molar superious mesial } \\
\text { cusp }\end{array}$ & The mesio-buccal cusp tip of the maxillary first molar \\
\hline Co & Condylion & The most supero-posterior point on the curvature of the condylar head \\
\hline Pg & Pogonion & The most prominent point of the chin \\
\hline ANS & Anterior Nasal Spine & The apex of the spina nasalis anterior \\
\hline A pt. & Subspinale & $\begin{array}{l}\text { The deepest point in the concavity of the anterior maxilla between the } \\
\text { Ans and alveolar crest }\end{array}$ \\
\hline PNS & Posterior Nasal Spine & $\begin{array}{l}\text { The most posterior point on the contour of the palate in the } \\
\text { midsagittal plane }\end{array}$ \\
\hline Me & Menton & The deepest point of the mandibular symphysis \\
\hline Go & Gonion & The lowest point of the bony contour of the angle of the mandible \\
\hline S & Sella & The center of Sella turcica \\
\hline N & Nasion & The most anterior point of the nasofrontal suture \\
\hline B pt. & Supramentale & $\begin{array}{l}\text { The innermost point on the contour of the mandible between the } \\
\text { incisor tooth and the bony chin }\end{array}$ \\
\hline Gn & Gnathion & The center of the inferior point on the mandibular symphysis \\
\hline
\end{tabular}

Table 3. Skeletal and Dental Landmarks

\begin{tabular}{|l|l|l|}
\hline Symbol & \multicolumn{1}{|c|}{ Name } & \multicolumn{1}{c|}{ Definition } \\
\hline NSL & Sella-Nasion Line & Reference line joining Nasion and Sella \\
\hline OL & Occlusal Line & $\begin{array}{l}\text { Reference line joining the maxillary incisal edge and the molar } \\
\text { superious mesial cusp tip }\end{array}$ \\
\hline OLp & $\begin{array}{l}\text { Occlusal Line } \\
\text { Perpendicular }\end{array}$ & $\begin{array}{l}\text { Reference line produced by dropping a perpendicular line from sella } \\
\text { to the occlusal plane }\end{array}$ \\
\hline Ols & Occlusal Line Sella & $\begin{array}{l}\text { Reference line parallel to OL passing through sella (perpendicular to } \\
\text { OLp passing through sella) }\end{array}$ \\
\hline NL & Maxillary Line & Reference line joining anterior nasal spine and posterior nasal spine \\
\hline ML & Mandibular Line & Reference line joining menton and gonion \\
\hline
\end{tabular}

Table 4. Definition of Reference lines

The measurement for each angular variable was performed by using a cephalometric protractor and was measured to the nearest 0.5 degree. The measurement 
for each sagittal and vertical measurement was performed with an electronic digital caliper and measured to the nearest $0.1 \mathrm{~mm}$. The caliper was calibrated to $0.0 \mathrm{~mm}$ prior to each measurement. Lateral cephalograms often present landmarks with right and left images; therefore, the midpoint bisecting the two images was used.

\section{Sagittal Measurements}

Sagittal skeletal and dental changes were measured by forming a reference grid based on the occlusal line (OL) and occlusal line perpendicular (OLp), obtained from the T1 lateral cephalogram. (Figure 2) This reference grid was used for all sagittal measurements between OLp and the cephalometric landmarks. The reference grid from T1 was transferred to $\mathrm{T} 2$ radiographs by superimposition on the anterior cranial base. Measurements were taken from OLp to landmarks as well as four other measurements: Condylion-A pt (Co-Apt); Condylion-Gnathion (Co-Gn); Condylion-Gnathion minus Condylion-A pt. (Co-Gn minus Co-Apt); and Wits analysis. (Table 5)

\begin{tabular}{|l|l|}
\hline \multicolumn{1}{|c|}{ Variables } & \multicolumn{1}{c|}{ Definition } \\
\hline Skeletal measuring points: & \\
\hline OLp-A pt. & Position of maxillary base \\
\hline OLp-Pg & Position of mandibular base \\
\hline OLp-Co & Position of Condyle \\
\hline Co-A pt. & Effective midface length \\
\hline Co-Gn & Effective mandibular length \\
\hline Co-Gn minus Co-A pt. & Maxillomandibular length differential \\
\hline Wits analysis & Position of the maxillary base relative to the mandibular base \\
\hline Dental measuring points: & \\
\hline Is-OLp & Position of maxillary central incisor \\
\hline Ii-OLp & Position of mandibular incisor \\
\hline Is-OLp minus Ii-OLp & Overjet \\
\hline Ms-OLp & Position of maxillary first permanent molar \\
\hline Mi-OLp & Position of mandibular first molar \\
\hline Ms-OLp minus Mi-OLp & Molar Relationship \\
\hline
\end{tabular}

Table 5. Sagittal Measurements 


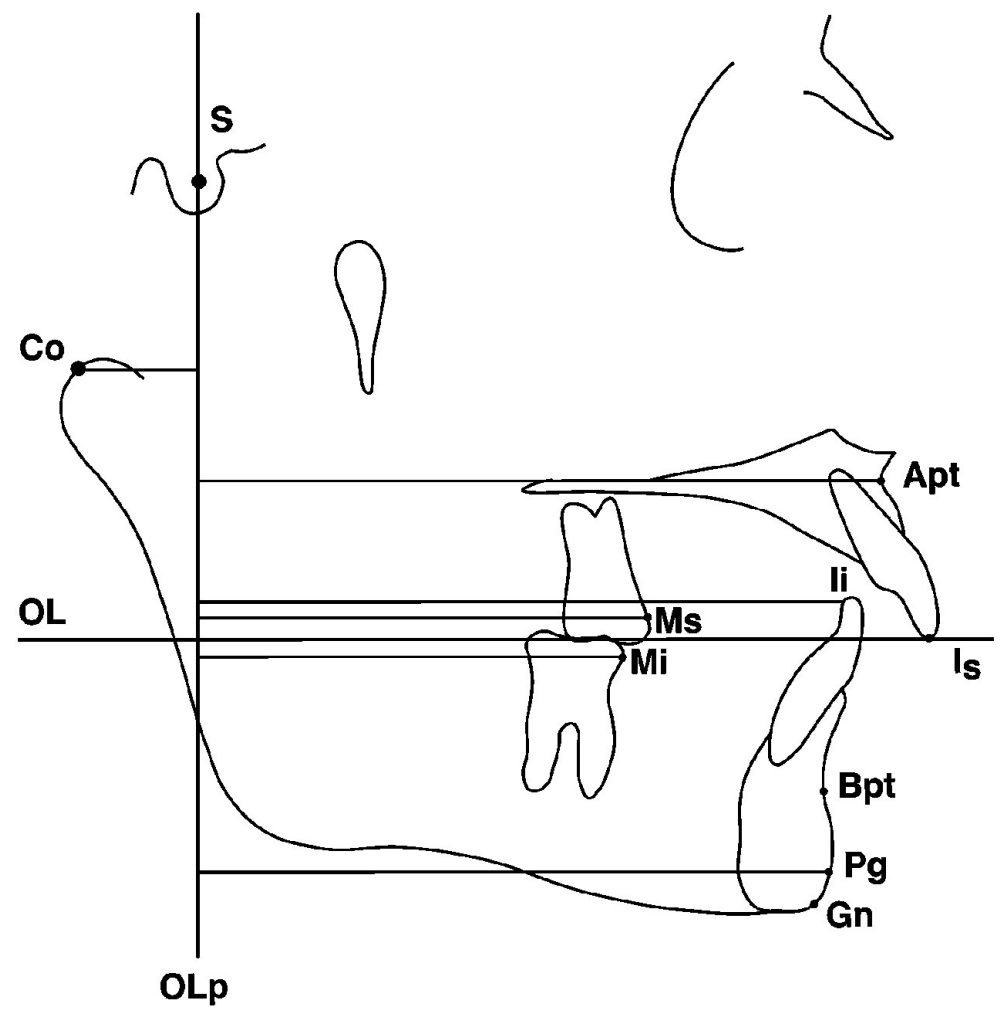

Figure 2. Cephalometric landmarks and lines for sagittal measurements

\section{Vertical Measurements}

Vertical measurements included OLs, NL, and ML, and OL (Figure 3). OLs was obtained from the T1 radiograph and transferred by superimposition on the anterior cranial base to the $\mathrm{T} 2$ radiographs. A measurement from ANS to Me (ANS-Me) was also included. The variables are listed in Table 6. 


\begin{tabular}{|l|l|}
\hline \multicolumn{1}{|c|}{ Variables } & \multicolumn{1}{c|}{ Definition } \\
\hline Skeletal measuring points: & \\
\hline OLs-A pt. & Maxillary vertical position \\
\hline ANS-Me & Lower facial height \\
\hline Dental measuring points: & \\
\hline Is-NL & Position of maxillary central incisor \\
\hline Ii-ML & Position of mandibular central incisor \\
\hline Distance from Ii perpendicular To OL & Overbite \\
\hline Msc-NL & Position of maxillary permanent first molar \\
\hline Mic-ML & Position of mandibular permanent first molar \\
\hline
\end{tabular}

Table 6. Vertical Measurements

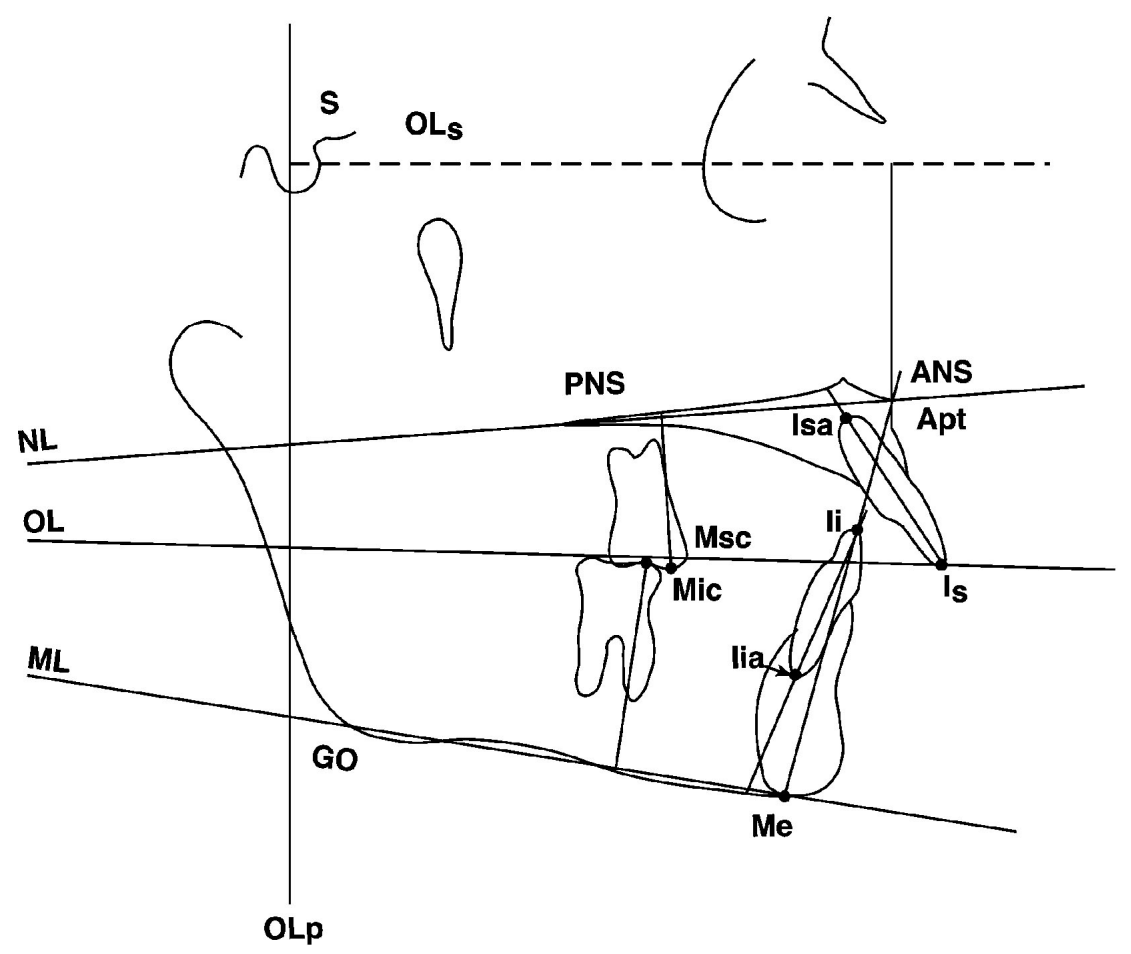

Figure 3. Cephalometric landmarks and lines for vertical measurements

\section{Angular Measurements}

Angular measurements were used to identify changes in the dentofacial complex

(Table 7). Cephalometric landmarks and lines for angular measurements are illustrated in

Figure 4. 


\begin{tabular}{|l|l|}
\hline \multicolumn{1}{|c|}{ Variables } & \multicolumn{1}{c|}{ Definition } \\
\hline Skeletal measuring points: & \\
\hline SNA & Maxillary base relative to SNL \\
\hline SNB & Mandibular base relative to SNL \\
\hline ANB & SNA minus SNB \\
\hline SNL-NL & Palatal plane angle \\
\hline SNL-ML & Mandibular plane angle \\
\hline SNL-OLf & Occlusal plane angle (Functional occlusal plane) \\
\hline Dental measuring points: & \\
\hline Is/NL & Maxillary central incisor angle \\
\hline Ii/ML & Mandibular central incisor angle \\
\hline Isa-Is/Iia-Ii & Interincisal angle \\
\hline
\end{tabular}

Table 7. Angular Measurements

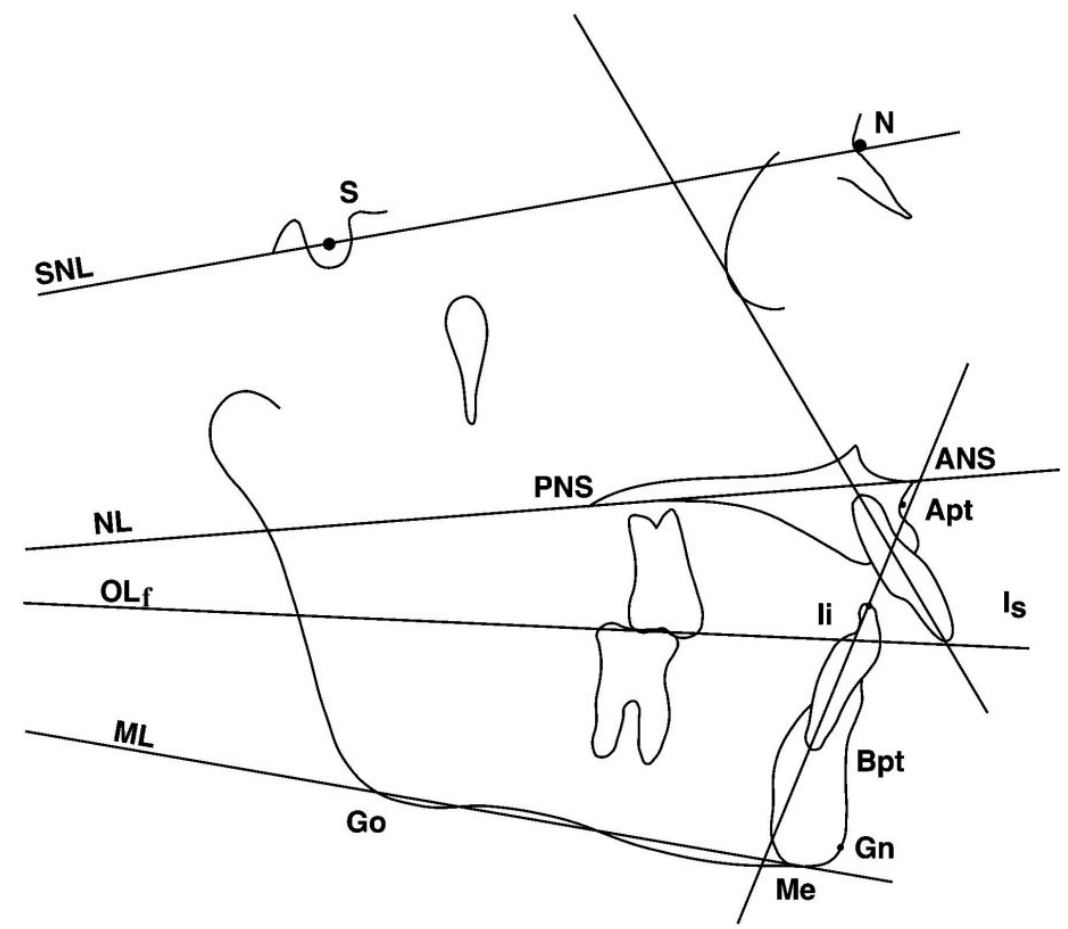

Figure 4. Cephalometric landmarks and lines for angular measurements

\section{Method Error}

The reliability of the cephalometric measurements was tested by evaluating the error in locating, superimposing and measuring the differences in the landmarks. Pre 
Treatment (T1), and Post Treatment (T2) radiographs of ten randomly selected patients were retraced two weeks after initial tracing and were analyzed to evaluate the error. For all cephalometric variables, differences between the measurements from the first and second tracings were compared for each individual at T1 and T2. A matched pairs t-test was performed to compare the two sets of measurements. A correlation coefficient was established for each variable at each time point to determine the degree of reliability (Table 8). 


\begin{tabular}{|c|c|c|c|c|c|c|}
\hline \multirow[b]{2}{*}{ Variables } & \multicolumn{3}{|c|}{$\mathrm{T} 1$} & \multicolumn{3}{|c|}{$\mathrm{T} 2$} \\
\hline & Mean (1st) & Mean (2nd) & Correlation & Mean (1st) & Mean (2nd) & Correlation \\
\hline \multicolumn{7}{|l|}{ Sagittal: } \\
\hline 1. Olp-A pt. & 70.3 & 70.6 & 0.99 & 74.1 & 73.8 & 0.97 \\
\hline 2. $\mathrm{Olp}-\mathrm{Pg}$ & 71.1 & 71.2 & 0.98 & 77.3 & 77.3 & 0.99 \\
\hline 3. Olp-Co & 10.5 & 10.2 & 0.99 & 12.3 & 12.6 & 0.98 \\
\hline 4. Co-A pt. & 81.3 & 81.4 & 0.98 & 87.1 & 86.9 & 0.98 \\
\hline 5. Co-Gn & 98.5 & 98.1 & 0.99 & 108.6 & 108.9 & 0.99 \\
\hline 6. Co-Gn minus Co-A pt. & 17.1 & 16.7 & 0.97 & 21.5 & 22.0 & 0.99 \\
\hline 7. Wits & 1.5 & 1.6 & 0.97 & -0.3 & -0.3 & 0.98 \\
\hline 8. Is-Olp & 78.4 & 78.6 & 0.99 & 80.9 & 80.9 & 0.99 \\
\hline 9. $\mathrm{li}-\mathrm{Olp}$ & 70.8 & 71.0 & 0.99 & 77.5 & 77.4 & 0.98 \\
\hline 10. Overjet & 7.7 & 7.6 & 0.99 & 3.4 & 3.5 & 0.89 \\
\hline 11. Ms-Olp & 48.1 & 48.1 & 0.99 & 52.9 & 53.0 & 0.98 \\
\hline 12. Mi-Olp & 47.4 & 48.0 & 0.95 & 55.4 & 54.8 & 0.98 \\
\hline 13. Molar Relationship & 0.8 & 0.1 & 0.90 & -2.5 & -1.8 & 0.79 \\
\hline \multicolumn{7}{|l|}{ Vertical: } \\
\hline 14. OLs-A pt. & 29.1 & 28.7 & 0.99 & 32.5 & 32.4 & 0.98 \\
\hline 15. ANS-Me & 58.0 & 57.8 & 0.99 & 62.9 & 62.9 & 0.99 \\
\hline 16. Is-NL & 29.0 & 29.1 & 0.98 & 30.3 & 30.5 & 0.99 \\
\hline 17. Ii-ML & 36.2 & 36.2 & 0.99 & 37.7 & 37.9 & 0.99 \\
\hline 18. Overbite & 3.9 & 3.9 & 0.98 & 2.2 & 2.3 & 0.98 \\
\hline 19. Msc-NL & 18.7 & 18.6 & 0.98 & 21.7 & 21.6 & 0.99 \\
\hline 20. Mic-ML & 25.2 & 25.4 & 0.98 & 29.0 & 29.2 & 0.98 \\
\hline \multicolumn{7}{|l|}{ Angular: } \\
\hline 21. SNA & 81.6 & 82.0 & 0.97 & 81.5 & 81.3 & 0.98 \\
\hline 22. SNB & 76.1 & 76.3 & 0.98 & 77.1 & 77.2 & 0.99 \\
\hline 23. ANB & 5.6 & 5.7 & 0.95 & 4.4 & 4.1 & 0.96 \\
\hline 24. SNL-NL & 6.9 & 6.5 & 0.96 & 7.0 & 7.2 & 0.98 \\
\hline 25. SNL-ML & 34.0 & 34.3 & 0.99 & 33.3 & 33.1 & 0.99 \\
\hline 26. SNL-OL & 20.3 & 20.6 & 0.97 & 19.5 & 19.7 & 0.97 \\
\hline 27. Is/NL & 115.6 & 115.4 & 0.98 & 112.3 & 112.9 & 0.98 \\
\hline 28. $\mathrm{li} / \mathrm{ML}$ & 92.2 & 91.5 & 0.99 & 96.3 & 95.8 & 0.99 \\
\hline 29. Interincisal Angle & 124.2 & 124.8 & 0.99 & 124.7 & 124.8 & 0.99 \\
\hline
\end{tabular}

Table 8. Correlation Coefficients for all variables at T1 and T2 
The method of cephalometric analysis used in this study was determined to be reliable. This included the identification of landmarks, superimposition of radiographs, and the measurements taken at each timepoint. The correlations ranged from .79 to .99 , which means that the method of data collection was reliable.

\section{Evaluation of Overjet and Molar Relationship Correction}

To determine the amount of skeletal and dental contribution to the overjet and molar relationship correction, the amount of dental change in the maxilla and mandible was calculated. The method of obtaining these measurements is shown below (Table 9).

\begin{tabular}{|c|l|}
\hline \multicolumn{1}{|c|}{ Overjet } & \multicolumn{1}{c|}{ Molar Relationship } \\
\hline Skeletal contributions: & Skeletal contributions: \\
1. OLp-Apt & 1. OLp-Apt \\
2. OLP-Pg & 2. OLP-Pg \\
Dental contributions: & Dental contributions: \\
3. Is-OLp minus OLp-Apt & 3. Ms-OLp minus OLp-Apt \\
4. Ii-OLp minus OLp-Pg & 4. Mi-OLp minus OLp-Pg \\
Overjet correction: & Molar relationship correction: \\
Sum of 1,2,3,and 4 & Sum of 1,2,3, and 4 \\
\hline
\end{tabular}

Table 9. Calculation of Overjet and Molar Relationship Changes

When adding figures from the above table, the following formula was used for overjet correction:

$$
\begin{aligned}
& \text { Overjet Correction }=\text { Maxilla }+ \text { Mx incisor }- \text { Mandible }- \text { Md incisor } \\
& \qquad \begin{array}{l}
\text { Maxilla }=\text { OLp-A pt. } \\
\text { Mx incisor }=\text { Is-OLp minus OLp-A pt. } \\
\text { Mandible }=\text { OLp-Pg } \\
\text { Mandibular incisor }=\text { Ii-OLp minus OLP-Pg }
\end{array}
\end{aligned}
$$


When adding figures from the above table, the following formula was used for molar relationship correction or increase;

Molar Relationship Correction = Maxilla + Mx Molar - Mandible - Md Molar

$$
\begin{aligned}
& \text { Maxilla = OLp-A pt. } \\
& \text { Maxillary molar }=\text { Ms-OLp minus OLp-A pt. } \\
& \text { Mandible = OLp-Pg } \\
& \text { Mandibular molar = Mi-OLp minus OLp-Pg }
\end{aligned}
$$

Net Overjet/Molar Relationship Changes: When determining the net treatment effect of overjet and molar relationship correction, the control group figures were subtracted from the treated group. Calculations were made for the treatment group minus the control group at various time periods and the same formulas were used to calculate net overjet and net molar relationship correction or change:

Net Overjet Correction $=$ Maxilla + Mx incisor - Mandible - Md incisor

Maxilla $=$ OLp-A pt. (treated) minus OLp-A pt. (control)

Mx incisor $=($ Is-OLp minus OLp-A pt. $($ treated $))$ minus (Is-OLp minus OLp-A pt.(control) $)$

Mandible $=$ OLp-Pg (treated) minus OLp-Pg (control)

Mandibular incisor $=(\mathrm{Ii}-\mathrm{OLp}$ minus OLp-Pg(treated $))$ minus $(\mathrm{Ii}-\mathrm{OLp}$ minus OLp-Pg(control) $)$ 
When comparing the treated and control subjects for net molar relationship correction the following formula was used:

Net Molar Relationship Correction = Maxilla + Mx molar - Mandible - Md molar

Maxilla $=$ OLp-A pt. (treated) minus OLp-A pt. (control)

Mx molar $=($ Ms-OLp minus OLp-A pt.(treated) $)$ minus (Ms-OLp minus OLp-A pt.(control)

Mandible $=$ OLp-Pg (treated) minus OLp-Pg (control)

Mandibular incisor $=($ Mi-OLp minus OLp-Pg(treated $))$ minus $($ Mi-OLp minus OLP-Pg(control $))$

\section{Statistical Analysis}

A matched pairs t-test was used to compare the starting forms between the treatment and control subjects at $\mathrm{T} 1$. The differences between the treatment and control subjects for each variable across the three time periods (T1 through T2) were analyzed for pooled subjects (males and females combined), male subjects, and female subjects. A repeated measures analysis of variance (ANOVA) was performed to determine if the differences between the treatment and control subjects were the same across the two time periods. A matched pairs t-test was performed for each variable to identify the overall treatment effects of the fixed orthodontic appliances and the Forsus FRD appliance (Tx (T2-T1)) minus (Control (t2-t1)). A level of significance of $\mathrm{p}<0.05$ (95\% confidence interval) was used in this study.

Reliability was tested by using a matched pairs t-test to evaluate the correlation between measurements made at the initial tracing and measurements made on the same tracing at a later time. (Table 8) Correlation coefficients were reported to determine how 
strongly the first measurements were associated with the second measurements for each variable at every time period in ten individuals. 


\section{CHAPTER IV: RESULTS}

\section{Distribution of Variable Measurements}

The measurements for each of the 29 variables in both the treatment and control groups were analyzed. The mean, standard deviation, maximum, and minimum for each variable measurement were recorded for pooled subjects, male subjects, and female subjects at each time period (T1 and T2). Distributions of the variable measurements in both the treatment and control groups for pooled, male and female subjects at each time period are reported in Appendix C-Appendix H.

\section{Pre-treatment Craniofacial Morphology of the Treatment vs. the Control Group}

The pre-treatment craniofacial morphology of the treatment group and the control group were analyzed to determine if there were any statistically significant differences in any of the 29 variables used in this study. Differences were analyzed at T1 for pooled, male, and female subjects.

For pooled subjects, only 7 of the 29 variables were significantly different between the treatment group and control group at T1 (Table 10). Wits, Overjet, Molar Relationship, Ols-Apt, Is-NL, and Overbite were significantly greater in the treatment group than in the control group. Mic-ML was significantly less in the treatment group than in the control group. All other variables showed no significant differences at T1 between the treatment and control groups.

For males, only 1 of the 29 variables was significantly different between the treatment group and control group at T1 (Table 11). Mic-ML was significantly less in the 
treatment group than in the control group. All other variables showed no significant differences at $\mathrm{T} 1$ between the treatment and control groups.

For females, 6 of the 29 variables were significantly different between the treatment group and control group at T1 (Table 12). Wits, Overjet, Molar Relationship, Overbite, and ANB were significantly greater in the treatment group than in the control group. Co-Gn minus Co-Apt was significantly less in the treatment group than in the control group. All other variables showed no significant differences at T1 between the treatment and control groups.

The data suggest that the pre-treatment craniofacial morphology of the treatment group and the control group were very similar; however, there were some differences. For pooled subjects, it appears that the treated group had a more slightly larger Class II malocclusion, as the ANB ( $0.8^{\circ}$ greater $)$, Wits $(1.2 \mathrm{~mm}$ greater $)$, and Overjet $(2.5 \mathrm{~mm}$ greater) were significantly larger in the $\mathrm{T} 1$ treatment group compared to the $\mathrm{T} 1$ control group. It also appears that the treatment group started with a slightly deeper overbite (.8mm greater), as confirmed with the increased Is-NL (2.6mm greater), and decreased Mic-ML (1.5mm less) suggesting more eruption of the upper central incisors and decreased eruption of the lower first molars. 


\begin{tabular}{|c|c|c|c|c|c|c|c|}
\hline \multicolumn{8}{|c|}{ POOLED (MALES AND FEMALES) } \\
\hline \multirow[b]{2}{*}{ Variable } & \multicolumn{2}{|c|}{ Control } & \multicolumn{2}{|c|}{ Treated } & \multirow[b]{2}{*}{$p$ value } & \multirow[b]{2}{*}{ Diff. } & \multirow[b]{2}{*}{ Sig } \\
\hline & Mean & S.D. & Mean & S.D. & & & \\
\hline \multicolumn{8}{|l|}{ Sagittal: } \\
\hline Olp-A pt. & 70.3 & 4.2 & 70.9 & 4.5 & 0.6684 & 0.6 & NS \\
\hline Olp-Pg & 73.9 & 4.8 & 72.4 & 5.3 & 0.3286 & -1.5 & NS \\
\hline Olp-Co & 10.0 & 2.2 & 9.8 & 3.4 & 0.7782 & -0.2 & NS \\
\hline Co-A pt. & 80.7 & 4.1 & 81.3 & 5.3 & 0.6852 & 0.6 & NS \\
\hline Co-Gn & 99.7 & 5.3 & 99.3 & 7.0 & 0.8091 & -0.5 & NS \\
\hline Co-Gn minus Co-A pt. & 19.0 & 3.0 & 18.0 & 3.5 & 0.2948 & -1.0 & NS \\
\hline Wits & 0.6 & 1.7 & 1.8 & 1.9 & 0.0269 & 1.2 & * \\
\hline Is-Olp & 77.2 & 5.5 & 78.9 & 5.4 & 0.2925 & 1.7 & NS \\
\hline Ii-Olp & 71.9 & 4.8 & 71.1 & 4.8 & 0.5618 & -0.8 & NS \\
\hline Overjet & 5.3 & 1.6 & 7.8 & 2.9 & 0.0008 & 2.5 & * \\
\hline Ms-Olp & 49.2 & 3.8 & 48.8 & 4.7 & 0.7440 & -0.4 & NS \\
\hline Mi-Olp & 49.0 & 4.3 & 47.5 & 4.6 & 0.2549 & -1.5 & NS \\
\hline Molar Relationship & 0.2 & 0.9 & 1.3 & 1.8 & 0.0117 & 1.1 & * \\
\hline \multicolumn{8}{|l|}{ Vertical: } \\
\hline Ols-Apt & 26.9 & 2.3 & 30.2 & 5.7 & 0.0131 & 3.3 & * \\
\hline ANS-Me & 59.0 & 5.1 & 57.5 & 5.8 & 0.3620 & -1.5 & NS \\
\hline Is-NL & 26.0 & 2.6 & 28.5 & 3.1 & 0.0036 & 2.6 & ${ }^{*}$ \\
\hline Ii-ML & 35.4 & 3.3 & 36.3 & 3.3 & 0.3720 & 0.9 & NS \\
\hline Overbite & 3.1 & 1.4 & 3.9 & 1.2 & 0.0255 & 0.8 & * \\
\hline Msc-NL & 18.5 & 2.0 & 18.6 & 2.1 & 0.8809 & 0.1 & NS \\
\hline Mic-ML & 27.0 & 2.4 & 25.5 & 2.4 & 0.0449 & -1.5 & ${ }^{*}$ \\
\hline \multicolumn{8}{|l|}{ Angular: } \\
\hline SNA & 80.1 & 2.8 & 81.1 & 3.1 & 0.2623 & 1.0 & NS \\
\hline SNB & 75.8 & 2.9 & 75.9 & 2.6 & 0.8411 & 0.2 & NS \\
\hline ANB & 4.3 & 1.3 & 5.1 & 1.8 & 0.0796 & 0.8 & NS \\
\hline SNL-NL & 6.4 & 2.9 & 7.2 & 3.0 & 0.3755 & 0.8 & NS \\
\hline SNL-ML & 33.4 & 4.8 & 32.8 & 5.9 & 0.6801 & -0.7 & NS \\
\hline SNL-Olf & 19.9 & 3.1 & 18.8 & 3.7 & 0.2901 & -1.1 & NS \\
\hline Is/NL & 110.1 & 5.0 & 110.9 & 22.4 & 0.8837 & 0.7 & NS \\
\hline li/ML & 95.1 & 6.0 & 93.7 & 6.7 & 0.4385 & -1.5 & NS \\
\hline Interincisal Angle & 127.5 & 7.5 & 125.2 & 11.7 & 0.4427 & -2.3 & NS \\
\hline
\end{tabular}

Table 10. Comparison of the pretreatment craniofacial morphology in pooled subjects 


\begin{tabular}{|c|c|c|c|c|c|c|c|}
\hline \multicolumn{8}{|c|}{ MALES } \\
\hline \multirow[b]{2}{*}{ Variable } & \multicolumn{2}{|c|}{ Control } & \multicolumn{2}{|c|}{ Treated } & \multirow[b]{2}{*}{$p$ value } & \multirow[b]{2}{*}{ Diff. } & \multirow[b]{2}{*}{ Sig } \\
\hline & Mean & S.D. & Mean & S.D. & & & \\
\hline \multicolumn{8}{|l|}{ Sagittal: } \\
\hline Olp-A pt. & 74.3 & 4.3 & 71.5 & 5.3 & 0.2394 & -2.8 & NS \\
\hline Olp-Pg & 76.4 & 5.8 & 73.4 & 6.3 & 0.3080 & -3.0 & NS \\
\hline Olp-Co & 9.6 & 2.3 & 9.9 & 3.7 & 0.8432 & 0.3 & NS \\
\hline Co-A pt. & 84.2 & 3.4 & 82.1 & 5.3 & 0.3594 & -2.1 & NS \\
\hline Co-Gn & 103.3 & 4.8 & 101.2 & 7.3 & 0.5040 & -2.1 & NS \\
\hline Co-Gn minus Co-A pt. & 19.1 & 3.2 & 19.1 & 3.6 & 0.9990 & 0.0 & NS \\
\hline Wits & 1.9 & 1.5 & 1.6 & 1.9 & 0.6963 & -0.3 & NS \\
\hline Is-Olp & 81.9 & 6.4 & 79.8 & 6.1 & 0.4490 & -2.2 & NS \\
\hline li-Olp & 75.6 & 5.8 & 71.8 & 5.7 & 0.1552 & -3.9 & NS \\
\hline Overjet & 6.3 & 1.9 & 8.0 & 3.4 & 0.2324 & 1.7 & NS \\
\hline Ms-Olp & 51.3 & 5.1 & 49.2 & 5.5 & 0.4170 & -2.0 & NS \\
\hline Mi-Olp & 51.3 & 5.6 & 48.0 & 5.4 & 0.2010 & -3.3 & NS \\
\hline Molar Relationship & -0.1 & 1.0 & 1.2 & 2.0 & 0.1407 & 1.3 & NS \\
\hline \multicolumn{8}{|l|}{ Vertical: } \\
\hline Ols-Apt & 26.5 & 2.0 & 31.3 & 6.2 & 0.0620 & 4.8 & NS \\
\hline ANS-Me & 63.4 & 4.7 & 58.5 & 6.4 & 0.0877 & -4.9 & NS \\
\hline Is-NL & 27.6 & 2.2 & 29.4 & 3.3 & 0.2132 & 1.8 & NS \\
\hline li-ML & 38.3 & 3.0 & 36.9 & 3.4 & 0.3833 & -1.3 & NS \\
\hline Overbite & 2.9 & 2.1 & 3.8 & 1.3 & 0.2181 & 0.9 & NS \\
\hline Msc-NL & 18.8 & 1.8 & 18.9 & 2.2 & 0.8882 & 0.1 & NS \\
\hline Mic-ML & 28.8 & 2.2 & 26.0 & 2.5 & 0.0195 & -2.8 & * \\
\hline \multicolumn{8}{|l|}{ Angular: } \\
\hline SNA & 79.4 & 1.6 & 80.4 & 3.0 & 0.3918 & 1.1 & NS \\
\hline SNB & 74.3 & 2.1 & 75.8 & 3.1 & 0.2623 & 1.5 & NS \\
\hline ANB & 5.1 & 1.1 & 4.7 & 1.6 & 0.5440 & -0.4 & NS \\
\hline SNL-NL & 6.1 & 2.7 & 6.6 & 2.8 & 0.7395 & 0.4 & NS \\
\hline SNL-ML & 35.6 & 3.5 & 32.5 & 7.3 & 0.3109 & -3.0 & NS \\
\hline SNL-Olf & 20.1 & 2.7 & 18.5 & 4.2 & 0.3478 & -1.7 & NS \\
\hline Is/NL & 109.9 & 4.3 & 109.5 & 27.8 & 0.9712 & -0.4 & NS \\
\hline li/ML & 94.3 & 3.7 & 93.7 & 7.6 & 0.8420 & -0.6 & NS \\
\hline Interincisal Angle & 126.1 & 4.7 & 124.0 & 12.8 & 0.6713 & -2.2 & NS \\
\hline
\end{tabular}

Table 11. Comparison of the pretreatment craniofacial morphology in male subjects 


\begin{tabular}{|c|c|c|c|c|c|c|c|}
\hline \multicolumn{8}{|c|}{ FEMALES } \\
\hline \multirow[b]{2}{*}{ Variable } & \multicolumn{2}{|c|}{ Control } & \multicolumn{2}{|c|}{ Treated } & \multirow[b]{2}{*}{$p$ value } & \multirow[b]{2}{*}{ Diff. } & \multirow[b]{2}{*}{ Sig } \\
\hline & Mean & S.D. & Mean & S.D. & & & \\
\hline \multicolumn{8}{|l|}{ Sagittal: } \\
\hline Olp-A pt. & 68.5 & 2.6 & 69.9 & 2.9 & 0.2260 & 1.4 & NS \\
\hline Olp-Pg & 72.7 & 3.9 & 70.7 & 2.4 & 0.1809 & -2.0 & NS \\
\hline Olp-Co & 10.2 & 2.2 & 9.6 & 3.0 & 0.5532 & -0.6 & NS \\
\hline Co-A pt. & 79.1 & 3.5 & 79.9 & 5.3 & 0.6555 & 0.8 & NS \\
\hline Co-Gn & 98.0 & 4.8 & 96.0 & 5.3 & 0.3364 & -2.1 & NS \\
\hline Co-Gn minus Co-A pt. & 18.9 & 3.0 & 16.1 & 2.7 & 0.0269 & -2.9 & * \\
\hline Wits & 0.0 & 1.5 & 2.2 & 1.8 & 0.0038 & 2.2 & * \\
\hline Is-Olp & 75.0 & 3.3 & 77.5 & 4.1 & 0.1105 & 2.5 & NS \\
\hline li-Olp & 70.2 & 3.3 & 70.0 & 2.8 & 0.8755 & -0.2 & NS \\
\hline Overjet & 4.8 & 1.3 & 7.5 & 2.1 & 0.0006 & 2.7 & * \\
\hline Ms-Olp & 48.2 & 2.8 & 48.1 & 3.0 & 0.8907 & -0.2 & NS \\
\hline Mi-Olp & 47.9 & 3.2 & 46.5 & 2.6 & 0.2988 & -1.3 & NS \\
\hline Molar Relationship & 0.4 & 0.8 & 1.5 & 1.2 & 0.0079 & 1.2 & ${ }^{*}$ \\
\hline \multicolumn{8}{|l|}{ Vertical: } \\
\hline Ols-Apt & 27.0 & 2.4 & 28.3 & 4.2 & 0.3462 & 1.3 & NS \\
\hline ANS-Me & 56.9 & 3.9 & 55.8 & 4.4 & 0.5092 & -1.2 & NS \\
\hline Is-NL & 25.2 & 2.5 & 27.2 & 2.1 & 0.0568 & 2.0 & NS \\
\hline Ii-ML & 34.1 & 2.5 & 35.3 & 3.1 & 0.3200 & 1.1 & NS \\
\hline Overbite & 3.2 & 0.9 & 4.2 & 0.9 & 0.0120 & 1.0 & ${ }^{*}$ \\
\hline Msc-NL & 18.4 & 2.2 & 18.1 & 1.8 & 0.7227 & -0.3 & NS \\
\hline Mic-ML & 26.2 & 2.0 & 24.7 & 2.3 & 0.1184 & -1.5 & NS \\
\hline \multicolumn{8}{|l|}{ Angular: } \\
\hline SNA & 80.4 & 3.2 & 82.1 & 3.1 & 0.2147 & 1.7 & NS \\
\hline SNB & 76.5 & 3.0 & 76.2 & 1.9 & 0.8295 & -0.2 & NS \\
\hline ANB & 3.9 & 1.3 & 5.9 & 1.9 & 0.0065 & 2.0 & * \\
\hline SNL-NL & 6.5 & 3.1 & 8.2 & 3.3 & 0.2132 & 1.7 & NS \\
\hline SNL-ML & 32.4 & 5.1 & 33.2 & 2.7 & 0.6932 & 0.7 & NS \\
\hline SNL-Olf & 19.8 & 3.3 & 19.4 & 2.7 & 0.7892 & -0.4 & NS \\
\hline Is/NL & 110.3 & 5.5 & 113.2 & 8.9 & 0.3315 & 2.9 & NS \\
\hline li/ML & 95.5 & 6.9 & 93.7 & 5.3 & 0.4914 & -1.9 & NS \\
\hline Interincisal Angle & 128.1 & 8.5 & 127.3 & 10.0 & 0.8321 & -0.8 & NS \\
\hline
\end{tabular}

Table 12. Comparison of the pretreatment craniofacial morphology in female subjects 


\section{Comparison of the Treatment Group and the Control Group Across the Time Periods}

Statistical analysis comparing the differences between the treatment and control groups across the time periods for all 29 variables for pooled, male and female subjects is shown in Table 13. For pooled subjects, significant differences were found between the treatment and control groups across the two time periods for sagittal, angular, and vertical measurements. For male subjects, significant differences were found between the treatment and control groups across the two time periods for sagittal, angular, and vertical measurements. For female subjects, significant differences were found between the treatment and control groups across the two time periods for sagittal, angular, and vertical measurements.

\section{Sagittal Variables}

For pooled subjects, significant differences between the treatment and control groups across the time periods were found the following sagittal variables $(\mathrm{p}<.05)$ : Wits ( $\mathrm{p}=.0001)$, Is-Olp ( $\mathrm{p}=.0220)$, Ii-Olp ( $\mathrm{p}=.0226)$, Overjet $(\mathrm{p}=.0001)$, Mi-Olp $(\mathrm{p}=.0481)$ and Molar Relationship ( $\mathrm{p}=.0001$ ). For male subjects, significant differences were found between the treatment and control groups for the following variables: Co-Gn minus CoApt $(\mathrm{p}=.0147)$, Wits $(\mathrm{p}=.0154)$, Overjet $(\mathrm{p}=.0024)$, and Molar Relationship $(\mathrm{p}=$ .0003). For female subjects, significant differences were found between the treatment and control groups for the following variables: Wits $(\mathrm{p}=.0001)$, Is-Olp $(\mathrm{p}=.0444)$, Overjet $(\mathrm{p}=.0001)$, and Molar Relationship $(\mathrm{p}=.0001)$. 


\section{Vertical Variables}

For pooled subjects, significant differences $(\mathrm{p}<.05)$ between the treatment and control groups across the time periods were found for the following vertical variables: Overbite $(\mathrm{p}=.0001)$ and Mic-ML $(\mathrm{p}=.0144)$. For male subjects, significant differences were found between the treatment and control groups for the following variables:

Overbite $(\mathrm{p}=.0025)$. For female subjects, significant differences were found between the treatment and control groups for the following variables: Ii-ML ( $\mathrm{p}=.0140)$, and Overbite $(\mathrm{p}=.0002)$.

\section{Angular Variables}

For pooled subjects, significant differences $(\mathrm{p}<.05)$ between the treatment and control groups across the time periods were found for the following angular measurements: SNA $(\mathrm{p}=.0013)$, ANB $(\mathrm{p}=.0001)$, and Ii-ML $(\mathrm{p}=.0005)$. For male subjects, significant differences were found between the treatment and control groups for the following variables: SNA $(\mathrm{p}=.0075)$, and ANB $(\mathrm{p}=.0005)$. For female subjects, significant differences were found between the treatment and control groups for the

following variables: ANB $(\mathrm{p}=.0079)$, SNL-OL $(\mathrm{p}=.0152)$, and Ii-ML $(\mathrm{p}=.0053)$. 


\begin{tabular}{|c|c|c|c|c|c|c|}
\hline \multirow[b]{2}{*}{ Variables } & \multicolumn{2}{|c|}{ Pooled Subjects } & \multicolumn{2}{|c|}{ Male Subjects } & \multicolumn{2}{|c|}{ Female Subjects } \\
\hline & $\begin{array}{c}\mathrm{p} \\
\text { value }\end{array}$ & Significant & $\begin{array}{c}\mathrm{p} \\
\text { value }\end{array}$ & Significant & $\begin{array}{c}p \\
\text { value }\end{array}$ & Significant \\
\hline \multicolumn{7}{|l|}{ Sagittal: } \\
\hline 1. Olp-A pt. & 0.1147 & NS & 0.0834 & NS & 0.2872 & NS \\
\hline 2. Olp-Pg & 0.5137 & NS & 0.9126 & NS & 0.9423 & NS \\
\hline 3. Olp-Co & 0.3941 & NS & 0.1056 & NS & 0.6582 & NS \\
\hline 4. Co-A pt. & 0.4338 & NS & 0.5997 & NS & 0.3822 & NS \\
\hline 5. Co-Gn & 0.3510 & NS & 0.3065 & NS & 0.5982 & NS \\
\hline 6. Co-Gn minus Co-A pt. & 0.0083 & NS & 0.0147 & ${ }^{*}$ & 0.5923 & NS \\
\hline 7. Wits & 0.0001 & ${ }^{*}$ & 0.0154 & * & 0.0001 & ${ }^{*}$ \\
\hline 8. Is-Olp & 0.0220 & * & 0.0922 & NS & 0.0444 & * \\
\hline 9. li-Olp & 0.0226 & * & 0.5443 & NS & 0.0930 & NS \\
\hline 10. Overjet & 0.0001 & * & 0.0024 & ${ }^{*}$ & 0.0001 & * \\
\hline 11. Ms-Olp & 0.0933 & NS & 0.2074 & NS & 0.0928 & NS \\
\hline 12. Mi-Olp & 0.0481 & ${ }^{*}$ & 0.3098 & NS & 0.2342 & NS \\
\hline 13. Molar Relationship & 0.0001 & * & 0.0003 & $*$ & 0.0001 & $*$ \\
\hline \multicolumn{7}{|l|}{ Vertical: } \\
\hline 14. OLs-A pt. & 0.5367 & NS & 0.4279 & NS & 0.6925 & NS \\
\hline 15. ANS-Me & 0.7458 & NS & 0.5583 & NS & 0.1793 & NS \\
\hline 16. Is-NL & 0.4140 & NS & 0.6101 & NS & 0.3321 & NS \\
\hline 17. Ii-ML & 0.0669 & NS & 0.2609 & NS & 0.0140 & ${ }^{*}$ \\
\hline 18. Overbite & 0.0001 & ${ }^{*}$ & 0.0025 & ${ }^{*}$ & 0.0002 & $*$ \\
\hline 19. Msc-NL & 0.4545 & NS & 0.8043 & NS & 0.0545 & NS \\
\hline 20. Mic-ML & 0.0144 & ${ }^{*}$ & 0.1842 & NS & 0.2247 & NS \\
\hline \multicolumn{7}{|l|}{ Angular: } \\
\hline 21. SNA & 0.0013 & * & 0.0075 & ${ }^{*}$ & 0.0549 & NS \\
\hline 22. SNB & 0.5147 & NS & 0.7032 & NS & 0.7948 & NS \\
\hline 23. ANB & 0.0001 & ${ }^{*}$ & 0.0005 & ${ }^{*}$ & 0.0079 & ${ }^{*}$ \\
\hline 24. SNL-NL & 0.2456 & NS & 0.0523 & NS & 0.8965 & NS \\
\hline 25. SNL-ML & 0.1634 & NS & 0.2593 & NS & 0.6728 & NS \\
\hline 26. SNL-OL & 0.1382 & NS & 0.7791 & NS & 0.0152 & ${ }^{*}$ \\
\hline 27. Is/NL & 0.5489 & NS & 0.6504 & NS & 0.8564 & NS \\
\hline 28. $\mathrm{li} / \mathrm{ML}$ & 0.0005 & ${ }^{*}$ & 0.0622 & NS & 0.0053 & * \\
\hline 29. Interincisal Angle & 0.2744 & NS & 0.6054 & NS & 0.1722 & NS \\
\hline
\end{tabular}

Table 13. Comparison of the Treatment group vs the Control group across the time periods 


\section{Comparison of the Treated Group vs. the Control Group}

Treatment effects of the Forsus FRD used in conjunction with orthodontic appliances were compared with an untreated control sample. The differences between time points were then analyzed. T2-T1: Treatment effects of orthodontic appliances and the Forsus FRD (Tx (T2-T1)) minus (Control (t2-t1)).

For both time periods, the change in the values of the variables for pooled, male and female subjects in the treatment group were compared to the changes in the values of the variables for pooled, male and female subjects in the control group. 29 variables were evaluated for each group including sagittal, vertical, and angular variables. Also, a calculation of the overjet and molar relationship correction for the treatment group and a calculation of the net overjet and net molar relationship correction for the treatment vs. control group at each time point for pooled subjects were performed.

\section{Comparison of T2-T1 (Treatment Effects of Orthodontic}

\section{Appliances and the Forsus FRD)}

Of the 29 variables investigated, 12 showed statistically significant differences between the treatment group and control group in pooled subjects from T2-T1 (Table 14). There were no significant differences found in the age from T2-T1 between the treatment and control groups. The average increase in age for the treated group was 45.4 months. Several of the sagittal and angular variables showed significant differences, however, only two of the vertical variables showed significant differences in pooled subjects. Significance differences in variables recorded for male and female subjects only are reported in Table 15 \& Table 16. Only pooled data is reported. 


\section{Sagittal Differences}

The following sagittal variables showed significant differences $(<.05)$ between treatment and control groups from T2-T1: Co-Gn minus Co-Apt, Wits, Is-OLp, Ii-OLp, Overjet, Mi-OLp, and Molar Relationship. The position of the maxillary base (OLp-Apt) came forward $3.9 \mathrm{~mm}$ in the treated group. There was a restriction of forward movement of the maxillary base relative to the control group $(-1.2 \mathrm{~mm})$; however, this change was not statistically significant. The position of the mandibular base (OLp-Pg) in the treated group came forward an additional $0.7 \mathrm{~mm}$ more than the control group, which also was not statistically significant. The position of the condyle (OL-Co) moved forward $0.5 \mathrm{~mm}$ in the treated group compared to the control group which was not statistically significant. The effective maxillary length (Co-Apt) came back $0.8 \mathrm{~mm}$ relative to the control group and was not significant. The effective mandibular length (Co-Gn) came forward $1.1 \mathrm{~mm}$ relative to the control group and was also not significant. The difference between effective maxillary and mandibular length (Co-Gn minus Co-Apt) between treatment and control groups was significant with a $1.9 \mathrm{~mm}$ difference. The position of the maxilla relative to the mandible along the functional occlusal plane (Wits) showed a difference of $-2.7 \mathrm{~mm}$ for the treatment group relative to the control which was significant. The position of the maxillary incisor (Is-OLp) came back -2.6 $\mathrm{mm}$ in the treatment group relative to the control group which was significant. The position of the mandibular incisors (Ii-OLp) came forward $2.0 \mathrm{~mm}$ in the treatment group relative to the control group which was significant. The overjet corrected by $4.6 \mathrm{~mm}$ in the treatment group relative to the control group which was significant. The maxillary molar (Ms-OLp) in the treatment group moved back $1.6 \mathrm{~mm}$ relative to the control group, but it was not 
significant. The mandibular molar (Mi-OLp) in the treatment group came forward 2.0 $\mathrm{mm}$ relative to the control group, which was significant. The molar relationship corrected by $3.6 \mathrm{~mm}$ in the treatment group relative to the control group which was significant.

\section{Vertical Differences}

There were no significant differences in any vertical measurements between treatment and control groups from T2-T1 except for Overbite and lower molar position (Mic-ML). Overbite decreased $2.0 \mathrm{~mm}$ in the treatment group relative to the control group which was significant. The lower molar (Mic-ML) in the treatment group erupted $1.4 \mathrm{~mm}$ relative to the control group which was significant.

\section{Angular Differences}

Significant differences in angular variables between treatment and control groups from T2-T1 were found for SNA, ANB, and Ii/ML. SNA decreased $1.5^{\circ}$ in the treatment group relative to the control group which was significant. SNB increased $0.3^{\circ}$ in the treated group relative to the control group, but this change was not significant. ANB decreased $1.8^{\circ}$ in the treatment group relative to the control group which was significant. The functional occlusal plane (SNL-OLf) increased $1.2^{\circ}$ in the treatment group relative to the control group; however, it was not significant. The inclination of the mandibular incisor (Ii/ML) increased $4.5^{\circ}$ in the treated group relative to the control group which was significant. 


\begin{tabular}{|c|c|c|c|c|c|c|c|}
\hline \multicolumn{8}{|c|}{ POOLED (MALES AND FEMALES) } \\
\hline \multirow[b]{2}{*}{ Variable } & \multicolumn{2}{|c|}{ Control (T2-T1) } & \multicolumn{2}{|c|}{ Treated (T2-T1) } & \multirow[b]{2}{*}{$p$ value } & \multirow[b]{2}{*}{ Diff. } & \multirow[b]{2}{*}{ Sig } \\
\hline & Mean & S.D. & Mean & S.D. & & & \\
\hline Age & 52.1 & 17.7 & 45.4 & 15.9 & 0.1849 & -6.7 & NS \\
\hline \multicolumn{8}{|l|}{ Sagittal: } \\
\hline Olp-A pt. & 5.1 & 2.5 & 3.9 & 2.4 & 0.1148 & -1.2 & NS \\
\hline Olp-Pg & 6.6 & 3.1 & 7.3 & 3.9 & 0.5216 & 0.7 & NS \\
\hline Olp-Co & 1.0 & 1.7 & 1.5 & 2.0 & 0.4038 & 0.5 & NS \\
\hline Co-A pt. & 6.2 & 3.3 & 5.4 & 3.2 & 0.4360 & -0.8 & NS \\
\hline Co-Gn & 9.3 & 3.7 & 10.4 & 4.1 & 0.3453 & 1.1 & NS \\
\hline Co-Gn minus Co-A pt. & 3.1 & 2.2 & 5.0 & 2.3 & 0.0086 & 1.9 & $*$ \\
\hline Wits & 0.5 & 1.5 & -2.2 & 1.9 & 0.0001 & -2.7 & $*$ \\
\hline Is-Olp & 5.6 & 2.7 & 2.9 & 4.6 & 0.0218 & -2.6 & $*$ \\
\hline ii-Olp & 5.5 & 2.5 & 7.5 & 3.0 & 0.0212 & 2.0 & $*$ \\
\hline Overjet & 0.1 & 1.3 & -4.5 & 2.9 & 0.0001 & -4.6 & $*$ \\
\hline Ms-Olp & 6.4 & 2.8 & 4.8 & 3.5 & 0.0928 & -1.6 & NS \\
\hline Mi-Olp & 7.0 & 2.9 & 8.9 & 3.6 & 0.0495 & 2.0 & $*$ \\
\hline Molar Relationship & -0.5 & 1.2 & -4.1 & 1.9 & 0.0001 & -3.6 & $*$ \\
\hline \multicolumn{8}{|l|}{ Vertical: } \\
\hline Ols-Apt & 3.2 & 1.7 & 2.8 & 1.9 & 0.5570 & -0.3 & NS \\
\hline ANS-Me & 4.8 & 2.5 & 5.1 & 3.6 & 0.7537 & 0.3 & NS \\
\hline Is-NL & 1.6 & 1.6 & 1.2 & 1.9 & 0.4031 & -0.4 & NS \\
\hline Ii-ML & 3.2 & 1.6 & 1.8 & 3.0 & 0.0680 & -1.4 & NS \\
\hline Overbite & 0.2 & 1.4 & -1.8 & 1.1 & 0.0001 & -2.0 & $*$ \\
\hline Msc-NL & 3.0 & 1.5 & 2.6 & 1.8 & 0.4641 & -0.4 & NS \\
\hline Mic-ML & 2.6 & 1.6 & 4.0 & 2.0 & 0.0126 & 1.4 & $*$ \\
\hline \multicolumn{8}{|l|}{ Angular: } \\
\hline SNA & 1.6 & 1.8 & 0.1 & 1.2 & 0.0013 & -1.5 & $*$ \\
\hline SNB & 1.4 & 1.3 & 1.7 & 1.3 & 0.5147 & 0.3 & NS \\
\hline ANB & 0.2 & 1.2 & -1.5 & 1.2 & 0.0001 & -1.8 & $*$ \\
\hline SNL-NL & 0.2 & 1.8 & -0.4 & 1.9 & 0.2456 & -0.6 & NS \\
\hline SNL-ML & -0.7 & 1.4 & -1.6 & 2.6 & 0.1634 & -0.9 & NS \\
\hline SNL-Olf & -2.0 & 3.1 & -0.8 & 2.2 & 0.1382 & 1.2 & NS \\
\hline Is/NL & -0.1 & 3.1 & 2.8 & 22.0 & 0.5489 & 2.9 & NS \\
\hline li/ML & -0.6 & 3.4 & 3.9 & 4.6 & 0.0005 & 4.5 & $*$ \\
\hline Interincisal Angle & 1.7 & 5.8 & -1.3 & 11.5 & 0.2744 & -3.0 & NS \\
\hline
\end{tabular}

Table 14. Comparison of the Treatment group vs the Control group in pooled subjects from T2-T1 


\begin{tabular}{|c|c|c|c|c|c|c|c|}
\hline \multicolumn{8}{|c|}{ MALES } \\
\hline \multirow[b]{2}{*}{ Variable } & \multicolumn{2}{|c|}{ Control (T2-T1) } & \multicolumn{2}{|c|}{ Treated (T2-T1) } & \multirow[b]{2}{*}{$p$ value } & \multirow[b]{2}{*}{ Diff. } & \multirow[b]{2}{*}{ Sig } \\
\hline & Mean & S.D. & Mean & S.D. & & & \\
\hline Age & 56.4 & 21.7 & 47.7 & 16.7 & 0.3109 & -8.7 & NS \\
\hline \multicolumn{8}{|l|}{ Sagittal: } \\
\hline Olp-A pt. & 6.4 & 2.4 & 4.2 & 2.7 & 0.0814 & -2.2 & NS \\
\hline Olp-Pg & 7.8 & 3.9 & 8.0 & 4.2 & 0.9110 & 0.2 & NS \\
\hline Olp-Co & 0.2 & 1.9 & 1.8 & 2.0 & 0.1034 & 1.5 & NS \\
\hline Co-A pt. & 6.6 & 3.1 & 5.9 & 2.8 & 0.6072 & -0.7 & NS \\
\hline Co-Gn & 9.9 & 4.2 & 11.7 & 3.6 & 0.3041 & 1.8 & NS \\
\hline Co-Gn minus Co-A pt. & 3.3 & 1.6 & 5.9 & 2.2 & 0.0148 & 2.5 & $*$ \\
\hline Wits & 0.3 & 1.4 & -2.0 & 2.1 & 0.0149 & -2.3 & $*$ \\
\hline Is-Olp & 7.0 & 3.3 & 3.4 & 4.9 & 0.0901 & -3.6 & NS \\
\hline li-Olp & 7.1 & 2.8 & 8.0 & 2.9 & 0.5245 & 0.8 & NS \\
\hline Overjet & -0.1 & 1.0 & -4.6 & 3.3 & 0.0024 & -4.5 & $*$ \\
\hline Ms-Olp & 7.5 & 4.1 & 5.3 & 3.4 & 0.2058 & -2.2 & NS \\
\hline Mi-Olp & 7.6 & 4.0 & 9.4 & 3.6 & 0.3090 & 1.8 & NS \\
\hline Molar Relationship & -0.1 & 1.2 & -4.1 & 2.2 & 0.0003 & -4.0 & $*$ \\
\hline \multicolumn{8}{|l|}{ Vertical: } \\
\hline Ols-Apt & 3.6 & 1.3 & 3.0 & 2.0 & 0.4281 & -0.7 & NS \\
\hline ANS-Me & 5.6 & 2.7 & 6.4 & 3.2 & 0.5730 & 0.8 & NS \\
\hline Is-NL & 1.9 & 1.2 & 1.4 & 2.0 & 0.5925 & -0.4 & NS \\
\hline Ii-ML & 4.0 & 1.4 & 2.6 & 3.1 & 0.2563 & -1.5 & NS \\
\hline Overbite & 0.6 & 1.9 & -1.7 & 1.2 & 0.0029 & -2.3 & $*$ \\
\hline Msc-NL & 3.0 & 1.2 & 3.2 & 1.8 & 0.7906 & 0.2 & NS \\
\hline Mic-ML & 3.3 & 1.7 & 4.6 & 2.1 & 0.1870 & 1.3 & NS \\
\hline \multicolumn{8}{|l|}{ Angular: } \\
\hline SNA & 2.0 & 1.4 & 0.2 & 1.3 & 0.0075 & -1.8 & $*$ \\
\hline SNB & 1.5 & 1.5 & 1.8 & 1.5 & 0.7032 & 0.3 & NS \\
\hline ANB & 0.5 & 0.4 & -1.6 & 1.3 & 0.0005 & -2.1 & $*$ \\
\hline SNL-NL & 0.5 & 1.6 & -0.8 & 1.3 & 0.0523 & -1.3 & NS \\
\hline SNL-ML & -0.4 & 2.0 & -1.9 & 3.0 & 0.2593 & -1.4 & NS \\
\hline SNL-Olf & -1.1 & 3.9 & -1.4 & 2.2 & 0.7791 & -0.4 & NS \\
\hline Is/NL & -0.8 & 3.7 & 4.0 & 26.9 & 0.6504 & 4.8 & NS \\
\hline li/ML & -0.4 & 3.3 & 3.7 & 5.1 & 0.0622 & 4.2 & NS \\
\hline Interincisal Angle & 2.4 & 6.5 & -0.2 & 12.5 & 0.6054 & -2.7 & NS \\
\hline
\end{tabular}

Table 15. Comparison of the Treatment group vs the Control group in male subjects from T2-T1 


\begin{tabular}{|c|c|c|c|c|c|c|c|}
\hline \multicolumn{8}{|c|}{ FEMALES } \\
\hline \multirow[b]{2}{*}{ Variable } & \multicolumn{2}{|c|}{ Control (T2-T1) } & \multicolumn{2}{|c|}{ Treated (T2-T1) } & \multirow[b]{2}{*}{$p$ value } & \multirow[b]{2}{*}{ Diff. } & \multirow[b]{2}{*}{ Sig } \\
\hline & Mean & S.D. & Mean & S.D. & & & \\
\hline Age & 50.0 & 16.0 & 41.4 & 14.7 & 0.2048 & -8.6 & NS \\
\hline \multicolumn{8}{|l|}{ Sagittal: } \\
\hline Olp-A pt. & 4.5 & 2.4 & 3.5 & 2.0 & 0.2924 & -1.0 & NS \\
\hline Olp-Pg & 6.1 & 2.6 & 6.2 & 3.2 & 0.9615 & 0.1 & NS \\
\hline Olp-Co & 1.4 & 1.6 & 1.0 & 2.1 & 0.6330 & -0.4 & NS \\
\hline Co-A pt. & 6.0 & 3.4 & 4.6 & 3.8 & 0.3796 & -1.4 & NS \\
\hline Co-Gn & 9.0 & 3.5 & 8.2 & 4.2 & 0.6021 & -0.8 & NS \\
\hline Co-Gn minus Co-A pt. & 3.1 & 2.5 & 3.6 & 1.8 & 0.5992 & 0.5 & NS \\
\hline Wits & 0.6 & 1.5 & -2.6 & 1.6 & 0.0001 & -3.2 & $*$ \\
\hline Is-Olp & 4.9 & 2.1 & 2.2 & 4.1 & 0.0452 & -2.7 & $*$ \\
\hline li-Olp & 4.8 & 2.1 & 6.7 & 3.1 & 0.0897 & 1.9 & NS \\
\hline Overjet & 0.1 & 1.5 & -4.4 & 2.2 & 0.0001 & -4.6 & $*$ \\
\hline Ms-Olp & 5.9 & 1.9 & 3.9 & 3.7 & 0.0933 & -2.0 & NS \\
\hline Mi-Olp & 6.7 & 2.4 & 8.2 & 3.8 & 0.2419 & 1.5 & NS \\
\hline Molar Relationship & -0.7 & 1.1 & -4.2 & 1.4 & 0.0001 & -3.5 & $*$ \\
\hline \multicolumn{8}{|l|}{ Vertical: } \\
\hline Ols-Apt & 2.9 & 1.9 & 2.6 & 1.8 & 0.7111 & -0.3 & NS \\
\hline ANS-Me & 4.4 & 2.4 & 2.8 & 3.1 & 0.1785 & -1.6 & NS \\
\hline IS-NL & 1.5 & 1.7 & 0.8 & 1.8 & 0.3345 & -0.7 & NS \\
\hline ii-ML & 2.8 & 1.5 & 0.5 & 2.6 & 0.0143 & -2.2 & $*$ \\
\hline Overbite & 0.0 & 1.1 & -2.0 & 0.9 & 0.0002 & -2.0 & $*$ \\
\hline Msc-NL & 3.0 & 1.7 & 1.6 & 1.3 & 0.0537 & -1.3 & NS \\
\hline Mic-ML & 2.3 & 1.5 & 3.1 & 1.4 & 0.2109 & 0.8 & NS \\
\hline \multicolumn{8}{|l|}{ Angular: } \\
\hline SNA & 1.4 & 1.9 & 0.1 & 0.9 & 0.0549 & -1.4 & NS \\
\hline SNB & 1.4 & 1.3 & 1.5 & 1.0 & 0.7948 & 0.1 & NS \\
\hline ANB & 0.1 & 1.4 & -1.4 & 1.0 & 0.0079 & -1.5 & $*$ \\
\hline SNL-NL & 0.1 & 1.9 & 0.2 & 2.7 & 0.8965 & 0.1 & NS \\
\hline SNL-ML & -0.8 & 1.0 & -1.1 & 1.9 & 0.6728 & -0.3 & NS \\
\hline SNL-OIf & -2.4 & 2.7 & 0.3 & 2.0 & 0.0152 & 2.7 & $*$ \\
\hline Is/NL & 0.2 & 2.8 & 0.8 & 11.1 & 0.8564 & 0.5 & NS \\
\hline li/ML & -0.6 & 3.6 & 4.2 & 3.9 & 0.0053 & 4.9 & $*$ \\
\hline Interincisal Angle & 1.4 & 5.6 & -3.1 & 10.0 & 0.1722 & -4.5 & NS \\
\hline
\end{tabular}

Table 16. Comparison of the Treatment group vs the Control group in female subjects from T2-T1 


\section{Overjet and Molar Relationship Correction-Treatment Group (T2-}

T1)

The amount of skeletal and dental contribution to the overjet and molar relationship correction in the treatment group at T2-T1 was calculated using the formulas in Table 9. The amount of overjet correction in the treatment group was $4.6 \mathrm{~mm}$. 3.4 $\mathrm{mm}(75 \%)$ of the correction was due to skeletal correction. $1.2 \mathrm{~mm} \mathrm{(25 \% )} \mathrm{of} \mathrm{the}$ correction was due to dental correction. The amount of molar relationship correction was $4.1 \mathrm{~mm} .3 .4 \mathrm{~mm}(82 \%)$ of the correction was skeletal in nature and $0.7 \mathrm{~mm}(18 \%)$ of the correction was dental in nature. Calculations are shown for the overjet and molar relationship correction on the following pages. Diagrams are also provided to illustrate the anterior and posterior movement of the maxilla, mandible, maxillary incisors, mandibular incisors, maxillary molars, and mandibular molars (Figure $5 \&$ Figure 6). A pitchfork analysis diagram describing the skeletal and dental components of overjet and molar correction is shown in Figure 7. 


\begin{tabular}{|cccc|}
\hline Overiet Correction: & & Molar relationship: & \\
\hline Skeletal Contribution: & 3.9 & Skeletal Contribution: & 3.9 \\
1) Maxilla & 7.3 & 1) Maxilla & 7.3 \\
2) Mandible & & 2) Mandible & \\
Dental Contribution: & -1.0 & Dental Contribution: & 0.9 \\
3) Mx incisor & 0.2 & 3) Mx molar & 1.6 \\
4) Md incisor & & 4) Md molar & \\
\hline
\end{tabular}

\section{Overjet Correction $=$ Maxilla + Mx incisor - Mandible - Md incisor}

Overjet Correction $=3.9+(-1.0)-7.3-0.2=-4.6$
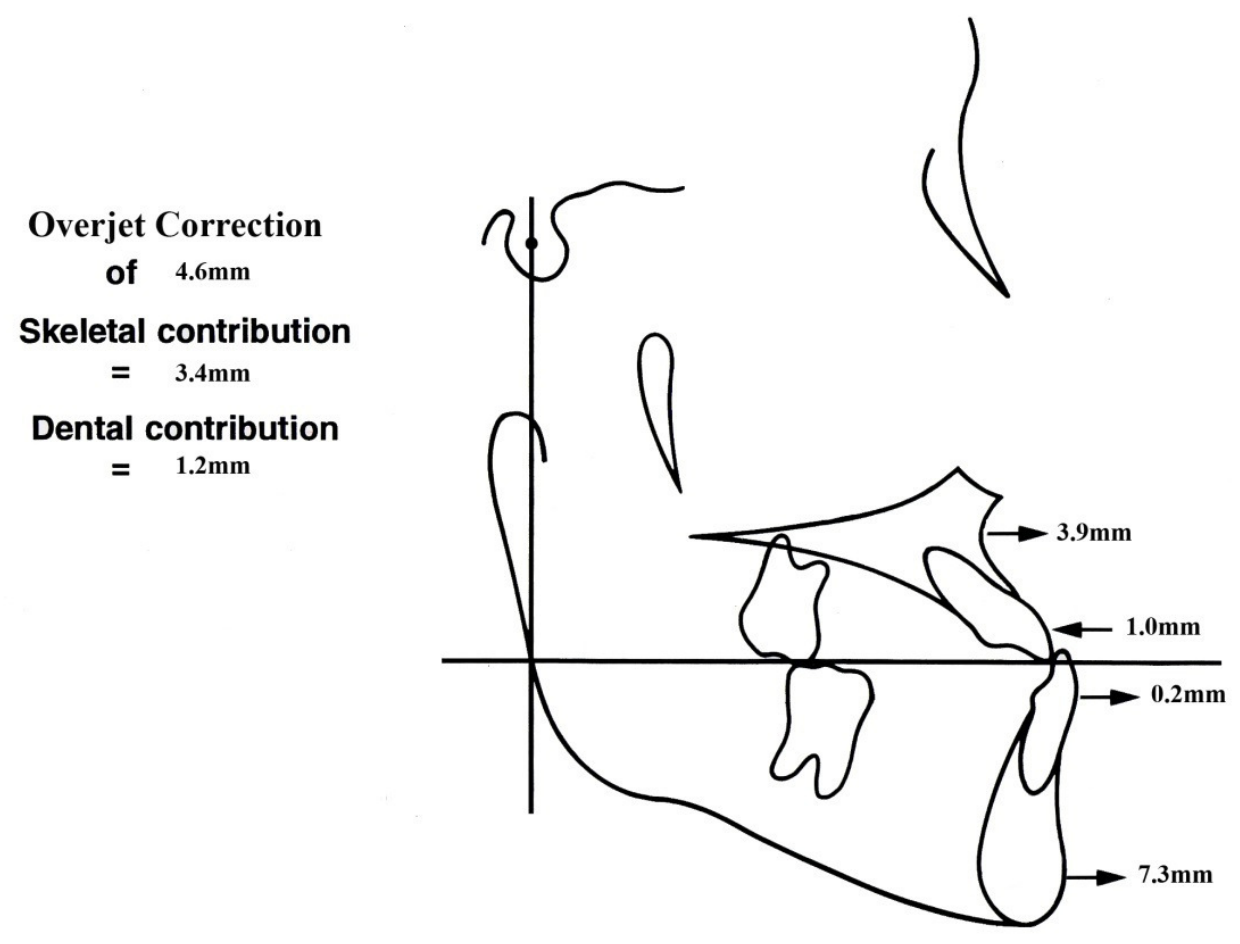

Figure 5. Components of Overjet Correction (T2-T1) 
Molar Relationship Correction $=$ Maxilla + Mx molar - Mandible - Md molar

Molar Relationship Correction $=3.9+.9-7.3-1.6=-4.1$

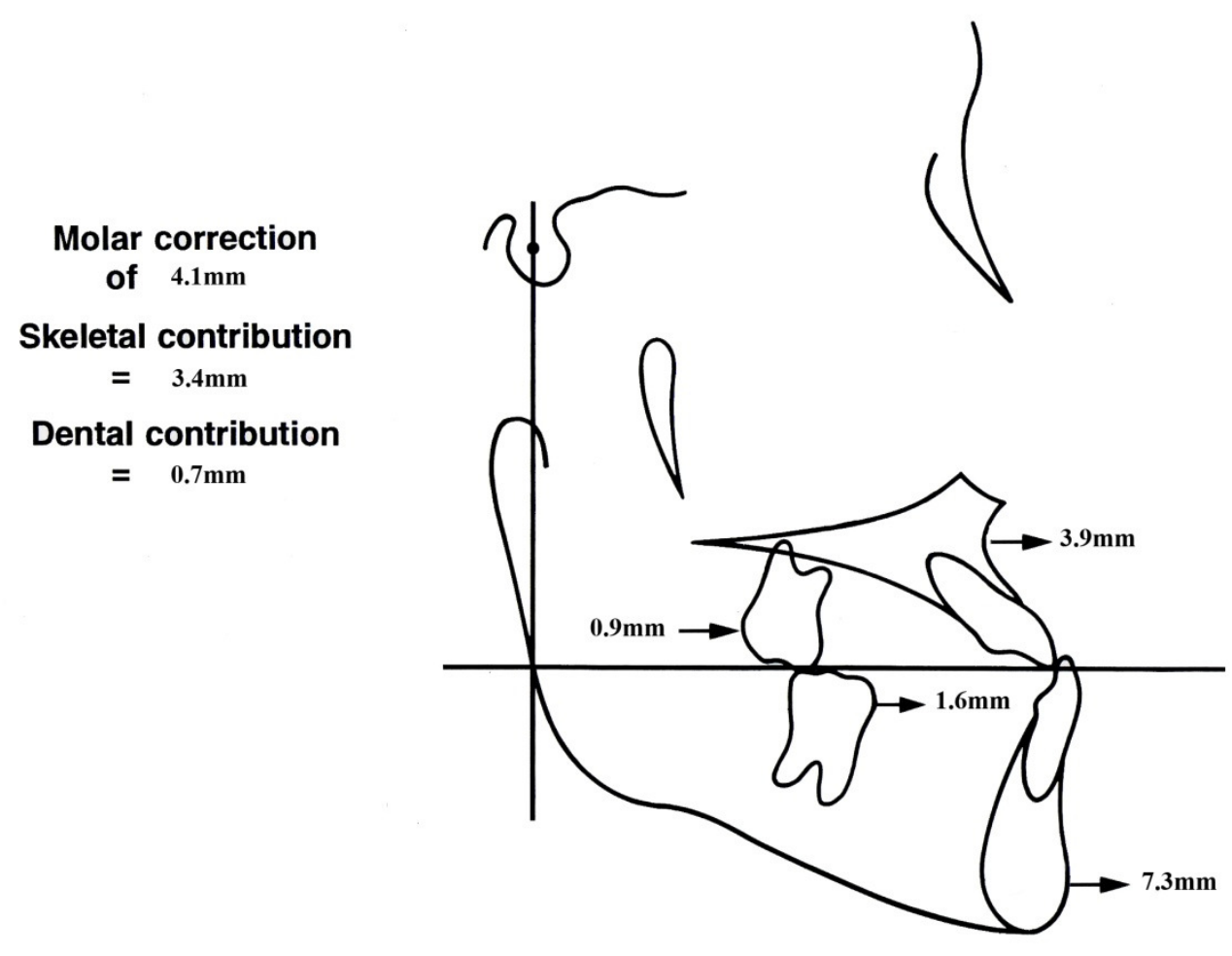

Figure 6. Components of Molar Correction (T2-T1) 

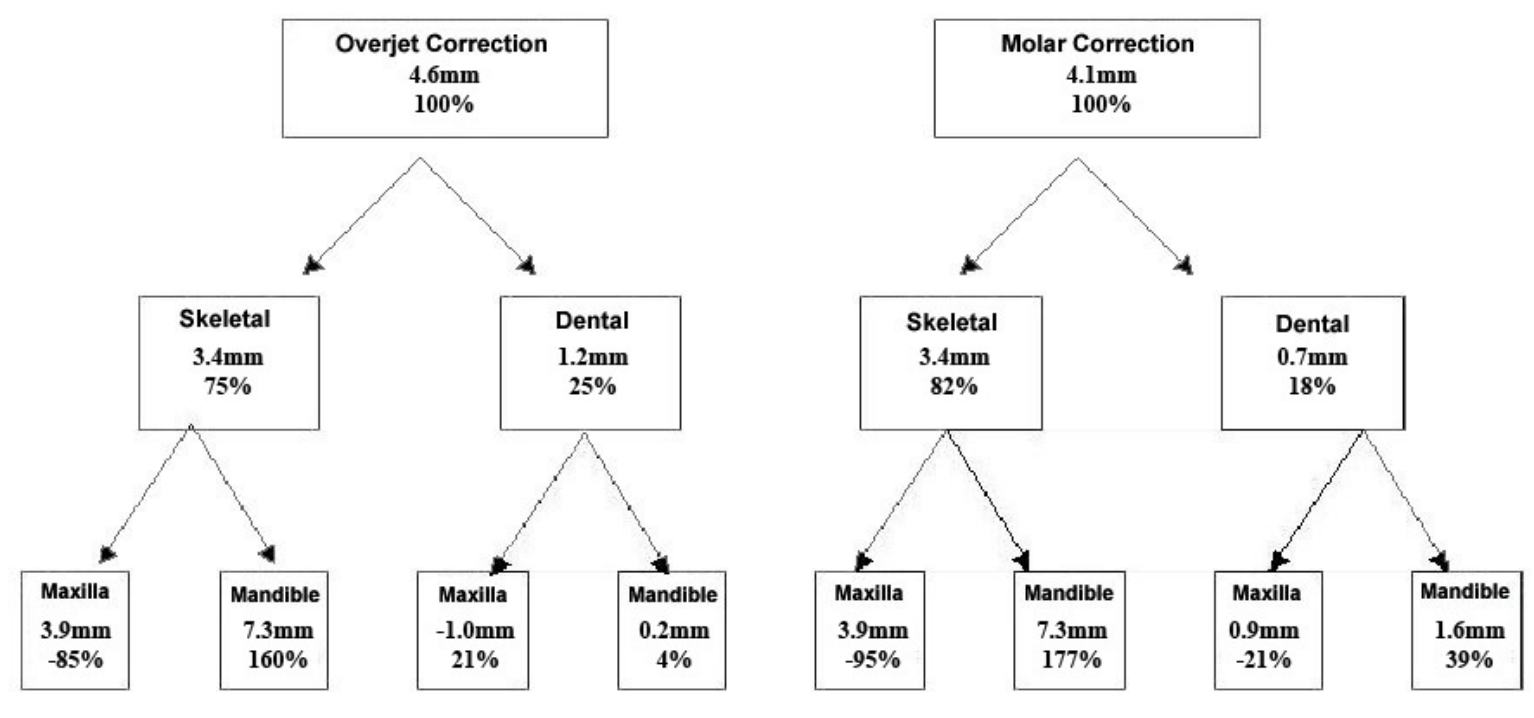

Figure 7. Pitchfork Analysis of Overjet and Molar Correction (T2-T1) 


\section{Net Overjet and Molar Relationship Correction - Tx vs Control Group (T2-T1)}

The amount of skeletal and dental contribution to the net overjet and net molar relationship correction in the treatment group compared to the control group at T2-T1 was calculated using the formulas in Table 9. The amount of net overjet correction in the treatment group relative to the control group was $4.7 \mathrm{~mm} .1 .9 \mathrm{~mm} \mathrm{(40 \% )}$ of the correction was due to skeletal movement. $2.8 \mathrm{~mm}(60 \%)$ of the correction was due to dental movement. The amount of net molar relationship correction was $3.7 \mathrm{~mm} . \quad 1.9$ $\mathrm{mm}(51 \%)$ of the correction was skeletal in nature and $1.8 \mathrm{~mm}(49 \%)$ of the correction was dental in nature. Calculations are shown for the net overjet and net molar relationship correction on the following pages. Diagrams are also provided to illustrate the net anterior and posterior movement of the maxilla, mandible, maxillary incisors, mandibular incisors, maxillary molars, and mandibular molars (Figure 8 \& Figure 9). A pitchfork analysis describing the net skeletal and dental contributions to overjet and molar relationship correction is shown in Figure 10.

\begin{tabular}{|cccc|}
\hline Net Overiet Correction: & & Net Molar relationship: & \\
\hline Skeletal Contribution: & -1.2 & Skeletal Contribution: & -1.2 \\
1) Maxilla & 0.7 & 1) Maxilla & 0.7 \\
2) Mandible & & 2) Mandible & \\
Dental Contribution: & -1.5 & Dental Contribution: & -0.5 \\
3) Mx incisor & 1.3 & 3) Mx molar & 1.3 \\
4) Md incisor & & 4) Md molar & \\
\hline
\end{tabular}

Net Overjet Correction $=$ Maxilla + Mx incisor - Mandible - Md incisor

Net Overjet Correction $=-1.2+(-1.5)-0.7-1.3=-4.7$ 

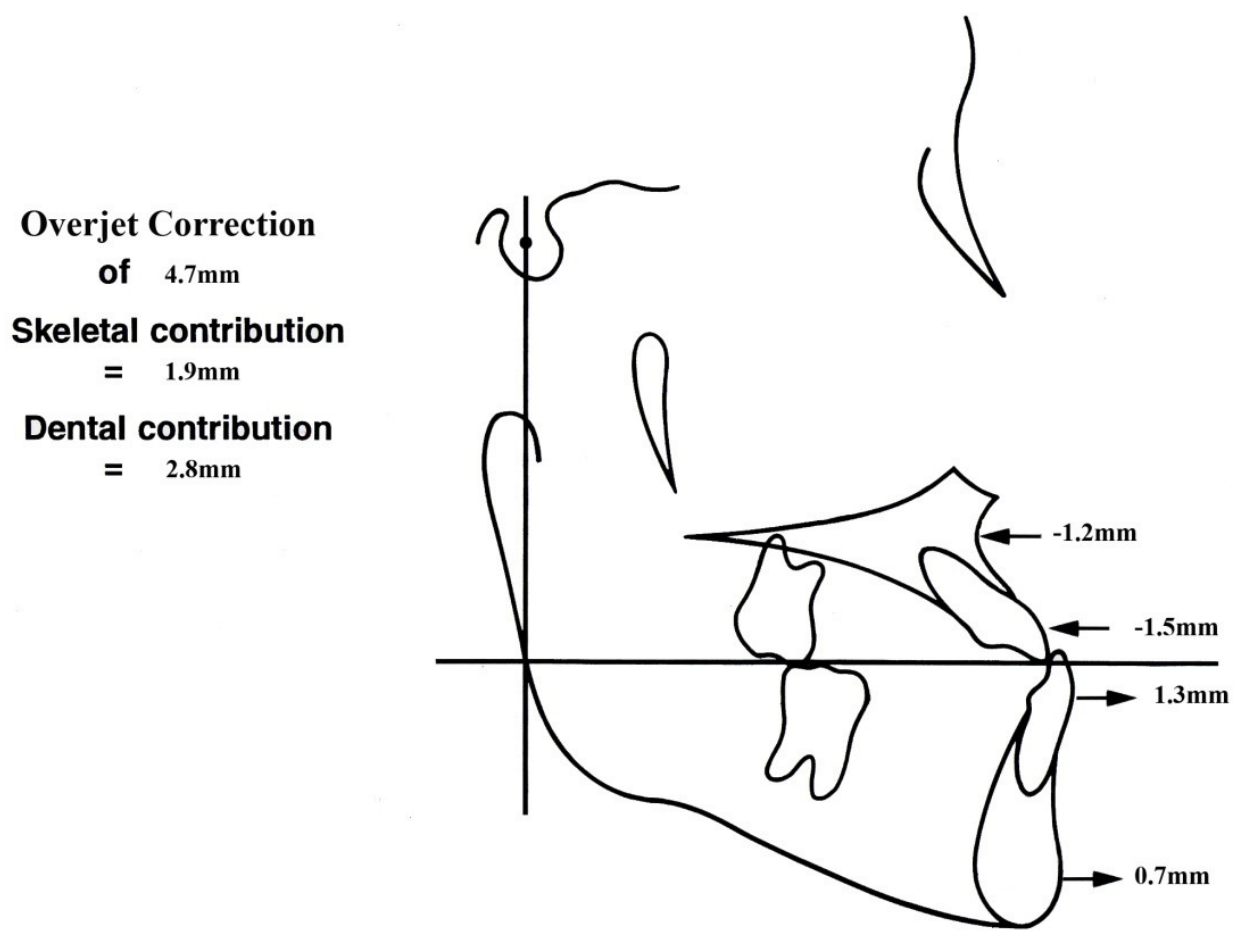

Figure 8. Components of Net Overjet Correction (T2-T1)

Net Molar Relationship Correction = Maxilla + Mx molar - Mandible - Md molar

Net Molar Relationship Correction $=-1.2+(-0.5)-0.7-1.3=-3.7$ 


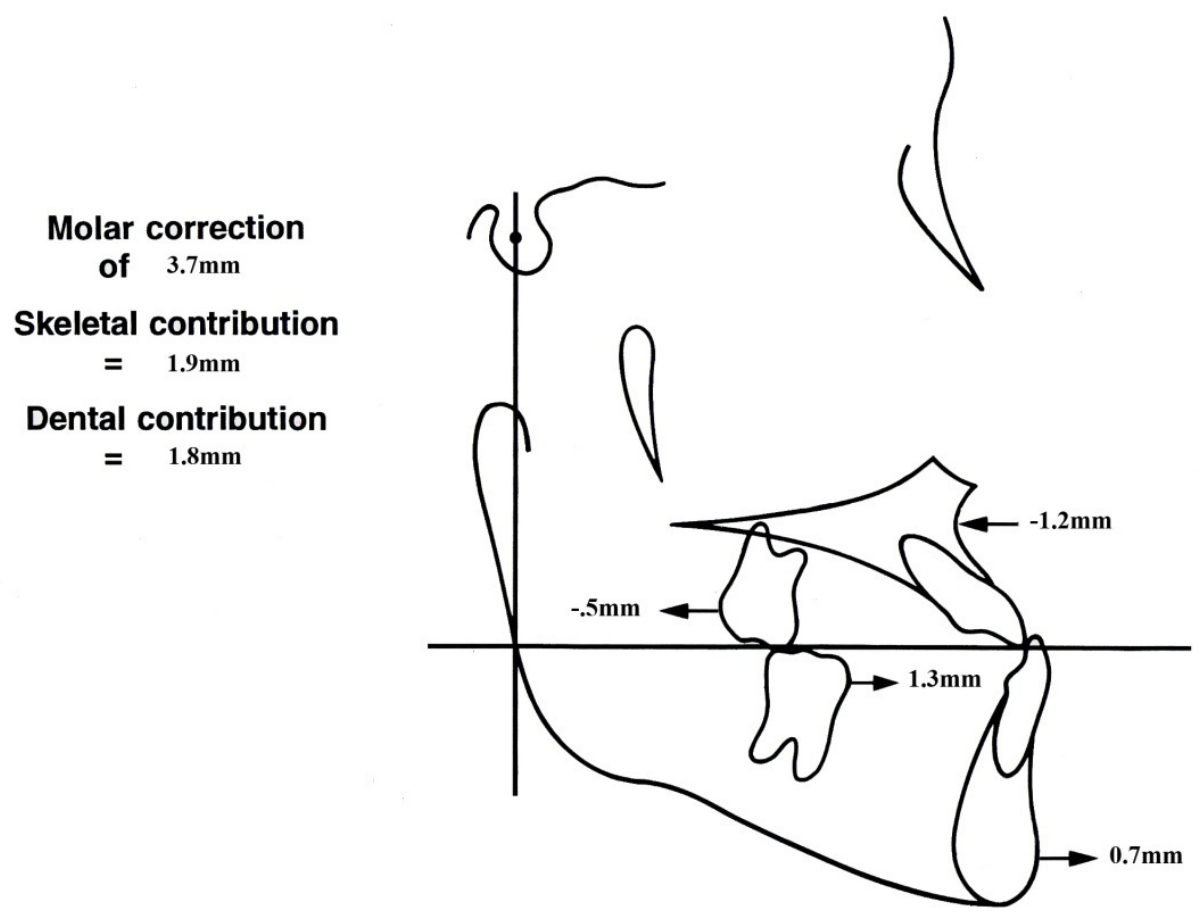

Figure 9. Components of Net Molar Correction (T2-T1) 

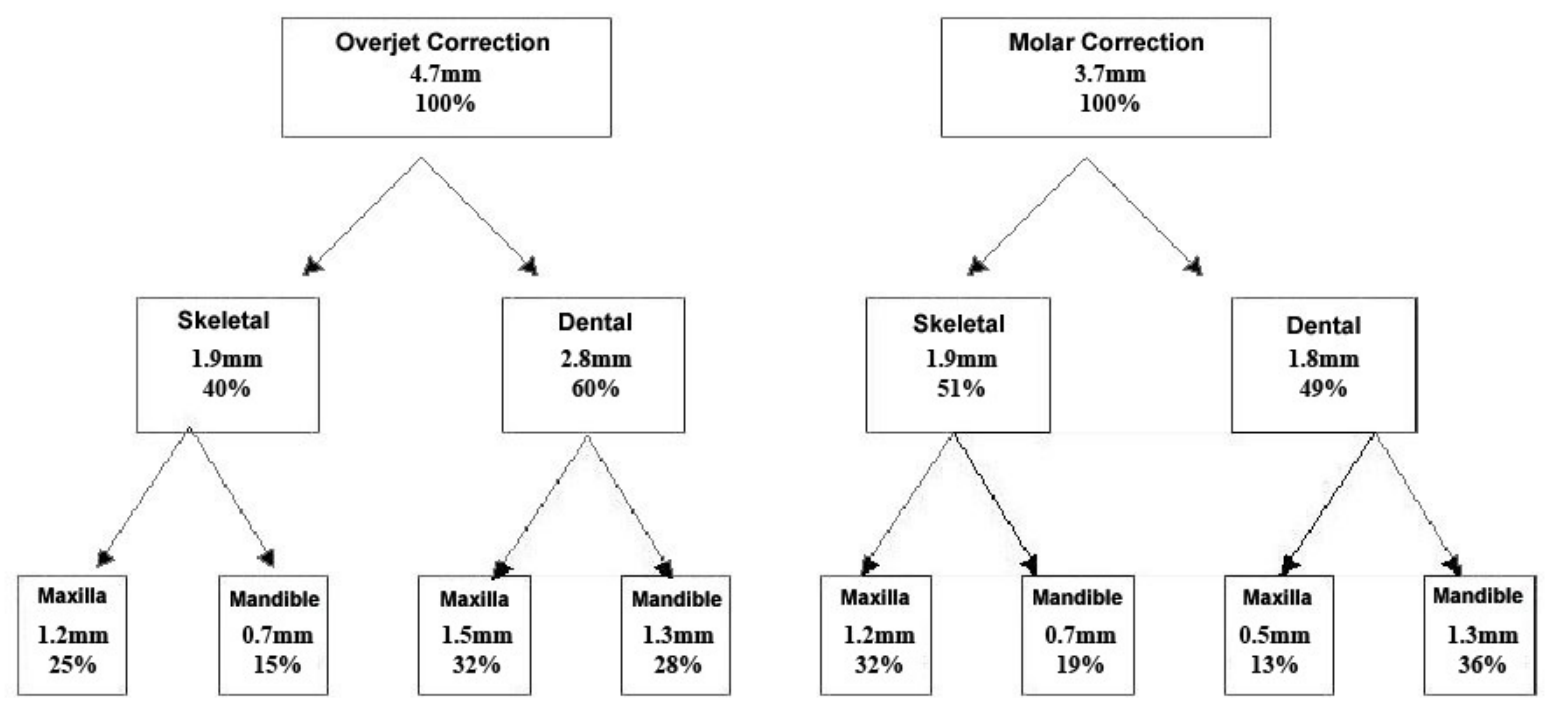

Figure 10. Pitchfork Analysis of Net Overjet and Molar Correction (T2-T1) 


\section{CHAPTER V: DISCUSSION}

\section{Age and Sex Distribution}

The age of the treated and control groups were fairly closely matched. The age distributions are presented in Table 2 . The average age at $\mathrm{T} 1$ for the control group was 10.3 years and 10.7 for the treatment group. The average age at $\mathrm{T} 2$ for the control group was 14.7 years and 14.5 years for the treatment group. There were no statistically significant differences between the ages of the two groups at any timepoint.

The sex of the treatment and control groups was matched as closely as possible; however, they did differ slightly. The control group consisted of 15 females and 7 males, and the treatment group consisted of 9 females and 15 males.

\section{Pretreatment Craniofacial Morphology}

The pretreatment craniofacial morphology of the treated and control groups was compared to determine if any statistically significant differences were present before treatment with the Forsus FRD and fixed orthodontic appliances. Seven out of 29 variables were found to be significantly different between the two groups, and are listed in Table 10. The Wits, Overjet, and Molar Relationship were larger in the treated group as compared to the control group indicating that the treated group had a more severe Class II anterior-posterior skeletal discrepancy than the control group. The Is-NL and Overbite were also larger, and Mic-ML was smaller in the treated group, indicating that the treated group had a deeper overbite with more maxillary incisor eruption and less 
mandibular molar eruption. Overall, the pretreatment morphology between the treatment and control groups were quite similar.

\section{Comparison of the Treated Group Versus the Control Group (T2-}

\section{T1)}

In the literature, three studies investigated the effects of the Forsus appliance. Heinig $^{121}$ studied the effects of the Forsus Niti Flat Spring on 13 patients over a period of 4 months. However, they did not compare the results of the treated group to an untreated control group to account for the effects of normal growth. Jones ${ }^{120}$ studied the effects of the Forsus FRD and compared the results to Class II elastics. No record is given regarding the average time the Forsus appliance was left in place. They only studied sagittal variables and also did not compare to an untreated control group to account for

the effects of normal growth. Karacay ${ }^{122}$ studied the effects of the Forsus Niti Flat Spring and compared the results to an untreated control group and to a group treated with the Jasper Jumper. The average length of time that the Forsus Niti Flat Spring was left in place was 5.28 months.

This study measured the effects of the Forsus FRD relative to an untreated control group. The average time the Forsus FRD was left in place was 9 months.

\section{$\underline{\text { Sagittal Differences }}$}

Significant differences were found in 7 of the 13 sagittal variables. When ruling out the effects of growth, changes in Co-Gn minus Co-Apt, Wits, Is-OLp, Ii-OLp, Overjet, Mi-OLp, and Molar Relationship were all statistically significant. Several other changes were noted, but not all were found to be statistically significant. 
The maxillary base (OLp-Apt.) moved forward $3.9 \mathrm{~mm}$ for the treated group and $5.1 \mathrm{~mm}$ for the control group. Therefore; there was a net restraint in forward movement of A point by $1.2 \mathrm{~mm}$, however, this was not found to be statistically significant. Heinig $^{121}$ found a forward movement of A point using the Forsus Flat Spring of $0.3 \mathrm{~mm}$. However, they left the spring in for a shorter amount of time, and did not measure net changes by comparing to a non treated control group to rule out the effects of growth. Jones $^{120}$ found a forward movement of A point using the Forsus FRD of $1.7 \mathrm{~mm}$. However, they did not measure net changes by comparing the results to an untreated control group. This study's result is similar to that found by Karacay ${ }^{122}$ who measured Forsus Flat Spring and found a net posterior movement of A point by $0.66 \mathrm{~mm}$. Our study showed slightly more net posterior movement of A point, and is probably due to the longer period of time that the Forsus FRD was left in place (average time 9 months). The amount of change in the maxillary base found in this study is slightly less, but similar to other studies which measured changes with the Herbst Appliance. Studies report 1.2-1.5 mm of maxillary restraint ${ }^{56,79,89}$. This would mean that the Forsus FRD appliance exerts a headgear effect on the maxilla and restrains maxillary growth slightly less but similar to that of the Herbst appliance.

The mandibular base (OLp-Pg) came forward $7.3 \mathrm{~mm}$ in the treated group and 6.6 $\mathrm{mm}$ in the control group. There was a net forward movement of the mandible $0.7 \mathrm{~mm}$, which was not statistically significant. Heinig ${ }^{121}$ found a $1.4 \mathrm{~mm}$ change with the Forsus Niti Flat Spring and and Jones ${ }^{120}$ found a $4.4 \mathrm{~mm}$ forward movement of the mandible with the Forsus FRD, but once again, they did not look at net treatment changes to account for growth. Karacay ${ }^{122}$ found a similar net forward movement of the mandibular 
base of $1.0 \mathrm{~mm}$ relative to a control with the Forsus Niti Flat Spring. This present study's change in mandibular base is similar to, but less than the Herbst appliance which showed a net forward movement of $0.9-4.5 \mathrm{~mm}^{79,81,128}$.

The Wits analysis decreased $2.2 \mathrm{~mm}$ in the treated group, while it increased 0.5 $\mathrm{mm}$ in the control group. There was a net reduction of the Wits by $2.7 \mathrm{~mm}$. This is slightly less, but similar to VanLaecken ${ }^{79}$ who found a $4.3 \mathrm{~mm}$ reduction in the Wits value during Herbst treatment.

The Overjet was reduced by $4.5 \mathrm{~mm}$ in the treatment group, while it increased by $0.1 \mathrm{~mm}$ in the control group. There was a net overjet reduction of $4.6 \mathrm{~mm}$. This is very similar to other studies. Heinig ${ }^{121}$ found a $4.7 \mathrm{~mm}$ reduction in overjet with the Forsus Flat Spring. Jones ${ }^{120}$ found a $3.2 \mathrm{~mm}$ reduction in overjet with the Forsus FRD. Karacay ${ }^{122}$ found a 3.69 reduction in net overjet with the Forsus Niti Flat Spring relative to an untreated control group. Our results are also similar to the effects of the Herbst appliance, where net overjet correction was found to be from $2.7-5.2 \mathrm{~mm}^{53,72,79,89}$.

Overjet correction has both dental and skeletal causes. The skeletal causes of overjet correction are due to the posterior movement of the maxillary base, and the anterior movement of the mandibular base as discussed before. The following is the amount of overjet correction due to dental causes. In this study, the amount of net overjet correction due to maxillary incisor retraction was $1.5 \mathrm{~mm}$. The amount of net overjet correction due to mandibular incisor protrusion was $1.3 \mathrm{~mm}$. This is similar to other studies. Heinig ${ }^{121}$ showed $1.7 \mathrm{~mm}$ retraction of the maxillary incisor and $1.8 \mathrm{~mm}$ of protrusion of the lower incisor with the Forsus Niti Flat Spring. Jones ${ }^{120}$ found $0.7 \mathrm{~mm}$ 
protrusion of the maxillary incisor and $1.2 \mathrm{~mm}$ protrusion of the mandibular incisor with the Forsus FRD. Karacay ${ }^{122}$ found a $1.44 \mathrm{~mm}$ net retraction of the maxillary incisor and a $2.16 \mathrm{~mm}$ net protrusion of the lower incisor when he compared the Forsus Niti Flat Spring treated group to an untreated control group. In regards to overjet correction, our study's findings along with the other studies on the Forsus appliance confirm the increased dental effects of the Forsus appliance compared to the Herbst appliance. The Herbst appliance has been reported to have 0.2-0.7 mm net maxillary incisor retraction $^{53,72,79}$, and 0.2-1.4 mm net mandibular incisor protrusion ${ }^{53,79,85}$.

The Molar relationship improved $4.1 \mathrm{~mm}$ in the treated group, and it improved 0.5 $\mathrm{mm}$ in the control group. There was a net improvement in the molar relationship of 3.6 mm. This is similar to the findings of Heinig ${ }^{121}$ and Jones ${ }^{120}$ who found a molar relationship improvement of $3.9 \mathrm{~mm}$ and $3.2 \mathrm{~mm}$, respectively. This is similar to the amount of molar correction with the Herbst appliance, which has been reported to be from 2.4 - $4.6 \mathrm{~mm}^{72,79,89}$. In this study, the molar relationship correction involved skeletal and dental causes. The skeletal causes of molar relationship correction are due to the posterior movement of the maxillary base, and the anterior movement of the mandibular base as discussed before. The following is the amount of molar relationship correction due to dental causes. The amount of net molar relationship correction due to distal movement of the maxillary molar was $1.6 \mathrm{~mm}$. The amount of net molar relationship correction due to mesial movement of the mandibular molar was $2.0 \mathrm{~mm}$. This is very similar to other studies on the Forsus Appliance. Heinig ${ }^{121}$ found $1.1 \mathrm{~mm}$ of distal maxillary molar movement and $1.7 \mathrm{~mm}$ of mesial mandibular molar movement with the Forsus Niti Flat Spring. Karacay ${ }^{122}$ found $1.97 \mathrm{~mm}$ of net distal maxillary molar 
movement and $1.75 \mathrm{~mm}$ of net mesial mandibular molar movement with the Forsus Niti Flat Spring compared to an untreated control. The Herbst appliance has similar results for dental correction of the molar relationship. Studies have shown $0.4-1.5 \mathrm{~mm}$ of distal maxillary molar movement and $-0.3-1.6 \mathrm{~mm}$ of mesial mandibular molar movement $^{72,79,85,89}$.

\section{Vertical Differences}

There were significant differences in only 2 of the 7 vertical variables. When ruling out the effects of growth, only changes in Overbite and Mic-ML were statistically significant.

Lower facial height (ANS-Me) showed an increase of $5.1 \mathrm{~mm}$ in the treated group, and a $4.8 \mathrm{~mm}$ increase in the control group. There was a net increase of $0.3 \mathrm{~mm}$ in the treated group, which was not significant. This is less than reported by Karacay ${ }^{122}$ who found a net increase in lower facial height of $4.87 \mathrm{~mm}$ with the Forsus Niti Flat Spring compared to a untreated control. However, the results of the present study are in agreement with current literature on the effect of the Herbst appliance, where VanLaecken ${ }^{79}$ showed a net increase in lower facial height of $0.3 \mathrm{~mm}$, and others have had similar findings with the Herbst appliance. ${ }^{11,71,81}$

The maxillary incisor (Is-NL) was found to extrude $1.2 \mathrm{~mm}$ in the treated group, and extruded $1.6 \mathrm{~mm}$ in the control group. There was a net intrusion of the maxillary

incisor of $0.4 \mathrm{~mm}$ in the treated group, which was not found to be significant. Karacay ${ }^{122}$ found a net extrusion of the maxillary incisor of $1.03 \mathrm{~mm}$ using the Forsus Niti Flat 
Spring. However, they measured the maxillary incisor position relative to SN instead of the palatal plane as this study did.

The mandibular incisor (Ii-NL) was found to extrude $1.8 \mathrm{~mm}$ in the treated group, and extrude $3.2 \mathrm{~mm}$ in the control group. There was a net intrusion of the mandibular incisor of $1.4 \mathrm{~mm}$ which was not found to be significant. Karacay ${ }^{122}$ measured $3.08 \mathrm{~mm}$ of net mandibular incisor intrusion, which is more than the present study found. The Herbst appliance has been shown to have similar effects on the vertical position of the mandibular incisor, and has been shown to have a net intrusion of $1.6-2.1 \mathrm{~mm}^{72,79,89}$.

Overbite was found to decrease in the treated group by $1.8 \mathrm{~mm}$, and it increased 0.2 in the control group. There was a net decrease in overbite of $2.0 \mathrm{~mm}$ which was found to be significant. Karacay ${ }^{122}$ found a very similar result in their study of the Forsus Niti Flat Spring, and found a net reduction of overbite by $1.41 \mathrm{~mm}$. The Herbst appliance has been shown to have a very similar decrease in overbite. VanLaecken ${ }^{79}$ reported a net decrease in overbite of $2.0 \mathrm{~mm}$ and $\mathrm{Croft}^{89}$ found a $2.4 \mathrm{~mm}$ decrease in overbite.

The vertical position of the maxillary molar (Msc-NL) was found to extrude 2.6 $\mathrm{mm}$ in the treated group and extrude $3.0 \mathrm{~mm}$ in the control group. There was a net intrusion of the maxillary molar of $0.4 \mathrm{~mm}$, but this change was not significant. Karacay $^{122}$ reported a net intrusion of the maxillary molar to be $3.93 \mathrm{~mm}$. This is significantly more than the present study; however, they measured the vertical position of the maxillary molar relative to $\mathrm{SN}$, and this study measured the vertical position of the maxillary molar relative to the Palatal Plane, which may account for the difference. 
The vertical position of the mandibular molar (Mic-ML) was found to extrude 4.0 $\mathrm{mm}$ in the treated group, and extrude $2.6 \mathrm{~mm}$ in the control group. There was a net extrusion of the mandibular molar of $1.4 \mathrm{~mm}$, which was found to be significant. Karacay $^{122}$ reported a net $1.13 \mathrm{~mm}$ extrusion of the mandibular molar, which is very similar.

\section{$\underline{\text { Angular Differences }}$}

Over the course of treatment, there were significant differences in 3 of the 9 angular variables. When ruling out the effects of growth, changes in SNA, ANB, and Ii/ML were all statistically significant. Several other changes were noted, but not all were found to be statistically significant.

SNA increased in the treatment group by $0.1^{\circ}$ and increased in the control group by $1.6^{\circ}$. There was a net decrease in SNA by $1.5^{\circ}$. This is similar to Karacay ${ }^{122}$ who found a net decrease in SNA by $0.66^{\circ}$ when comparing the Forsus Niti Flat Spring to an untreated control group. Heinig ${ }^{121}$ reported a $0.12^{\circ}$ increase in SNA for the Forsus Niti Flat Spring; however, they did not compare to an untreated control group to account for the effects of growth. Our study's findings are also very similar to findings on the Herbst

appliance which show a decrease in SNA ranging from $0.5^{\circ}-2.6^{\circ} \cdot .^{79,89,125,128}$ This would seem to indicate that the Forsus FRD does have a significant headgear effect and limits the forward growth of the maxilla.

SNB increased by $1.7^{\circ}$ in the treated group and increased by $1.4^{\circ}$ in the control group. There was a net increase in $\mathrm{SNB}$ of $0.3^{\circ}$ which was not significant. Heinig ${ }^{121}$ reported a $0.54^{\circ}$ increase in SNB for the Forsus Niti Flat Spring; however, they did not 
compare to an untreated control group to account for the effects of growth. Karacay ${ }^{122}$ found a net increase in SNB of $1.97^{\circ}$ which was significantly more than reported in this study. The Herbst appliance has been reported to have an increase in SNB from $1.0^{\circ}$ $1.6^{\circ 79,89,128}$. These findings would seem to indicate that the Forsus FRD may have less effect on the stimulation of forward growth of the mandible than the Herbst appliance.

The difference between the position of the maxilla and mandible (ANB) decreased by $1.5^{\circ}$ in the treated group, while it increased by $0.2^{\circ}$ in the control group. There was a net decrease in ANB of $1.8^{\circ}$ in this study, which was significant. Heinig ${ }^{121}$ reported a $0.42^{\circ}$ decrease in ANB for the Forsus Niti Flat Spring; however, they did not compare to an untreated control group to account for the effects of growth. Karacay ${ }^{122}$ found a net decrease in ANB of $3.13^{\circ}$ which was significantly more than reported in this study. The Herbst appliance has reported a $1.2^{\circ}-2.6^{\circ}$ decrease in $\mathrm{ANB}^{79,89,125,128}$.

The palatal plane (SNL-NL), mandibular plane (SNL-ML), and Occlusal Plane (SNL-OLf) all showed changes which were not statistically significant. There was a $0.6^{\circ}$ net reduction in the palatal plane, a $0.9^{\circ}$ net reduction in the mandibular plane, and a $1.2^{\circ}$ increase in the occlusal plane. Similar slight reductions in the palatal plane and mandibular plane are reported for the Forsus Niti Flat Spring and Forsus FRD ${ }^{121,122}$, as well as with the Herbst appliance ${ }^{11,71,79,91}$. Karacay ${ }^{122}$ reported a net increase of $2.81^{\circ}$ for the occlusal plane with the Forsus Niti Flat Spring, and Heinig ${ }^{121}$ found a $4.17^{\circ}$ increase in the occlusal plane, which are slightly larger than the increase found in this study. This may be due to the fact that there are different definitions of where to measure the functional occlusal plane and may explain the differences between the studies. 
The maxillary incisor inclination (Is/NL) increased $2.8^{\circ}$ in the treated group, and decreased $0.1^{\circ}$ in the control group. There was a net increase in maxillary incisor inclination of $2.9^{\circ}$ which was not found to be significant. This is significantly different than reported by Heinig ${ }^{121}$ and Karacay ${ }^{122}$ who reported a decrease in maxillary incisor inclination of $5.33^{\circ}$ and $5.01^{\circ}$ respectively. However, both reported the inclination of the maxillary incisor relative to $\mathrm{SN}$, where this study reported the inclination of the maxillary incisor relative to the palatal plane. This difference in reference line may explain the difference, but also post-Forsus orthodontic mechanics may as well. In this study, MBT brackets were used which have a $17^{\circ}$ maxillary anterior inclination built into the bracket to preserve inclination during retraction. This study's results are comparable to the treatment effects of the Herbst appliance as described by VanLaecken ${ }^{79}$ who found a $5.3^{\circ}$ increase in maxillary incisor inclination.

The mandibular incisor inclination (Ii-ML) increased by $3.9^{\circ}$ for the treatment group, and decreased by $0.6^{\circ}$ for the control group. There was a net increase in inclination of the lower incisor by $4.5^{\circ}$ which was found to be significant. Heinig ${ }^{121}$ reported a $9.60^{\circ}$ increase in lower incisor inclination for the Forsus Niti Flat Spring. Karacay $^{122}$ found a net increase in lower incisor inclination of $4.88^{\circ}$ which was very similar to the results found in this study. The Herbst appliance has been shown to increase the mandibular incisor inclination $1.6^{\circ}-2.4^{\circ 79,82,89}$. This would indicate that the Forsus FRD appliance is associated with more incisor proclination than with the Herbst appliance.

\section{$\underline{\text { Overall Correction in Comparison to Other Appliances }}$}


This study found that the effects of the Forsus FRD used in conjunction with fixed orthodontic appliances results in the following: Total net overjet correction was $4.7 \mathrm{~mm}$. Of that $1.9 \mathrm{~mm}(40 \%)$ was due to skeletal movement of the maxilla and mandible, and $2.8 \mathrm{~mm}(60 \%)$ was due to dental movement. Heinig ${ }^{121}$ found overjet correction was due to $34 \%$ skeletal effects and $66 \%$ dental effects for the Forsus Niti Flat Spring; however, they did not compare to an untreated control group to account for the effects of growth. Also, their average treatment time with the Forsus Flat Spring in place was 4 months, were this study's average treatement time with the Forsus FRD was 9 months.

The components of overjet correction for the Jasper Jumper have been studied and reported from $3-40 \%$ skeletal changes and $60-97 \%$ dental changes ${ }^{94-97}$. The results of this study would indicate that the Forsus FRD used in conjunction with fixed orthodontic appliances has similar to slightly more amount of overjet correction due to skeletal changes, and similar to slightly less amount of overjet correction due to dental changes.

Nelson ${ }^{101}$ studied the components of overjet correction for Class II elastics and found that $10 \%$ of the changes were skeletal and $90 \%$ of the changes were dental. This study would indicate that there is a higher component of skeletal correction with the Forsus FRD used in conjunction with fixed orthodontic appliances than Class II elastics and orthodontic appliances alone. Jones ${ }^{120}$ found that with the exception of lower molar mesial movement and total molar correction which were greater in the Forsus FRD group, there were no other statistically significant differences between patients treated with the Forsus FRD and Class II elastics. 
The Treatment effects of the Herbst Appliance were described by VanLaecken ${ }^{79}$. His study looked at the net treatment changes associated with the Edgewise Herbst Appliance compared to an untreated control group. The ages and time period studied closely approximated the age range and time period in this study. They found that the net overjet correction was due to $85 \%$ skeletal movement and $15 \%$ dental movement. This would indicate that the Forsus FRD and fixed orthodontic appliances has a higher dental and a lower skeletal component to the correction when compared to the Herbst appliance. 


\section{CHAPTER VI: SUMMARY AND CONCLUSIONS}

\section{Summary}

The purpose of this study was to investigate the skeletal and dental changes associated with the Forsus Fatigue Resistant Device (FRD) when used in conjunction with orthodontic therapy. These changes would then be compared to an untreated control group to rule out the effects of normal growth.

The treated group consisted of 24 subjects ( 9 females and 15 males) who were treated by Dr. Imad Shammaa at his private office in Charleston, WV. The control group consisted of 22 untreated subjects (15 females and 7 males) from the Case Western Reserve University Bolton Brush Study, and all data for them was collected from Wigal $^{125}$. The groups were matched as closely as possible in age, sex and craniofacial morphology.

A custom cephalometric analysis was performed as described by Bjork ${ }^{127}$, Pancherz $^{91}$, VanLaecken ${ }^{79}$ and Wigal ${ }^{125}$. Matched pairs t-test and ANOVA was used to determine if there were any statistical differences between the time periods. The following hypothesis was tested: There are no mean changes over time between the maxillary and mandibular growth in patients treated with the Forsus FRD and an untreated control group. 


\section{Conclusions}

The hypothesis was rejected as the following statistically significant changes were observed:

1. There were some significant net skeletal differences found following treatment with the Forsus FRD and fixed orthodontic appliances. There was a significant improvement in the Wits analysis by $2.7 \mathrm{~mm}$, and SNA and ANB significantly improved $\left(-1.5^{\circ}\right.$ and $-1.8^{\circ}$ respectively).

2. There was a significant net overjet correction of $4.7 \mathrm{~mm}$, net molar correction of $3.7 \mathrm{~mm}$, and overbite correction of $2.0 \mathrm{~mm}$.

3. There were some significant net dental differences found following treatment with the Forsus FRD and fixed orthodontic appliances. The upper incisor was retracted $1.5 \mathrm{~mm}$ and the lower incisor was protruded $1.3 \mathrm{~mm}$. The mandibular molar moved mesially $1.3 \mathrm{~mm}$. Also the mandibular incisor inclination increased $4.5^{\circ}$. The mandibular molar also erupted $1.4 \mathrm{~mm}$.

There were also changes noted which were not statistically significant:

1. There was an inhibition of forward maxillary growth $(-1.2 \mathrm{~mm})$, and some slight stimulation of forward mandibular growth $(0.7 \mathrm{~mm})$. As well, SNB slightly increased $\left(.3^{\circ}\right)$.

2. Other net dental differences were noted which were not statistically significant. The maxillary molar moved distally $0.5 \mathrm{~mm}$, and the maxillary incisor inclination increased $2.9^{\circ}$. Also the interincisal angle increased $3.0^{\circ}$ 
Overall, net overjet correction was $40 \%$ skeletal and $60 \%$ dental and net molar correction was $51 \%$ skeletal and $49 \%$ dental. Skeletal changes included decreased of forward movement of the maxilla (headgear effect) and increased forward movement of the mandible. Dental changes included retraction of the maxillary incisors and molars and protrusion of the mandibular incisors and molars. 


\section{CHAPTER VII: RECOMMENDATIONS FOR FUTURE}

\section{RESEARCH}

\section{Recommendations}

1. A new control sample could be obtained, to better match the treated group in age, sex and craniofacial morphology. This would allow all radiographs to be traced by 1 operator.

2. This study was limited to pre treatment and post treatment radiographs. This means that this study investigated the effects of the Forsus FRD and fixed orthodontic appliances used in conjunction and therefore cannot determine which effects are due completely to the Forsus FRD alone. A study that investigates radiographs taken immediately once the Forsus is placed and immediately after the Forsus is removed would give a better indication of which effects are due to the Forsus FRD alone.

3. Long term results could be obtained by studying post treatment radiographs 1 or 2 years after Forsus treatment to determine the amount of long term stability of the changes associated with the Forsus FRD appliance.

4. A 3D cone beam study on patients treated with the Forsus FRD appliance would allow the study of the effects of the Forsus FRD device in all 3 dimensions, as well as the condyle growth and position. 


\section{Reference List}

1. McNamara JA Jr., Bookstein FL \& Shaughnessy TG Skeletal and dental changes following functional regulator therapy on Class II patients. Am J Orthod Dentofacial Orthop 88, 91-110 (1985).

2. Pancherz H A Cephalometric analysis of skeletal and dental changes contributing to Class II correction in activator treatment. Am J Orthod Dentofacial Orthop 85, 123-133 (1984).

3. Falck, F. \& Frankel, R. Clinical relevance of step-by-step mandibular advancement in the treatment of mandibular retrusion using the Frankel appliance. Am. J. Orthod. Dentofacial Orthop. 96, 333-341 (1989).

4. Sahm G, Bartsch A \& Witt E Micro-electronic monitoring of functional appliance wear. Eur J Orthod 12, 297-301 (1990).

5. Papadopoulos MA Orthodontic Treatment of the Class II Noncompliant Patient. Mosby Elsevier Limited, Philadelphia, PA (2006).

6. Konik, M., Pancherz, H. \& Hansen, K. The mechanism of Class II correction in late Herbst treatment. Am J Orthod Dentofacial Orthop 112, 87-91 (1997).

7. Manfredi, C., Cimino, R., Trani, A. \& Pancherz, H. Skeletal changes of Herbst appliance therapy investigated with more conventional cephalometrics and European norms. Angle Orthod 71, 170-176 (2001).

8. Pancherz, H. \& Fischer, S. Amount and direction of temporomandibular joint growth changes in Herbst treatment: a cephalometric long-term investigation. Angle Orthod. 73, 493-501 (2003).

9. Pancherz, H., Ruf, S. \& Kohlhas, P. "Effective condylar growth" and chin position changes in Herbst treatment: a cephalometric roentgenographic long-term study. Am J Orthod Dentofacial Orthop 114, 437-446 (1998).

10. Pancherz, H. \& Fackel, U. The skeletofacial growth pattern pre- and postdentofacial orthopaedics. A long-term study of Class II malocclusions treated with the Herbst appliance. Eur J Orthod 12, 209-218 (1990).

11. Pancherz, H. The Herbst appliance--its biologic effects and clinical use. Am J Orthod 87, 1-20 (1985).

12. Pancherz, H. The mechanism of Class II correction in Herbst appliance treatment. A cephalometric investigation. Am J Orthod 82, 104-113 (1982). 
13. Ruf, S. \& Pancherz, H. The mechanism of Class II correction during Herbst therapy in relation to the vertical jaw base relationship: a cephalometric roentgenographic study. Angle Orthod 67, 271-276 (1997).

14. Ruf, S. \& Pancherz, H. Dentoskeletal effects and facial profile changes in young adults treated with the Herbst appliance. Angle Orthod 69, 239-246 (1999).

15. Flores-Mir C, Ayeh A, Goswani A \& Charkhandeh S Skeletal and dental changes in Class II division 1 malocclusions treated with splint-type Herbst appliances. A systematic review. Angle Orthod 77, 376-381 (2007).

16. Proffit WR \& Fields HW Contermporary Orthodontics 4th Edition. Moseby Inc., St. Louis, MO (2007).

17. Angle EH Treatment of malocclusioin of the teeth and fracture of the maxillae. SS White Dental Mfg. Co., Philadelphia PA (1900).

18. McNamara JA Jr. \& Brudon W Orthodontic and Orthopedic treatment in the Mixed Dentition. Needham Press Inc., Ann Arbor, MI (1993).

19. Moyers RE Handbook of Orthodontics. 4th Edition. Year Book Medical Pub., Chicago, IL (1988).

20. Enlow DH Facial Growth 3rd Edition. Saunders Co., (1990).

21. McLain JB \& Proffit WR Oral Health Status in the United States. J Dent Educ 49, 386-396 (1985).

22. Kelly JE, Sanchez M \& Vankirk LE An Assesment of the occlusion of the teeth of children, DHEW Publication No. (HRA) 74-1612. National Center for Health Statistics, Washington, DC (1973).

23. Kelly JE \& Harvey, C. An assessment of the teeth of youths 12-17 years, DHEW Publication No (HRA) 77-1644. National Center for Health Statistics, Washington, DC (1977).

24. McLain JB, Steedle JR \& Vig PS Face height and dental relationships in 1600 children:A survey. J Dent Res 62, 308 (1983).

25. Henry, R. A classification of Class II, division 1 molocclusions. Angle Orthod 27, 83-92 (1957).

26. Moyers, R. E., Riolo, M. L., Guire, K. E., Wainright, R. L. \& Bookstein, F. L. Differential diagnosis of class II malocclusions. Part 1. Facial types associated with class II malocclusions. Am J Orthod 78, 477-494 (1980).

27. McNamara, J. A., Jr. Components of class II malocclusion in children 8-10 years of age. Angle Orthod 51, 177-202 (1981). 
28. Drelich RC A cephalometric study of untreated Class II, division 1 malocclusion. Angle Orthod 18, $70-75$ (1948).

29. Nelson WE \& Highly LB Length of mandibular basal bone in normal occlusion and Class I malocclusion compared to Class II, division 1 Malocclusion. Am J Orthod 34, 610-617 (1948).

30. Renfroe EW A study of the facial patterns associated with Class I, Class II, division 1 and Class II division 2 malocclusions. Angle Orthod 19, 12-15 (1948).

31. Gilmore, W. Morphology of the adult mandible in Class II, Division 1 malocclusion and in excellent occlusion. Angle Orthod 20, 137-146 (1950).

32. Craig CE. The skeletal patterns characteristic of Class I and Class II, Division I malocclusions in norma lateralis. Angle Orthod 21, 44-56 (1951).

33. Riedel RA The relationship of maxillary structures to cranium in malocclusion and normal occlusion. Angle Orthod 22, 142-145 (1952).

34. Blair ES A cephalometric roentographic appraisal of the skeletal morphology of Class I, Class II division 1, and Class II division 2 malocclusion. Angle Orthod 24, 106-119 (1952).

35. Altemus LA Horizontal and vertical dentofacial relationships in normal and Class II division 1 malocclusions in girls 11-15 years. Angle Orthod 25, 120-137 (1955).

36. Hunter, W. S. The vertical dimensions of the face and skeletodental retrognathism. Am J Orthod 53, 586-595 (1967).

37. Rothstein, T. L. Facial morphology and growth from 10 to 14 years of age in children presenting Class II, Division 1 Malocclusion: a comparative roentgenographic cephalometric study. Am J Orthod 60, 619-620 (1971).

38. Hitchcock, H. P. A cephalometric description of Class II, Division 1 malocclusion. Am J Orthod 63, 414-423 (1973).

39. Carter, N. E. Dentofacial changes in untreated Class II division 1 subjects. Br. $J$ Orthod 14, 225-234 (1987).

40. Williams, A. \& Woodhouse, C. The crown to root angle of maxillary central incisors in different incisal classes. Br. J Orthod 10, 159-161 (1983).

41. Hitchcock, H. P. The cephalometric distinction of class II, division 2 malocclusion. Am J Orthod 69, 447-454 (1976).

42. Ngan, P. W., Byczek, E. \& Scheick, J. Longitudinal evaluation of growth changes in Class II division 1 subjects. Semin. Orthod 3, 222-231 (1997). 
43. Bishara, S. E., Hoppens, B. J., Jakobsen, J. R. \& Kohout, F. J. Changes in the molar relationship between the deciduous and permanent dentitions: a longitudinal study. Am J Orthod Dentofacial Orthop 93, 19-28 (1988).

44. Bjork, A. Variations in the growth pattern of the human mandible: longitudinal radiographic study by the implant method. J Dent Res 42(1)Pt 2, 400-411 (1963).

45. McNamara, J. A., Jr., Peterson, J. E., Jr. \& Alexander, R. G. Three-dimensional diagnosis and management of Class II malocclusion in the mixed dentition.

Semin. Orthod 2, 114-137 (1996).

46. Steiner CC Cephalometrics for you and me. Am J Orthod 39, 729-755 (1953).

47. McNamara, J. A., Jr. \& Ellis, E., III Cephalometric analysis of untreated adults with ideal facial and occlusal relationships. Int. J Adult. Orthodon. Orthognath. Surg. 3, 221-231 (1988).

48. McNamara, J. A., Jr. A method of cephalometric evaluation. Am J Orthod 86, 449-469 (1984).

49. Ricketts RM The influence of orthodontic treatment on facial growth and development. Angle Orthod 30, 103-133 (1960).

50. Schudy FF Vertical growth versus antero-posterior growth as related to function and treatment. Angle Orthod 35, 36-50 (1965).

51. Schudy FF The rotation of the mandible resulting from growth: Its implications in orthodontic treatment. Angle Orthod 35, 36-50 (1965).

52. Tollaro, I., Baccetti, T., Franchi, L. \& Tanasescu, C. D. Role of posterior transverse interarch discrepancy in Class II, Division 1 malocclusion during the mixed dentition phase. Am J Orthod Dentofacial Orthop 110, 417-422 (1996).

53. Baccetti, T., Franchi, L., McNamara, J. A., Jr. \& Tollaro, I. Early dentofacial features of Class II malocclusion: a longitudinal study from the deciduous through the mixed dentition. Am J Orthod Dentofacial Orthop 111, 502-509 (1997).

54. Arya, B. S., Savara, B. S. \& Thomas, D. R. Prediction of first molar occlusion. Am J Orthod 63, 610-621 (1973).

55. Spillane, L. M. \& McNamara, J. A., Jr. Maxillary adaptation to expansion in the mixed dentition. Semin. Orthod 1, 176-187 (1995).

56. Wieslander, L. Intensive treatment of severe Class II malocclusions with a headgear-Herbst appliance in the early mixed dentition. Am. J. Orthod. 86, 1-13 (1984). 
57. Moore, R. N. Principles of dentofacial orthopedics. Semin. Orthod 3, 212-221 (1997).

58. Andrews, L. \& Andrews WA Syllabus of the Andrews Philosophy and Techniques 8th Edition. Lawrence F. Andrews Foundation, San Diego, CA (1999).

59. Graber, T. Removable Orthodontic Appliances, 2nd Edition. WB Saunders, Philadelphia, PA (1984).

60. Graber, T., Rakosi T \& Petrovic AG Dentofacial orthopedics with functional appliances. Mosby, St. Louis, MO (1997).

61. Frankel, R. The treatment of Class II, Division 1 malocclusion with functional correctors. Am. J. Orthod. 55, 265-275 (1969).

62. Bishara, S. E. \& Ziaja, R. R. Functional appliances: a review. Am. J. Orthod. Dentofacial Orthop. 95, 250-258 (1989).

63. Stangl, D. P. A cephalometric analysis of six Twin Block patients. A study of mandibular (body and ramus) growth and development. Funct. Orthod. 14, 4-14, 17 (1997).

64. Nelson, C., Harkness, M. \& Herbison, P. Mandibular changes during functional appliance treatment. Am. J. Orthod. Dentofacial Orthop. 104, 153-161 (1993).

65. Mills, J. R. The effect of functional appliances on the skeletal pattern. $B r . J$. Orthod. 18, 267-275 (1991).

66. Teuscher, U. A growth-related concept for skeletal class II treatment. Am. J. Orthod. 74, 258-275 (1978).

67. Robertson, N. R. An examination of treatment changes in children treated with the function regulator of Frankel. Am. J. Orthod. 83, 299-310 (1983).

68. Creekmore, T. D. \& Radney, L. J. Frankel appliance therapy: orthopedic or orthodontic? Am. J. Orthod. 83, 89-108 (1983).

69. Rudzki-Janson, I. \& Noachtar, R. Functional appliance therapy with the Bionator. Semin. Orthod. 4, 33-45 (1998).

70. Aelbers, C. M. \& Dermaut, L. R. Orthopedics in orthodontics: Part I, Fiction or reality--a review of the literature. Am. J. Orthod. Dentofacial Orthop. 110, 513519 (1996).

71. Pancherz, H. Treatment of class II malocclusions by jumping the bite with the Herbst appliance. A cephalometric investigation. Am. J. Orthod. 76, 423-442 (1979). 
72. Pancherz H The Herbst Appliance Editorial Aquarium. Barcelona, Spain (1995).

73. Herbst, E. Dresissigjahrige Erahrungen mit dem Retentionsscharnier. Zahnarztl Rundschau 43, 1515-1524, 1563-1568, 1611-1616 (1934).

74. McNamara, J. A. Fabrication of the acrylic splint Herbst appliance. Am. $J$. Orthod. Dentofacial Orthop. 94, 10-18 (1988).

75. Paulsen, H. U. Morphological changes of the TMJ condyles of 100 patients treated with the Herbst appliance in the period of puberty to adulthood: a longterm radiographic study. Eur. J. Orthod. 19, 657-668 (1997).

76. Goodman, P. \& McKenna, P. Modified Herbst appliance for the mixed dentition. J. Clin. Orthod. 19, 811-814 (1985).

77. Dischinger, T. G. Edgewise bioprogressive Herbst appliance. J. Clin. Orthod. 23, 608-617 (1989).

78. Dischinger, T. Edgewise Herbst Appliance. J. Clin. Orthod. 29, 738-742 (1995).

79. VanLaecken, R., Martin, C. A., Dischinger, T., Razmus, T. \& Ngan, P. Treatment effects of the edgewise Herbst appliance: a cephalometric and tomographic investigation. Am. J. Orthod. Dentofacial Orthop. 130, 582-593 (2006).

80. Cozza, P., Baccetti, T., Franchi, L., De, T. L. \& McNamara, J. A., Jr. Mandibular changes produced by functional appliances in Class II malocclusion: a systematic review. Am J Orthod Dentofacial Orthop. 129, 599-12 (2006).

81. Pancherz, H. \& Hagg, U. Dentofacial orthopedics in relation to somatic maturation. An analysis of 70 consecutive cases treated with the Herbst appliance. Am J Orthod 88, 273-287 (1985).

82. Lai, M. \& McNamara, J. A., Jr. An evaluation of two-phase treatment with the Herbst appliance and preadjusted edgewise therapy. Semin Orthod 4, 46-58 (1998).

83. Pancherz, $\mathrm{H}$. The effects, limitations, and long-term dentofacial adaptations to treatment with the Herbst appliance. Semin Orthod 3, 232-243 (1997).

84. Hagg, U. \& Pancherz, H. Dentofacial orthopaedics in relation to chronological age, growth period and skeletal development. An analysis of 72 male patients with Class II division 1 malocclusion treated with the Herbst appliance. Eur. $J$ Orthod 10, 169-176 (1988).

85. Valant, J. R. \& Sinclair, P. M. Treatment effects of the Herbst appliance. Am J Orthod Dentofacial Orthop. 95, 138-147 (1989). 
86. McNamara, J. A., Jr., Howe, R. P. \& Dischinger, T. G. A comparison of the Herbst and Frankel appliances in the treatment of Class II malocclusion. Am J Orthod Dentofacial Orthop. 98, 134-144 (1990).

87. Pancherz, $\mathrm{H}$. The effect of continuous bite jumping on the dentofacial complex: a follow-up study after Herbst appliance treatment of class II malocclusions. Eur. J Orthod 3, 49-60 (1981).

88. Decrue, A. \& Wieslander, L. [Fossa articularis changes using Herbst appliance after mandibular advancement]. Zahnarztl. Prax. 41, 360-365 (1990).

89. Croft, R. S., Buschang, P. H., English, J. D. \& Meyer, R. A cephalometric and tomographic evaluation of Herbst treatment in the mixed dentition. Am J Orthod Dentofacial Orthop. 116, 435-443 (1999).

90. Pancherz, H. \& nehus-Pancherz, M. The headgear effect of the Herbst appliance: a cephalometric long-term study. Am J Orthod Dentofacial Orthop. 103, 510-520 (1993).

91. Pancherz, H. Vertical dentofacial changes during Herbst appliance treatment. A cephalometric investigation. Swed. Dent. J Suppl 15, 189-196 (1982).

92. DeVincenzo, J. P. Changes in mandibular length before, during, and after successful orthopedic correction of Class II malocclusions, using a functional appliance. Am J Orthod Dentofacial Orthop. 99, 241-257 (1991).

93. Pancherz, H. The nature of Class II relapse after Herbst appliance treatment: a cephalometric long-term investigation. Am J Orthod Dentofacial Orthop. 100, 220-233 (1991).

94. Cope, J. B., Buschang, P. H., Cope, D. D., Parker, J. \& Blackwood, H. O., III Quantitative evaluation of craniofacial changes with Jasper Jumper therapy. Angle Orthod 64, 113-122 (1994).

95. Kucukkeles, N., Ilhan, I. \& Orgun, I. A. Treatment efficiency in skeletal Class II patients treated with the jasper jumper. Angle Orthod 77, 449-456 (2007).

96. Covell, D. A., Jr., Trammell, D. W., Boero, R. P. \& West, R. A cephalometric study of class II Division 1 malocclusions treated with the Jasper Jumper appliance. Angle Orthod 69, 311-320 (1999).

97. Weiland, F. J. \& Bantleon, H. P. Treatment of Class II malocclusions with the Jasper Jumper appliance--a preliminary report. Am J Orthod Dentofacial Orthop. 108, 341-350 (1995).

98. Stucki, N. \& Ingervall, B. The use of the Jasper Jumper for the correction of Class II malocclusion in the young permanent dentition. Eur. J Orthod 20, 271-281 (1998). 
99. Manfredi, C., Cimino, R., Trani, A. \& Pancherz, H. Skeletal changes of Herbst appliance therapy investigated with more conventional cephalometrics and European norms. Angle Orthod 71, 170-176 (2001).

100. Pancherz, H. \& Fischer, S. Amount and direction of temporomandibular joint growth changes in Herbst treatment: a cephalometric long-term investigation. Angle Orthod. 73, 493-501 (2003).

101. Nelson, B., Hagg, U., Hansen, K. \& Bendeus, M. A long-term follow-up study of Class II malocclusion correction after treatment with Class II elastics or fixed functional appliances. Am. J Orthod Dentofacial Orthop. 132, 499-503 (2007).

102. Case CS Expansion of the dental arches. Dent Rev (1893).

103. Breitner $\mathrm{C}$ Bone changes resulting from experimental orthodontic treatment. Am J Orthod Oral Surg 26, 521-47 (1940).

104. Meikle, M. C. The effect of a Class II intermaxillary force on the dentofacial complex in the adult Macaca mulatta monkey. Am J Orthod 58, 323-340 (1970).

105. Payne, G. S. The effect of intermaxillary elastic force on the temporomandibular articulation in the growing macaque monkey. Am J Orthod 60, 491-504 (1971).

106. Petrovic, A., Stutzmann, J. \& Gasson, N. [Is the final shape of the mandible, as such, genetically predetermined?]. Orthod Fr. 50, 751-767 (1979).

107. Swain, B. F. \& Ackerman, J. L. An evaluation of the Begg technique. Am J Orthod 55, 668-687 (1969).

108. Ball, J. V. \& Hunt, N. P. The effect of Andresen, Harvold, and Begg treatment on overbite and molar eruption. Eur. J Orthod 13, 53-58 (1991).

109. Thompson, W. J. Current application of Begg mechanics. Am J Orthod 62, 245271 (1972).

110. Ellen, E. K., Schneider, B. J. \& Sellke, T. A comparative study of anchorage in bioprogressive versus standard edgewise treatment in Class II correction with intermaxillary elastic force. Am J Orthod Dentofacial Orthop. 114, 430-436 (1998).

111. Gianelly, A. A., Arena, S. A. \& Bernstein, L. A comparison of Class II treatment changes noted with the light wire, edgewise, and Frankel appliances. Am J Orthod 86, 269-276 (1984).

112. Nelson, B., Hansen, K. \& Hagg, U. Class II correction in patients treated with class II elastics and with fixed functional appliances: a comparative study. Am J Orthod Dentofacial Orthop. 118, 142-149 (2000). 
113. Remmer, K. R., Mamandras, A. H., Hunter, W. S. \& Way, D. C. Cephalometric changes associated with treatment using the activator, the Frankel appliance, and the fixed appliance. Am J Orthod 88, 363-372 (1985).

114. Vogt, W. The Forsus Fatigue Resistant Device. J Clin. Orthod 40, 368-377 (2006).

115. Jung, M.-H. \& Vogt, W. Orthodontic Perspectives. Volume XVI No.1. 2009. 3M Unitek.

Ref Type: Pamphlet

116. Ross, A. P., Gaffey, B. J. \& Quick, A. N. Breakages using a unilateral fixed functional appliance: a case report using The Forsus Fatigue Resistant Device. $J$ Orthod 34, 2-5 (2007).

117. El-Sheikh, M. M., Godfrey, K., Manosudprasit, M. \& Viwattanatipa, N. Forcedeflection characteristics of the fatigue-resistant device spring: an in vitro study. World J Orthod 8, 30-36 (2007).

118. Held AJ, Spirgi M \& Cimasoni G An orthopedically treated adult case of Class II malocclusion. Am J Orthod 49, 761-765 (1963).

119. Egermark-Eriksson, I., Carlsson, G. E. \& Ingervall, B. Function and dysfunction of the masticatory system in individuals with dual bite. Eur. J Orthod 1, 107-117 (1979).

120. Jones, G., Buschang, P. H., Kim, K. B. \& Oliver, D. R. Class II non-extraction patients treated with the Forsus Fatigue Resistant Device versus intermaxillary elastics. Angle Orthod 78, 332-338 (2008).

121. Heinig, N. \& Goz, G. Clinical application and effects of the Forsus spring. A study of a new Herbst hybrid. J Orofac. Orthop 62, 436-450 (2001).

122. Karacay, S., Akin, E., Olmez, H., Gurton, A. U. \& Sagdic, D. Forsus Nitinol Flat Spring and Jasper Jumper corrections of Class II division 1 malocclusions. Angle Orthod 76, 666-672 (2006).

123. Ye, J., Wang, C. L., Liu, D. X., Guo, J. \& Zhang, F. [Clinical effect of modified forsus appliance to children with mandibular retrusion]. Hua Xi. Kou Qiang. Yi. Xиe. Za Zhi. 24, 246-249 (2006).

124. Liu, Y. P., Zhou, H., Zou, M. \& Ming, L. F. [Treatment of mandibular retrusion patients with Forsus appliance following growth spurts]. Shanghai Kou Qiang. Yi. Хие. 16, 391-394 (2007).

125. Wigal, T. Long-term follow-up of patients treated with the edgewise crowned Herbst appliance in the mixed dentition. 2008.

Ref Type: Thesis/Dissertation 
126. Baccetti, T., Franchi, L. \& McNamara, J. A., Jr. An improved version of the cervical vertebral maturation (CVM) method for the assessment of mandibular growth. Angle Orthod. 72, 316-323 (2002).

127. Bjork A The face in profile: An anthoropological x-ray investigation of Swedish children and conscripts. Lund: Berlingska Boktrycheriet 40-58 (1947).

128. Hansen, K. \& Pancherz, H. Long-term effects of Herbst treatment in relation to normal growth development: a cephalometric study. Eur J Orthod 14, 285-295 (1992). 


\section{APPENDICIES}




\section{Appendix A}

IRB Approval

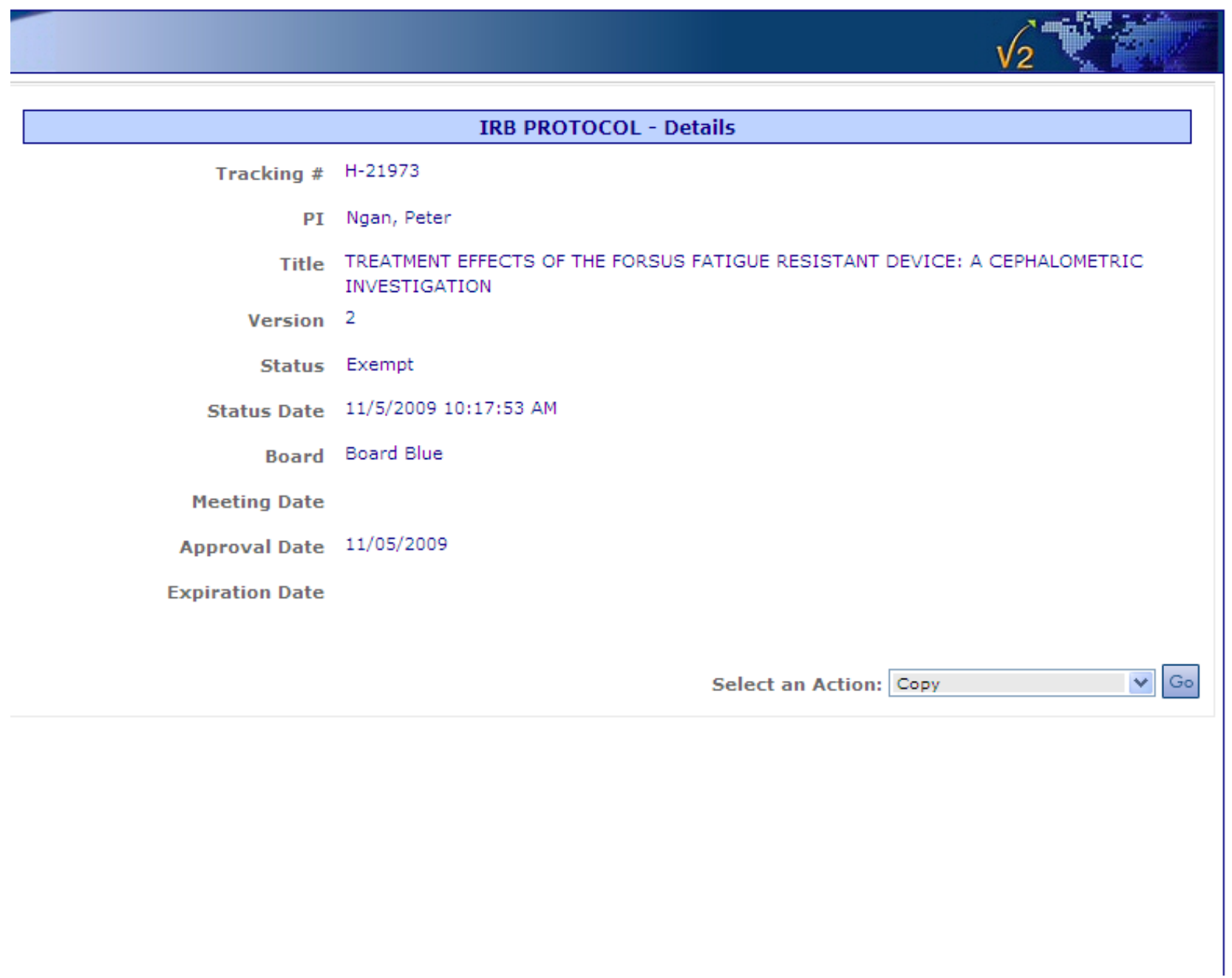




\section{Appendix B}

Approval for use of orthodontic records from Dr. Imad Shammaa

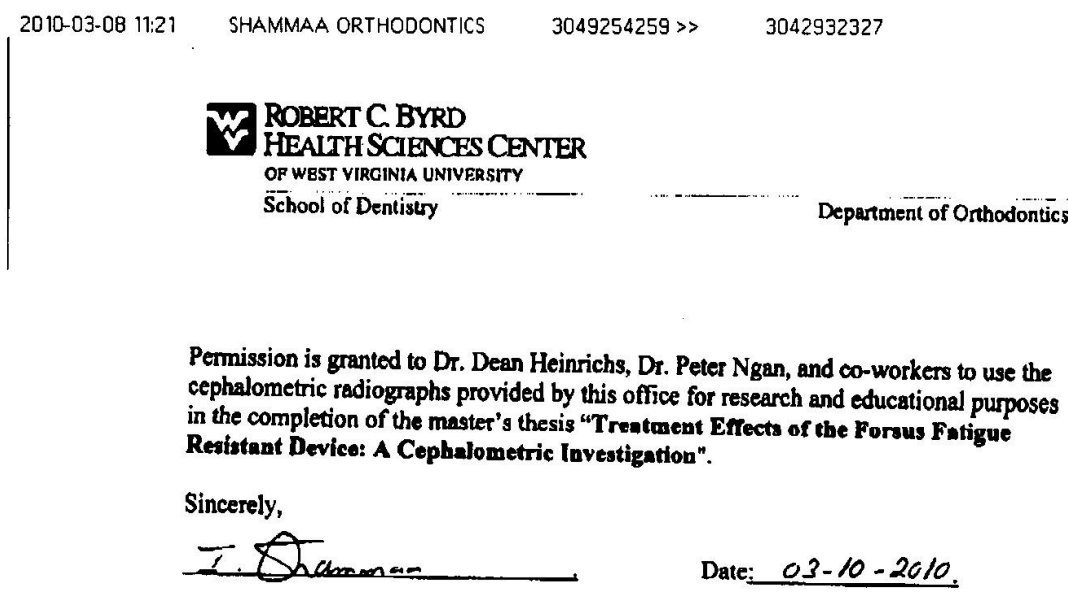

Dr. Imad Shammaa 


\section{Appendix C}

Distribution of Control Group Measurements - Pooled Subjects

\begin{tabular}{|c|c|c|c|c|c|c|c|c|}
\hline \multirow[b]{2}{*}{ Variable } & \multicolumn{4}{|c|}{ T1 } & \multicolumn{4}{|c|}{$\mathrm{T} 2$} \\
\hline & Mean & S.D. & Min & Max & Mean & S.D. & Min & Max \\
\hline \multicolumn{9}{|l|}{ Sagittal: } \\
\hline Olp-A pt. & 70.3 & 4.2 & 79.8 & 64.8 & 75.4 & 5.0 & 86.7 & 68.6 \\
\hline Olp-Pg & 73.9 & 4.8 & 85.7 & 67.7 & 80.5 & 5.1 & 91.3 & 72.1 \\
\hline Olp-Co & 10.0 & 2.2 & 14.0 & 6.4 & 11.0 & 2.2 & 14.0 & 4.6 \\
\hline Co-A pt. & 80.7 & 4.1 & 88.0 & 73.4 & 86.9 & 3.9 & 94.5 & 80.4 \\
\hline Co-Gn & 99.7 & 5.3 & 110.5 & 89.7 & 109.0 & 5.7 & 121.3 & 99.9 \\
\hline Co-Gn minus Co-A pt. & 19.0 & 3.0 & 24.3 & 14.4 & 22.1 & 3.6 & 31.3 & 17.1 \\
\hline Wits & 0.6 & 1.7 & 4.0 & -4.0 & 1.1 & 2.0 & 4.3 & -2.8 \\
\hline Is-Olp & 77.2 & 5.5 & 90.0 & 67.7 & 82.8 & 6.0 & 96.6 & 73.0 \\
\hline li-Olp & 71.9 & 4.8 & 83.9 & 63.9 & 77.5 & 5.8 & 91.7 & 68.6 \\
\hline Overjet & 5.3 & 1.6 & 9.2 & 3.3 & 5.3 & 1.5 & 8.8 & 3.3 \\
\hline Ms-Olp & 49.2 & 3.8 & 60.0 & 43.7 & 55.6 & 4.7 & 65.8 & 48.1 \\
\hline Mi-Olp & 49.0 & 4.3 & 61.8 & 42.2 & 55.9 & 4.8 & 66.8 & 48.4 \\
\hline Molar Relationship & 0.2 & 0.9 & 1.5 & -1.8 & -0.3 & 0.7 & 1.3 & -1.4 \\
\hline \multicolumn{9}{|l|}{ Vertical: } \\
\hline Ols-Apt & 26.9 & 2.3 & 31.1 & 22.7 & 30.0 & 1.9 & 33.8 & 27.5 \\
\hline ANS-Me & 59.0 & 5.1 & 70.6 & 49.6 & 63.7 & 5.8 & 73.9 & 52.7 \\
\hline Is-NL & 26.0 & 2.6 & 31.2 & 21.2 & 27.6 & 2.4 & 33.2 & 22.4 \\
\hline Ii-ML & 35.4 & 3.3 & 42.1 & 29.9 & 38.6 & 3.8 & 45.7 & 32.6 \\
\hline Overbite & 3.1 & 1.4 & 6.2 & 0.7 & 3.3 & 1.1 & 5.9 & 1.2 \\
\hline Msc-NL & 18.5 & 2.0 & 21.7 & 13.7 & 21.5 & 2.5 & 26.6 & 17.0 \\
\hline Mic-ML & 27.0 & 2.4 & 31.7 & 23.3 & 29.6 & 2.9 & 35.7 & 24.9 \\
\hline \multicolumn{9}{|l|}{ Angular: } \\
\hline SNA & 80.1 & 2.8 & 85.5 & 74.0 & 81.7 & 3.0 & 88.5 & 76.0 \\
\hline SNB & 75.8 & 2.9 & 82.0 & 71.0 & 77.2 & 3.1 & 83.5 & 72.0 \\
\hline ANB & 4.3 & 1.3 & 6.5 & 2.0 & 4.5 & 1.6 & 7.5 & 1.5 \\
\hline SNL-NL & 6.4 & 2.9 & 11.5 & 0.0 & 6.6 & 3.4 & 14.0 & 1.0 \\
\hline SNL-ML & 33.4 & 4.8 & 41.0 & 22.5 & 32.8 & 5.5 & 40.0 & 21.5 \\
\hline SNL-Olf & 19.9 & 3.1 & 27.5 & 15.5 & 18.0 & 4.0 & 26.0 & 11.5 \\
\hline Is/NL & 110.1 & 5.0 & 120.0 & 102.0 & 110.1 & 5.2 & 119.0 & 101.5 \\
\hline li/ML & 95.1 & 6.0 & 107.0 & 85.0 & 94.6 & 4.8 & 102.5 & 85.0 \\
\hline Interincisal Angle & 127.5 & 7.5 & 140.0 & 115.0 & 129.2 & 7.8 & 145.0 & 116.0 \\
\hline
\end{tabular}




\section{Appendix D}

Distribution of Control Group Measurements - Male Subjects

\begin{tabular}{|c|c|c|c|c|c|c|c|c|}
\hline \multirow[b]{2}{*}{ Variable } & \multicolumn{4}{|c|}{$\mathrm{T} 1$} & \multicolumn{4}{|c|}{ T2 } \\
\hline & Mean & S.D. & Min & Max & Mean & S.D. & Min & Max \\
\hline \multicolumn{9}{|l|}{ Sagittal: } \\
\hline Olp-A pt. & 74.3 & 4.3 & 79.8 & 68.1 & 80.6 & 4.8 & 86.7 & 73.4 \\
\hline Olp-Pg & 76.4 & 5.8 & 85.7 & 69.8 & 84.1 & 6.0 & 91.3 & 76.8 \\
\hline Olp-Co & 9.6 & 2.3 & 13.8 & 6.4 & 9.8 & 2.8 & 13.1 & 4.6 \\
\hline Co-A pt. & 84.2 & 3.4 & 88.0 & 78.5 & 90.8 & 3.7 & 94.5 & 83.9 \\
\hline Co-Gn & 103.3 & 4.8 & 110.5 & 97.0 & 113.2 & 5.9 & 121.3 & 103.2 \\
\hline Co-Gn minus Co-A pt. & 19.1 & 3.2 & 24.3 & 14.4 & 22.4 & 3.4 & 27.0 & 18.9 \\
\hline Wits & 1.9 & 1.5 & 4.0 & -0.6 & 2.3 & 1.9 & 4.3 & -0.8 \\
\hline Is-Olp & 81.9 & 6.4 & 90.0 & 70.9 & 88.9 & 6.2 & 96.6 & 78.6 \\
\hline li-Olp & 75.6 & 5.8 & 83.9 & 67.6 & 82.8 & 6.4 & 91.7 & 74.0 \\
\hline Overjet & 6.3 & 1.9 & 9.2 & 3.3 & 6.2 & 1.3 & 8.0 & 4.6 \\
\hline Ms-Olp & 51.3 & 5.1 & 60.0 & 44.0 & 58.8 & 5.7 & 65.8 & 51.7 \\
\hline Mi-Olp & 51.3 & 5.6 & 61.8 & 44.8 & 59.0 & 5.9 & 66.8 & 51.5 \\
\hline Molar Relationship & -0.1 & 1.0 & 0.9 & -1.8 & -0.2 & 0.6 & 0.8 & -1.0 \\
\hline \multicolumn{9}{|l|}{ Vertical: } \\
\hline Ols-Apt & 26.5 & 2.0 & 30.3 & 23.9 & 30.1 & 1.8 & 33.0 & 27.9 \\
\hline ANS-Me & 63.4 & 4.7 & 70.6 & 57.1 & 69.0 & 4.2 & 73.9 & 63.3 \\
\hline Is-NL & 27.6 & 2.2 & 31.2 & 25.2 & 29.4 & 1.8 & 33.2 & 27.3 \\
\hline li-ML & 38.3 & 3.0 & 42.1 & 34.2 & 42.3 & 2.8 & 45.7 & 37.7 \\
\hline Overbite & 2.9 & 2.1 & 6.2 & 0.7 & 3.4 & 1.6 & 5.9 & 1.2 \\
\hline Msc-NL & 18.8 & 1.8 & 21.2 & 16.3 & 21.8 & 1.8 & 24.1 & 19.6 \\
\hline Mic-ML & 28.8 & 2.2 & 31.7 & 26.2 & 32.1 & 2.1 & 35.7 & 29.8 \\
\hline \multicolumn{9}{|l|}{ Angular: } \\
\hline SNA & 79.4 & 1.6 & 81.5 & 77.0 & 81.4 & 1.6 & 83.0 & 78.5 \\
\hline SNB & 74.3 & 2.1 & 77.0 & 71.0 & 75.8 & 2.4 & 78.0 & 72.0 \\
\hline ANB & 5.1 & 1.1 & 6.5 & 3.5 & 5.6 & 1.2 & 7.5 & 4.5 \\
\hline SNL-NL & 6.1 & 2.7 & 11.0 & 3.0 & 6.6 & 3.5 & 13.0 & 2.5 \\
\hline SNL-ML & 35.6 & 3.5 & 39.5 & 30.0 & 35.1 & 4.8 & 40.0 & 28.5 \\
\hline SNL-Olf & 20.1 & 2.7 & 23.5 & 16.0 & 19.1 & 4.3 & 24.0 & 11.5 \\
\hline Is/NL & 109.9 & 4.3 & 116.0 & 105.0 & 109.1 & 6.0 & 117.0 & 102.5 \\
\hline li/ML & 94.3 & 3.7 & 99.0 & 88.0 & 93.9 & 4.6 & 102.0 & 89.0 \\
\hline Interincisal Angle & 126.1 & 4.7 & 134.0 & 120.0 & 128.6 & 8.9 & 140.0 & 118.0 \\
\hline
\end{tabular}




\section{Appendix E}

Distribution of Control Group Measurements - Female Subjects

\begin{tabular}{|c|c|c|c|c|c|c|c|c|}
\hline \multirow[b]{2}{*}{ Variable } & \multicolumn{4}{|c|}{ T1 } & \multicolumn{4}{|c|}{ T2 } \\
\hline & Mean & S.D. & Min & Max & Mean & S.D. & Min & Max \\
\hline \multicolumn{9}{|l|}{ Sagittal: } \\
\hline Olp-A pt. & 68.5 & 2.6 & 73.9 & 64.8 & 73.0 & 2.8 & 77.2 & 68.6 \\
\hline Olp-Pg & 72.7 & 3.9 & 80.7 & 67.7 & 78.8 & 3.8 & 85.3 & 72.1 \\
\hline Olp-Co & 10.2 & 2.2 & 14.0 & 6.6 & 11.6 & 1.6 & 14.0 & 8.3 \\
\hline Co-A pt. & 79.1 & 3.5 & 83.6 & 73.4 & 85.1 & 2.5 & 88.5 & 80.4 \\
\hline Co-Gn & 98.0 & 4.8 & 106.4 & 89.7 & 107.1 & 4.6 & 115.4 & 99.9 \\
\hline Co-Gn minus Co-A pt. & 18.9 & 3.0 & 24.1 & 15.1 & 22.0 & 3.7 & 31.3 & 17.1 \\
\hline Wits & 0.0 & 1.5 & 2.7 & -4.0 & 0.5 & 1.8 & 4.3 & -2.8 \\
\hline Is-Olp & 75.0 & 3.3 & 81.0 & 67.7 & 79.9 & 3.2 & 84.9 & 73.0 \\
\hline li-Olp & 70.2 & 3.3 & 75.1 & 63.9 & 75.0 & 3.4 & 79.7 & 68.6 \\
\hline Overjet & 4.8 & 1.3 & 7.3 & 3.6 & 4.9 & 1.4 & 8.8 & 3.3 \\
\hline Ms-Olp & 48.2 & 2.8 & 53.4 & 43.7 & 54.2 & 3.5 & 58.9 & 48.1 \\
\hline Mi-Olp & 47.9 & 3.2 & 53.2 & 42.2 & 54.5 & 3.6 & 59.9 & 48.4 \\
\hline Molar Relationship & 0.4 & 0.8 & 1.5 & -1.8 & -0.4 & 0.7 & 1.3 & -1.4 \\
\hline \multicolumn{9}{|l|}{ Vertical: } \\
\hline Ols-Apt & 27.0 & 2.4 & 31.1 & 22.7 & 30.0 & 2.0 & 33.8 & 27.5 \\
\hline ANS-Me & 56.9 & 3.9 & 64.2 & 49.6 & 61.3 & 4.9 & 69.9 & 52.7 \\
\hline Is-NL & 25.2 & 2.5 & 28.4 & 21.2 & 26.7 & 2.2 & 30.8 & 22.4 \\
\hline li-ML & 34.1 & 2.5 & 40.0 & 29.9 & 36.9 & 2.8 & 42.4 & 32.6 \\
\hline Overbite & 3.2 & 0.9 & 5.3 & 1.8 & 3.2 & 0.8 & 4.9 & 1.8 \\
\hline Msc-NL & 18.4 & 2.2 & 21.7 & 13.7 & 21.3 & 2.8 & 26.6 & 17.0 \\
\hline Mic-ML & 26.2 & 2.0 & 30.0 & 23.3 & 28.5 & 2.5 & 34.0 & 24.9 \\
\hline \multicolumn{9}{|l|}{ Angular: } \\
\hline SNA & 80.4 & 3.2 & 85.5 & 74.0 & 81.8 & 3.6 & 88.5 & 76.0 \\
\hline SNB & 76.5 & 3.0 & 82.0 & 71.5 & 77.8 & 3.3 & 83.5 & 72.5 \\
\hline ANB & 3.9 & 1.3 & 5.5 & 2.0 & 4.0 & 1.5 & 7.5 & 1.5 \\
\hline SNL-NL & 6.5 & 3.1 & 11.5 & 0.0 & 6.6 & 3.4 & 14.0 & 1.0 \\
\hline SNL-ML & 32.4 & 5.1 & 41.0 & 22.5 & 31.6 & 5.6 & 40.0 & 21.5 \\
\hline SNL-Olf & 19.8 & 3.3 & 27.5 & 15.5 & 17.4 & 3.9 & 26.0 & 12.0 \\
\hline Is/NL & 110.3 & 5.5 & 120.0 & 102.0 & 110.5 & 4.9 & 119.0 & 101.5 \\
\hline li/ML & 95.5 & 6.9 & 107.0 & 85.0 & 94.9 & 5.1 & 102.5 & 85.0 \\
\hline Interincisal Angle & 128.1 & 8.5 & 140.0 & 115.0 & 129.5 & 7.6 & 145.0 & 116.0 \\
\hline
\end{tabular}




\section{Appendix F}

Distribution of Treatment Group Measurements - Pooled Subjects

\begin{tabular}{|c|c|c|c|c|c|c|c|c|}
\hline \multirow[b]{2}{*}{ Variable } & \multicolumn{4}{|c|}{ T1 } & \multicolumn{4}{|c|}{ T2 } \\
\hline & Mean & S.D. & Min & Max & Mean & S.D. & Min & Max \\
\hline \multicolumn{9}{|l|}{ Sagittal: } \\
\hline Olp-A pt. & 70.9 & 4.5 & 60.5 & 84.6 & 74.8 & 4.3 & 64.8 & 84.4 \\
\hline Olp-Pg & 72.4 & 5.3 & 59.0 & 84.3 & 79.7 & 6.0 & 69.3 & 89.8 \\
\hline Olp-Co & 9.8 & 3.4 & 1.9 & 16.9 & 11.3 & 3.7 & 1.7 & 17.3 \\
\hline Co-A pt. & 81.3 & 5.3 & 74.3 & 94.3 & 86.7 & 4.9 & 77.6 & 97.2 \\
\hline Co-Gn & 99.3 & 7.0 & 88.4 & 115.7 & 109.7 & 7.0 & 97.8 & 126.0 \\
\hline Co-Gn minus Co-A pt. & 18.0 & 3.5 & 12.5 & 25.5 & 22.9 & 4.9 & 12.7 & 32.3 \\
\hline Wits & 1.8 & 1.9 & -0.7 & 6.2 & -0.4 & 1.5 & -4.4 & 2.0 \\
\hline Is-Olp & 78.9 & 5.4 & 69.1 & 95.4 & 81.8 & 4.9 & 70.1 & 91.2 \\
\hline li-Olp & 71.1 & 4.8 & 57.6 & 80.6 & 78.6 & 4.9 & 65.8 & 87.7 \\
\hline Overjet & 7.8 & 2.9 & 2.6 & 14.8 & 3.3 & 1.0 & 0.4 & 5.2 \\
\hline Ms-Olp & 48.8 & 4.7 & 37.6 & 61.7 & 53.6 & 4.2 & 43.2 & 62.1 \\
\hline Mi-Olp & 47.5 & 4.6 & 34.0 & 56.3 & 56.4 & 4.5 & 46.2 & 64.7 \\
\hline Molar Relationship & 1.3 & 1.8 & -1.6 & 5.4 & -2.8 & 0.9 & -4.1 & -0.7 \\
\hline \multicolumn{9}{|l|}{ Vertical: } \\
\hline Ols-Apt & 30.2 & 5.7 & 19.8 & 39.8 & 33.0 & 5.1 & 24.6 & 42.4 \\
\hline ANS-Me & 57.5 & 5.8 & 44.7 & 68.7 & 62.6 & 7.1 & 46.0 & 76.8 \\
\hline Is-NL & 28.5 & 3.1 & 24.6 & 35.2 & 29.7 & 3.2 & 24.2 & 36.5 \\
\hline li-ML & 36.3 & 3.3 & 30.3 & 41.6 & 38.1 & 3.5 & 31.5 & 44.6 \\
\hline Overbite & 3.9 & 1.2 & 1.2 & 6.5 & 2.1 & 1.1 & -0.8 & 3.6 \\
\hline Msc-NL & 18.6 & 2.1 & 14.3 & 21.4 & 21.2 & 2.7 & 16.1 & 26.6 \\
\hline Mic-ML & 25.5 & 2.4 & 21.8 & 30.9 & 29.5 & 2.5 & 24.6 & 33.5 \\
\hline \multicolumn{9}{|l|}{ Angular: } \\
\hline SNA & 81.1 & 3.1 & 75.0 & 87.5 & 81.2 & 3.3 & 76.0 & 88.0 \\
\hline SNB & 75.9 & 2.6 & 70.5 & 81.0 & 77.6 & 3.3 & 69.5 & 83.5 \\
\hline ANB & 5.1 & 1.8 & 2.0 & 9.5 & 3.6 & 2.0 & -1.0 & 7.0 \\
\hline SNL-NL & 7.2 & 3.0 & 3.0 & 14.0 & 6.8 & 2.9 & 3.0 & 11.5 \\
\hline SNL-ML & 32.8 & 5.9 & 13.5 & 43.5 & 31.2 & 7.4 & 9.0 & 45.0 \\
\hline SNL-Olf & 18.8 & 3.7 & 9.0 & 27.0 & 18.1 & 3.8 & 8.5 & 24.0 \\
\hline Is/NL & 110.9 & 22.4 & 18.0 & 140.5 & 113.6 & 5.4 & 103.5 & 122.5 \\
\hline li/ML & 93.7 & 6.7 & 81.5 & 107.0 & 97.6 & 7.4 & 81.0 & 116.0 \\
\hline Interincisal Angle & 125.2 & 11.7 & 103.5 & 144.5 & 123.9 & 6.3 & 115.0 & 135.0 \\
\hline
\end{tabular}




\section{Appendix G}

Distribution of Treatment Group Measurements - Male Subjects

\begin{tabular}{|c|c|c|c|c|c|c|c|c|}
\hline \multirow[b]{2}{*}{ Variable } & \multicolumn{4}{|c|}{ T1 } & \multicolumn{4}{|c|}{ T2 } \\
\hline & Mean & S.D. & Min & Max & Mean & S.D. & Min & Max \\
\hline \multicolumn{9}{|l|}{ Sagittal: } \\
\hline Olp-A pt. & 71.5 & 5.3 & 60.5 & 84.6 & 75.7 & 4.9 & 64.8 & 84.4 \\
\hline Olp-Pg & 73.4 & 6.3 & 59.0 & 84.3 & 81.4 & 6.4 & 70.7 & 89.8 \\
\hline Olp-Co & 9.9 & 3.7 & 1.9 & 16.9 & 11.7 & 4.2 & 1.7 & 17.3 \\
\hline Co-A pt. & 82.1 & 5.3 & 74.8 & 94.3 & 88.0 & 5.2 & 77.6 & 97.2 \\
\hline Co-Gn & 101.2 & 7.3 & 91.3 & 115.7 & 113.0 & 6.6 & 103.4 & 126.0 \\
\hline Co-Gn minus Co-A pt. & 19.1 & 3.6 & 13.9 & 25.5 & 24.9 & 4.4 & 18.5 & 32.3 \\
\hline Wits & 1.6 & 1.9 & -0.7 & 5.1 & -0.4 & 1.7 & -4.4 & 2.0 \\
\hline Is-Olp & 79.8 & 6.1 & 69.1 & 95.4 & 83.1 & 5.4 & 70.1 & 91.2 \\
\hline li-Olp & 71.8 & 5.7 & 57.6 & 80.6 & 79.7 & 5.4 & 65.8 & 87.7 \\
\hline Overjet & 8.0 & 3.4 & 2.6 & 14.8 & 3.4 & 1.1 & 0.4 & 5.2 \\
\hline Ms-Olp & 49.2 & 5.5 & 37.6 & 61.7 & 54.6 & 4.6 & 43.2 & 62.1 \\
\hline Mi-Olp & 48.0 & 5.4 & 34.0 & 56.3 & 57.4 & 4.9 & 46.2 & 64.7 \\
\hline Molar Relationship & 1.2 & 2.0 & -1.6 & 5.4 & -2.9 & 0.9 & -4.0 & -0.7 \\
\hline \multicolumn{9}{|l|}{ Vertical: } \\
\hline Ols-Apt & 31.3 & 6.2 & 19.8 & 39.8 & 34.3 & 5.6 & 24.6 & 42.4 \\
\hline ANS-Me & 58.5 & 6.4 & 44.7 & 68.7 & 64.9 & 7.4 & 46.0 & 76.8 \\
\hline Is-NL & 29.4 & 3.3 & 25.1 & 35.2 & 30.8 & 3.2 & 24.4 & 36.5 \\
\hline Ii-ML & 36.9 & 3.4 & 30.3 & 41.6 & 39.5 & 3.4 & 31.5 & 44.6 \\
\hline Overbite & 3.8 & 1.3 & 1.2 & 6.5 & 2.1 & 1.2 & -0.8 & 3.4 \\
\hline Msc-NL & 18.9 & 2.2 & 14.3 & 21.4 & 22.1 & 2.7 & 17.6 & 26.6 \\
\hline Mic-ML & 26.0 & 2.5 & 21.9 & 30.9 & 30.6 & 2.4 & 24.6 & 33.5 \\
\hline \multicolumn{9}{|l|}{ Angular: } \\
\hline SNA & 80.4 & 3.0 & 75.0 & 85.0 & 80.6 & 3.3 & 76.0 & 85.0 \\
\hline SNB & 75.8 & 3.1 & 70.5 & 81.0 & 77.5 & 3.8 & 69.5 & 83.5 \\
\hline ANB & 4.7 & 1.6 & 2.0 & 8.0 & 3.1 & 2.1 & -1.0 & 6.5 \\
\hline SNL-NL & 6.6 & 2.8 & 3.0 & 11.5 & 5.8 & 2.4 & 3.0 & 10.0 \\
\hline SNL-ML & 32.5 & 7.3 & 13.5 & 43.5 & 30.7 & 8.9 & 9.0 & 45.0 \\
\hline SNL-Olf & 18.5 & 4.2 & 9.0 & 27.0 & 17.0 & 3.9 & 8.5 & 24.0 \\
\hline Is/NL & 109.5 & 27.8 & 18.0 & 140.5 & 113.4 & 5.3 & 103.5 & 122.5 \\
\hline li/ML & 93.7 & 7.6 & 81.5 & 107.0 & 97.4 & 8.6 & 81.0 & 116.0 \\
\hline Interincisal Angle & 124.0 & 12.8 & 103.5 & 144.5 & 123.7 & 6.5 & 115.5 & 135.0 \\
\hline
\end{tabular}




\section{Appendix $\mathrm{H}$}

Distribution of Treatment Group Measurements - Female Subjects

\begin{tabular}{|c|c|c|c|c|c|c|c|c|}
\hline \multirow[b]{2}{*}{ Variable } & \multicolumn{4}{|c|}{ T1 } & \multicolumn{4}{|c|}{ T2 } \\
\hline & Mean & S.D. & Min & Max & Mean & S.D. & Min & Max \\
\hline \multicolumn{9}{|l|}{ Sagittal: } \\
\hline Olp-A pt. & 69.9 & 2.9 & 66.7 & 75.3 & 73.4 & 2.6 & 68.8 & 76.9 \\
\hline Olp-Pg & 70.7 & 2.4 & 66.0 & 73.6 & 76.9 & 4.0 & 69.3 & 83.1 \\
\hline Olp-Co & 9.6 & 3.0 & 5.9 & 14.4 & 10.6 & 3.0 & 4.9 & 14.4 \\
\hline Co-A pt. & 79.9 & 5.3 & 74.3 & 89.7 & 84.5 & 3.6 & 77.8 & 89.6 \\
\hline Co-Gn & 96.0 & 5.3 & 88.4 & 103.6 & 104.2 & 3.2 & 97.8 & 108.9 \\
\hline Co-Gn minus Co-A pt. & 16.1 & 2.7 & 12.5 & 18.8 & 19.6 & 3.7 & 12.7 & 24.5 \\
\hline Wits & 2.2 & 1.8 & 0.4 & 6.2 & -0.5 & 1.0 & -2.2 & 1.1 \\
\hline Is-Olp & 77.5 & 4.1 & 72.8 & 84.5 & 79.7 & 3.3 & 74.1 & 85.8 \\
\hline li-Olp & 70.0 & 2.8 & 66.3 & 75.4 & 76.7 & 3.1 & 71.5 & 82.2 \\
\hline Overjet & 7.5 & 2.1 & 4.6 & 10.4 & 3.0 & 0.5 & 2.5 & 3.6 \\
\hline Ms-Olp & 48.1 & 3.0 & 45.0 & 54.1 & 52.0 & 3.0 & 46.3 & 56.5 \\
\hline Mi-Olp & 46.5 & 2.6 & 42.3 & 51.2 & 54.7 & 3.3 & 48.6 & 60.4 \\
\hline Molar Relationship & 1.5 & 1.2 & -0.7 & 3.0 & -2.7 & 1.0 & -4.1 & -1.3 \\
\hline \multicolumn{9}{|l|}{ Vertical: } \\
\hline Ols-Apt & 28.3 & 4.2 & 21.4 & 32.7 & 30.9 & 3.6 & 25.1 & 35.7 \\
\hline ANS-Me & 55.8 & 4.4 & 48.8 & 61.2 & 58.6 & 4.4 & 51.3 & 65.8 \\
\hline Is-NL & 27.2 & 2.1 & 24.6 & 30.1 & 27.9 & 2.4 & 24.2 & 31.2 \\
\hline li-ML & 35.3 & 3.1 & 31.3 & 40.1 & 35.8 & 2.1 & 33.4 & 39.3 \\
\hline Overbite & 4.2 & 0.9 & 2.9 & 5.4 & 2.2 & 0.9 & 0.6 & 3.6 \\
\hline Msc-NL & 18.1 & 1.8 & 15.6 & 20.4 & 19.7 & 2.0 & 16.1 & 21.9 \\
\hline Mic-ML & 24.7 & 2.3 & 21.8 & 27.7 & 27.8 & 1.5 & 25.1 & 29.6 \\
\hline \multicolumn{9}{|l|}{ Angular: } \\
\hline SNA & 82.1 & 3.1 & 77.0 & 87.5 & 82.2 & 3.2 & 77.0 & 88.0 \\
\hline SNB & 76.2 & 1.9 & 73.0 & 80.0 & 77.7 & 2.6 & 73.5 & 83.5 \\
\hline ANB & 5.9 & 1.9 & 4.0 & 9.5 & 4.4 & 1.7 & 2.0 & 7.0 \\
\hline SNL-NL & 8.2 & 3.3 & 4.5 & 14.0 & 8.4 & 2.8 & 4.0 & 11.5 \\
\hline SNL-ML & 33.2 & 2.7 & 29.0 & 38.0 & 32.1 & 4.1 & 27.5 & 40.5 \\
\hline SNL-Olf & 19.4 & 2.7 & 13.0 & 22.5 & 19.8 & 3.3 & 12.5 & 23.5 \\
\hline Is/NL & 113.2 & 8.9 & 101.0 & 126.5 & 113.9 & 5.7 & 104.0 & 122.0 \\
\hline li/ML & 93.7 & 5.3 & 87.5 & 102.5 & 97.9 & 5.3 & 90.5 & 105.5 \\
\hline Interincisal Angle & 127.3 & 10.0 & 112.0 & 141.5 & 124.2 & 6.4 & 115.0 & 132.5 \\
\hline
\end{tabular}

